\title{
Geophysical and geochemical constraints on the evolution of oceanic lithosphere from formation to subduction
}

\author{
By \\ Gregory Horning \\ B.S., Western Washington University, 2010 \\ Submitted in partial fulfillment of the requirements for the degree of \\ Doctor of Philosophy \\ at the \\ MASSACHUSETTS INSTITUTE OF TECHNOLOGY \\ and the \\ WOODS HOLE OCEANOGRAPHIC INSTITUTION
}

February 2017

(C) 2017 Gregory Horning

All rights reserved.

The author hereby grants to MIT and WHOI permission to reproduce and To distribute publicly paper and electronic copies of this thesis document In whole or in part in any medium now known or hereafter created.

Signature of Author

MIT/WHOI Joint Program in Oceanography / Applied Ocean Science and Engineering January 25, 2017 Certified by

Juan Pablo Canales

Thesis Supervisor

Accepted by

Timothy Grove

Chair, Joint Committee for Marine Geology and Geophysics

Massachusetts Institute of Technology 


\title{
Geophysical and geochemical constraints on the evolution of oceanic lithosphere from formation to subduction
}

\author{
By \\ Gregory Horning \\ Submitted to the Joint Program for Marine Geology and Geophysics on 25 January, 2017 \\ in partial fulfillment of the requirements for the degree of Doctor of Philosophy in \\ Marine Geophysics
}

\begin{abstract}
This thesis investigates the evolution of the oceanic lithosphere in a broad sense from formation to subduction, in a focused case at the ridge, and in a focused case proximal to subduction. In general, alteration of the oceanic lithosphere begins at the ridge through focused and diffuse hydrothermal flow, continues off axis through low temperature circulation, and may occur approaching subduction zones as bending related faulting provides fluid pathways. In Chapter 2 I use a dataset of thousands of microearthquakes recorded at the Rainbow massif on the Mid-Atlantic Ridge to characterize the processes which are responsible for the long-term, high-temperature, hydrothermal discharge found hosted in this oceanic core complex. I find that the detachment fault responsible for the uplift of the massif is inactive and that the axial valleys show no evidence for faulting or active magma intrusion. I conclude that the continuous, low-magnitude seismicity located in diffuse pattern in a region with seismic velocities indicating ultramafic host rock suggests that serpentinization may play a role in microearthquake generation but the seismic network was not capable of providing robust focal mechanism solutions to constrain the source characteristics. In Chapter 3 I find that the Juan de Fuca plate, which represents the young/hot end-member of oceanic plates, is lightly hydrated at upper crustal levels except in regions affected by propagator wakes where hydration of lower crust and upper mantle is evident. I conclude that at the subduction zone the plate is nearly dry at upper mantle levels with the majority of water contained in the crust. Finally, in Chapter 4 I examine samples of cretaceous age serpentinite sampled just before subduction at the Puerto Rico Trench. I show that these upper mantle rocks were completely serpentinized under static conditions at the Mid-Atlantic Ridge. Further, they subsequently underwent $100 \mathrm{Ma}$ of seafloor weathering wherein the alteration products of serpentinization themselves continue to be altered. I conclude that complete hydration of the upper mantle is not the end point in the evolution of oceanic lithosphere as it spreads from the axis to subduction.
\end{abstract}

Thesis Supervisors: Juan Pablo Canales, Associate Scientist with Tenure, WHOI Robert A. Sohn, Associate Scientist with Tenure, WHOI 


\section{ACKNOLWEDGEMENTS}

Funding was provided by the National Science Foundation through grants OCE-1029305 and OCE-0961680, the Deep Ocean Exploration Institute - Ocean Ridge Initiative, and by the WHOI Academic Programs office 


\section{TABLE OF CONTENTS}

$1 \quad$ Introduction 7

2 Local Seismicity of the Rainbow Massif on the Mid-Atlantic Ridge 9

2.1 Introduction

2.2 Geological Setting

2.3 Data Processing and Results

2.4 Discussion

2.5 Conclusions

3 A 2-D Tomographic Model of the Juan de Fuca Plate from Accretion at Axial Seamount to Subduction at the Cascadia Margin from an Active Source OBS survey

3.1 Introduction

3.2 Tectonic Setting

3.3 Data Acquisition

3.4 Data Processing

3.5 Velocity Modeling

3.6 Analysis and Interpretation of the Velocity Model

3.7 Discussion

3.8 Conclusions

4 Geochemical Investigation of Cretaceous Age Serpentinites from the Puerto Rico Trench

4.1 Introduction

4.2 Methods

4.3 Results

4.4 Discussion

4.5 Conclusions

References 


\section{Chapter 1:}

\section{Introduction}

The total water content of the oceanic lithosphere is the sum of the free water in pore spaces in the sedimentary cover and highly porous upper crust, chemically bound water in sediment clay minerals, chemically bound water in the upper and lower crust resulting from the precipitation of secondary hydrous alteration products, free water in fault zones, and bound water of hydrous minerals in the uppermost mantle resulting from serpentinization of peridotite. This thesis is focused on characterizing the location, extent, and timing of the processes that result in this alteration of the lithosphere.

In Chapter $2 \mathrm{I}$ focus on the alteration that occurs in the near axis region at an oceanic core complex located on the slow spreading Mid-Atlantic Ridge. At the Rainbow massif long-lived high-T hydrothermal venting has chemistry that indicates alteration of ultramafic rocks and thus extensive incorporation of water. Using a catalog of microearthquakes I find that the detachment is currently inactive and that the abundance of seismic activity is may be partially related to the volume increasing serpentinization reaction. The lack of an active detachment indicates that once initiated, long-lived high-T hydrothermal flow that alters the lithosphere can be maintained through positive feedback in regions that are not actively deforming along slow spreading ridges.

In Chapter 3 I use active source reflection/refraction seismology to look at the evolution of seismic velocity of the Juan de Fuca plate as a proxy for the extent of hydration. I focus on the large scale features that are evident along a 2-D transect oriented 
parallel to the spreading direction of the plate that extends from the near axis region $(0.8$ $\mathrm{Ma})$ to just beyond the subduction zone $(9.4 \mathrm{Ma})$. After correcting for a baseline velocity evolution that would be expected based on a cooling model and presumed lithology I calculate the total amount of water present in the plate. The state of hydration of the JdF plate is important as it reflects the young/hot and thus presumably dry end-member of subducting oceanic plates.

In Chapter 4 I focus on characterizing the processes that have affected some of the oldest oceanic lithosphere. I use petrographic and spectroscopic techniques to investigate a unique cretaceous age serpentinite that was directly sampled from the seafloor at the Puerto Rico Trench. I find that complete serpentinization occurred during static conditions which was followed by $100 \mathrm{Ma}$ of seafloor weathering. The results of this chapter indicate that even oceanic lithosphere which is completely hydrated at the ridge continues to evolve through alteration of secondary mineral assemblages.

In summary, this thesis focuses on characterizing alteration of the oceanic lithosphere as recorded by large scale shifts in seismic properties, by seismic activity related to the alteration itself, and through the investigation of alteration textures present within samples of oldest oceanic lithosphere. 


\title{
Chapter 2:
}

\section{Local Seismicity of the Rainbow Massif on the Mid-Atlantic Ridge}

\begin{abstract}
The Rainbow massif, an oceanic core complex (OCC) located in a non-transform discontinuity on the Mid-Atlantic Ridge (MAR, $\left.36^{\circ} \mathrm{N}\right)$, is notable for hosting hightemperature hydrothermal discharge through ultramafic rocks. Here we report results from a 9-month microearthquake survey conducted with a network of 13 ocean bottom seismometers deployed on and around the Rainbow Massif as part of the MARINER experiment in 2013-2014. High rates (300/day) of low-magnitude (average $M_{\mathrm{L}} \sim 0.5$ ) microearthquakes were detected beneath the massif. The hypocenters do not cluster along fault surfaces, do not exhibit mainshock/aftershock sequences, and are largely absent from the surrounding axial rift valleys. Instead, the hypocenters demarcate a diffuse zone of deformation at relatively shallow $(<5 \mathrm{~km})$ depths beneath the massif, supporting the idea that the faulting associated with the exhumation of the massif is currently inactive. Most of the continuous, low-magnitude seismicity is located in regions with seismic velocities indicating ultramafic host rock, and the diffuse seismogenic zone is located above seismic reflectors interpreted to be magmatic sills driving hydrothermal convection in the ultramafic massif. Although the seismic network was not capable of providing robust focal mechanism solutions to constrain the source characteristics, these geological constraints suggest that serpentinization may play an important role in microearthquake generation at the Rainbow massif.
\end{abstract}




\section{INTRODUCTION}

The Rainbow massif, located in a non-transform discontinuity (NTD) on the MidAtlantic Ridge $\left(\mathrm{MAR}, 36^{\circ} \mathrm{N}\right)$, is notable for hosting high-temperature $\left(365^{\circ} \mathrm{C}\right)$ hydrothermal discharge through ultramafic rocks [Douville et al., 2002]. While exposures of mantle rocks are common at slow-to-ultraslow mid-ocean ridges (MORs) like the MAR, particularly along sections with reduced magma supply [e.g., Cannat, 1993; Cannat et al., 1995], high-temperature hydrothermal discharge is more prevalently associated with volcanically accreted, rather than tectonically exhumed, terrains [Singh et $a l ., 2006]$ and it has been argued that high-temperature discharge requires an underlying melt body, in general [Cann and Strens, 1982], and at Rainbow, in particular [Thurnherr and Richards, 2001]. However, the nearest known neovolcanic activity to the Rainbow hydrothermal field is located $15-20 \mathrm{~km}$ away on the AMAR segment [German and Parson, 1998], and models for NTD formation typically invoke tectonic processes in an amagmatic environment [e.g., Gràcia et al., 2000; Grindlay and Fox, 1993; Spencer et al., 1997]. These apparently contradictory observations and models raise important questions about how the Rainbow massif was formed, and the tectonic and magmatic processes that allow it to generate and sustain high-temperature hydrothermal fluid discharge.

The MARINER experiment [Canales et al., 2013] utilized shipboard geophysical surveys [Eason et al., 2016; Paulatto et al., 2015], active-source seismic refraction and reflection [Canales et al., 2017] and a passive microearthquake survey to examine these 
issues. Here we report results from the microearthquake survey conducted with a network of ocean bottom seismometers (OBSs). We detected high rates of small microearthquakes beneath the massif that allow us to constrain the seismogenic processes presently deforming the ultramafic massif and examine the possible role of serpentinization in these processes. By interpreting our results along with those from the shipboard geophysical surveys, the active-source seismic surveys, and the extant geological data from the Rainbow site, we can also constrain the geological processes that formed the ultramafic massif and generate high-temperature hydrothermal convection.

\section{GEOLOGICAL SETTING}

The Rainbow massif is located in a small NTD of the MAR surrounded by en échelon nodal basins [Gràcia et al., 2000; Parson et al., 2000] that offset the AMAR and AMAR minor segments of the ridge by $19.6 \mathrm{~km}$ in distance and $1.1 \mathrm{Myr}$ in age[German et al., 1996]. Rainbow is one of a sequence of ten NTDs found south of the Azores; many of which host active or fossil hydrothermal systems [Gràcia et al., 2000]. Based on morphological and lithological observations, Andreani et al. [2014] argue that the dome-shaped massif is an oceanic core complex (OCC) uplifted along a west dipping detachment fault that is currently inactive. They find that the oblique orientation of fault traces crosscutting the massif and one available focal mechanism [Dziewonski et al., 1981; Ekstrom et al., 2012] just south of the massif both indicate a $\sim 30^{\circ}$ clockwise rotation of the axis of least compressive stress with respect to the spreading direction. In 2005-2007 the MARCHE autonomous hydrophone array [Simao et al., 2010] recorded scattered seismic activity in this region demonstrating that it is seismically active (Fig 2- 
1, yellow circles) but not indicating any obvious tectonic features. Paulatto et al. [2015] estimate that tectonic strain accommodates $60-80 \%$ of crustal accretion at the Rainbow NTD. Using bathymetry, gravity and magnetics, Paulatto et al. [2015] document the presence of at least two other oceanic core complexes on the fossil trace of the NTD, suggesting that exhumation of mantle rocks by detachment faulting has been a common process within the NTD during at least the last $\sim 3.5 \mathrm{Myr}$.

Rainbow massif is largely covered by pelagic sediments with minor amounts of carbonates [Andreani et al., 2014; Eason et al., 2016]. Where basement is exposed, dredges and submersible observations document that the most abundant rock types are highly serpentinized mantle rocks, which are present throughout the massif except at its southernmost extreme [Andreani et al., 2014]. Ultramafics show varied textures representing a history of plastic deformation, hydrothermal alteration, static and syntectonic serpentinization, as well intrusions of mafic material showing greenschist facies alteration (talc-tremolite-chlorite) [Andreani et al., 2014]. Exposures of mafic plutonic rocks are rare (recovered in only 6 of the 29 dredges reported in Andreani et al., [2014]) but consistently associated with serpentinized peridotites throughout the core of the massif [Andreani et al., 2014]. Most of these rocks are undeformed, although some present evidence for plastic deformation or ductile-to-brittle deformation bands [Andreani et al., 2014]. Exposures of volcanic rocks are rare, and outcrop preferentially on the northern and southern edges of the massif [Andreani et al., 2014].

High-temperature hydrothermal venting on the massif presently occurs through 10 active black smoker chimneys [Fouquet et al., 1998], forming the Rainbow Hydrothermal Field (RHF). Two fossil low-temperature hydrothermal sites (Ghost City and Clamstone) 
have also been documented [Lartaud et al., 2010; 2011]. Vent fluids from the RHF are high in $\mathrm{H}_{2}$ and $\mathrm{CH}_{4}$ compared to other MAR systems, indicating that serpentinization influences vent fluid chemistry at Rainbow [Fouquet et al., 1998]. Through a detailed investigation of the Rainbow plume, German et al. [2010] estimated volume and heat fluxes from the RHF of $450 \mathrm{~L} / \mathrm{s}$ and $0.5 \mathrm{GW}$, respectively, whereas Thurnherr and Richards [2001] estimate a heat flow of 1-5 GW. Active and fossil hydrothermal activity at Rainbow is associated with recent faults and fractures, suggesting that normal faulting throughout the center of the massif localizes fluid discharge zones [Andreani et al., 2014].

\section{DATA PROCESSING AND RESULTS}

Fifteen OBSs were deployed on and around the Rainbow Massif (Fig. 2-1) as part of the MARINER experiment aboard the R/V Marcus G. Langseth on cruise MGL1305 [Canales et al., 2013]. The seismic network consisted of three rings of instruments centered on the massif, each with a different aperture: 1) four instruments were deployed on a $5 \mathrm{~km}$ radius ring, 2) five instruments were deployed on a $2 \mathrm{~km}$ radius ring, and 3) six instruments were deployed in a tight cluster around the active venting site $(<500 \mathrm{~m}$ separation) (Fig 2-1). The deployment strategy allowed us to detect seismicity at scales ranging from tectonic activity associated with extension and deformation within the NTD to very small events associated with hydrothermal flow. Each instrument contained a short-period, three-component seismometer and a hydrophone, with each channel recording at $200 \mathrm{~Hz}$. The instruments started recording in May, 2013, and were recovered aboard the RV Pelagia in January, 2014, providing 9 months of continuous data. Two of 
the instruments could not be recovered due to failures in the anchor release system (Fig. 2-1), resulting in 13 complete records. Data quality was generally good with comparable noise levels on all instruments (Fig. 2-2), and high levels of seismic activity were recorded by all instruments.

The raw data was band-pass filtered at $8-20 \mathrm{~Hz}$ for event detection using the short-term average/long-term average (STA/LTA) algorithm available in the Antelope software package (www.brtt.com). More than 65,000 events were identified by associating arrivals on at least four stations during a two second window on the vertical channel, yielding a rate of $\sim 300 /$ day over $20 \mathrm{~km}$ of the ridge axis. The preliminary arrival times from the STA/LTA algorithm were refined by an algorithm that identifies the maximum value of the slope of the signal to noise ratio (SNR) for $P$ - and $S$-wave arrivals, where the noise levels were estimated from the data acquired 2 seconds before the $P$ arrival. $S$-wave picks were constrained to be after the $P$-wave arrival, and were made on both horizontal channels with the pick of maximum SNR being kept for cases where $S$ wave arrivals were found on both channels. The picking methodology was developed empirically based on visual inspection of algorithm performance on a subset of $\sim 300$ events, and it effectively captures the first break motion for typical events in the catalog (Fig. 2-2). The seismicity rate is nearly linear throughout the 9-month deployment (Fig. 2-3), with no indication of foreshock-aftershock sequences or swarms.

Earthquake hypocenters were estimated using a grid-search algorithm that calculated the weighted root mean square (RMS) residual between the observed arrival times and those predicted by tracing rays through a 3D velocity model, with each arrival time pick weighted by the inverse of its uncertainty. Hypocenter estimates correspond to 
the grid point that minimizes the RMS residual for each event. Uncertainties in the hypocentral estimate arise from picking errors on $P$ and $S$ arrivals, velocity model errors, raytracing errors, and station effects. A $P$-wave velocity model with $250 \mathrm{~m}$ grid spacing was generated for a $32 \times 32 \times 16(x-y-z) \mathrm{km}$ domain centered on the massif based on the active-source tomography results of the MARINER experiment [Canales et al., 2013]. A rayshooting algorithm (RAYTRACE3D [Menke, 2005]) was used to estimate $P$-wave travel times from each grid point in the velocity model to each instrument on the seafloor. $S$-wave travel times were predicted by multiplying the $P$-wave times by a constant factor (i.e., $V_{p} / V_{s}$ ratio), chosen by systematically varying $V_{p} / V_{s}$ from 1.5 to 2.1 and finding the value that minimized the RMS residual for a subset of the 3457 best recorded events. The best-fitting $V_{p} / V_{s}$ of 2.05 is at the high end of the range measured in MAR gabbroic rocks [Miller and Christensen, 1997] but consistent with estimates for serpentinite (1.78-2.21) [Christensen, 2004]. The final hypocenter estimates (Fig. 2-4, 2-5) were refined by applying a station correction to the $P$ - and $S$-arrival times for each instrument to ensure that the mean RMS for each station was $\sim 0 \mathrm{~s}$.

Earthquake moments were estimated based on the spectral levels of each event in the 4-20 Hz frequency band (Fig. 2-6) and then correcting for propagation distance and radiation pattern [Brune, 1970]. The average moment magnitude of all events is $\sim 0.5$ with most events falling between -0.1 and 2 (Fig. 2-7). The $b$-value for the catalog of events is $\sim 1.7$ (Fig. 2-8)

Focal mechanism estimates were attempted based on $P$-wave first arrival polarities using the HASH software [Hardebeck and Shearer, 2002; 2003]. However, given the low number of instruments, the generally high azimuthal gap for events, the 
data quality, and the lack of horizontal channel rotation information; the results are generally unconstrained by the data and we are not able to reliably determine unique focal mechanisms. For instruments $48,50,54$ and 55 we were able to determine horizontal rotation information by using the direct water arrival polarity from active source shooting which occurred while the instruments were recording. For 10 of the largest and best recorded events we used the approach of Jechumtalova et al. [2014] using $P$-wave polarity along with $P$ - and $S$-wave amplitudes to constrain the moment tensor both for a double couple case and a shear-tensile crack (STC) source model. P-wave polarity information is available for all stations while the S-wave amplitude information is only available for the four stations that have a known rotation. The Combining the P-wave polarity with the ratios of $\mathrm{P}$ to $\mathrm{S}$ wave amplitudes helps to constrain the orientation of the source mechanism. The best-constrained mechanisms are typically oblique with an extensional component (Fig. 2-9).

The performance of the relative relocation method hypoDD [Waldhauser and Ellsworth, 2000] was evaluated on a subset of 1000 well recorded events. In cases with similar source process and consequently similar waveforms the hypoDD method can offer an improvement on the relative locations for a cloud of earthquakes potentially elucidating underlying structures by dimishing the effects of improper velocity model characteristics and station effects. Using cross correlation the pick times for a cluster of similar events can be made more consistent and the arrival lag times between similar events can be used to determine the relative spacing between events. For our dataset the hypoDD method offered no improvements to the locations as the events had no clusters of well correlated $(>0.7)$ event waveforms. 
A statistically based collapsing method was employed to evaluate the ability of a simple subsurface structures to adequately explain the distribution of seismicity. The method of Jones and Stewart [1997] moves events with overlapping uncertainty ellipsoids within their individual uncertainty ellipsoids towards the centroid of all overlapping events in an iterative process that results in the simplest pattern of events that is still consistent with the location and confidence ellipsoid data. This method reduces the smearing effects due to pick uncertainty and errors in the velocity model on a cloud of events, while not formally increasing the absolute location accuracy. The results of this relocation method are presented in figure 2-10. There is a general tendency to move the shallowest events downward and to move all events towards the center of the cloud. The overall pattern of seismicity occurring above $4 \mathrm{~km}$ depth does not change and there are no obviously revealed fault structures in the new pattern so we prefer to interpret the unrelocated pattern of seismicity in the discussion.

\section{DISCUSSION}

Our study represents the first local earthquake survey of a slow-spreading NTD, and it provides the largest event catalog to-date for an actively serpentinizing region of a mid-ocean ridge. In addition, interpretation of the local seismicity at Rainbow is greatly facilitated by the collocated results from the multi-channel seismic imaging conducted as part of the MARINER experiment [Canales et al., 2017]. We begin the discussion by considering the implications of our results for the tectonics of the Rainbow NTD, and then compare and contrast our local seismicity patterns with those imaged at other OCCs on the MAR. We conclude by integrating our seismicity results with those from the 
active-source seismic components of the MARINER experiment to examine the implications for hydrothermal convection and serpentinization in the Rainbow massif.

\subsection{Tectonics of the Rainbow NTD}

Our microearthquake catalog contains 65000 events with a total moment release of $3 \times 10^{21}$ dyne-cm, equivalent to a single $M_{L}=3.6$ event. These events occurred at a roughly constant rate of 300 events/day (Fig. 2-3) with a notable lack of mainshock/aftershock sequences or swarming activity. These results demonstrate that the massif was deformed by a high and essentially constant rate of low-magnitude, shallow seismicity during our deployment, with the majority of events occurring at depths less than $4 \mathrm{~km}$ depth below the seafloor and extending to the shallowest resolvable depths (250 m bsf) (Fig. 2-5). There is a paucity of seismicity that can be attributed to faults in the axial rift valleys and nodal basins (Fig. 2-5) around Rainbow, and we thus find no evidence for seismic activity related to exhumation of the massif during this deployment.

Whereas previous microearthquake surveys of active oceanic detachment faults and OCCS have identified distinct faulting and deformation structures associated with regional-scale lithospheric extension [Collins et al., 2012; deMartin et al., 2007; ParnellTurner et al., 2017; Grevemeyer et al., 2013], the lack of any such features in our data suggests that if the Rainbow massif was exhumed along a detachment fault, such fault is no longer active. This supports the interpretation of [Andreani et al., 2014], based on the observation of a continuous and undisrupted sediment cover between the western flank of the massif and the nodal basin, that the Rainbow massif is no longer being exhumed. This interpretation is also consistent with shipboard geophysical data from the MARINER 
experiment, which indicates that the ridge offset that formed the Rainbow NTD is migrating to the north into the AMAR Minor N segment where a new detachment fault is possibly forming, having accumulated $1 \mathrm{~km}$ of offset [Paulatto et al., 2015]. This possible nascent detachment fault is located beyond the range of our OBS network, and so we are unable to determine if it is seismically active.

The Rainbow massif is transected at an oblique angle by a set of roughly parallel faults, which have been interpreted to indicate that the massif itself is presently being extended rather than exhumed [Andreani et al., 2014; Eason et al., 2016]. Shallow, oblique extension on these faults is broadly consistent with our microearthquake data, and we examine this hypothesis in more detail, below. Our interpretation that the massif is no longer being exhumed must be caveated by the fact that our observation period ( 9 months) was short relative to tectonic and magmatic cycles at mid-ocean ridges, so we cannot rule out the possibility that large-scale faults associated with exhumation of the massif remain active but were dormant during our experiment.

\section{$\underline{4.2 \text { Seismicity compared to other Oceanic Core Complexes }}$}

Seismicity at the TAG segment of the MAR is related to an active oceanic detachment fault. deMartin et al. [2007] found a similar level of activity (19,232 events) during an eight-month period at TAG. Earthquakes there delineate a $15 \mathrm{~km}$ long detachment fault surface with a curving shape in plan view which extends to down to 7 $\mathrm{km}$ depth but is apparently aseismic at $<3 \mathrm{~km}$ depth. The seismicity we detected at Rainbow is fundamentally different from that at TAG in several aspects: it is distributed 
in a diffuse pattern and predominantly located within the presumed footwall, rather than along a well-defined fault surface; and shows significant activity to shallowest depths.

Atlantis massif is an inside-corner OCC bounded by a transform fault, and consisting of a large gabbroic core surrounded by serpentinized peridotites [e.g., Blackman et al., 2011; Harding et al., 2016]. Collins et al. [2012] found that the majority of seismicity recorded during a 6-month period at Atlantis was concentrated in the axial valley rather than the massif itself, with more than half of the total recorded events consisting of mainshock-aftershock sequences. This contrasts with our observation that seismicity at Rainbow maintains a nearly constant rate during the 9-month deployment (Fig. 2-3). During the 6 month deployment Collins et al. [2012] did record a $\sim 100$ day period of nearly constant rate seismicity between the two mainshock-aftershock sequences which is on the same order of the length of the deployment at Rainbow which could make this difference in seismic character more apparent than real. The survey at Atlantis Massif was not designed to determine if the detachment fault responsible for its uplift was currently active or not. However, the asymmetry in the rift valley seismicity suggests that it is possible that asymmetric detachment faulting is currently active at Atlantis [Collins et al., 2012], and ridge-parallel normal-faulting events located on the massif are consistent with flexural deformation of the exposed detachment surface [Collins et al., 2012].

A deployment of OBSs within the $15^{\circ} \mathrm{N}$ spreading segment of the MAR, which includes the serpentine-hosted Logatchev hydrothermal field, recorded an average of 24 locatable earthquakes per day on a similar sized array [Grevemeyer et al., 2013]. With respect to the Logatchev, seismicity at Rainbow is an order of magnitude more abundant 
with a much higher proportion of small events relative to large events. Seismicity in the vicinity of the Logatchev OCC is asymmetric relative to the spreading axis, while elsewhere along the $15^{\circ} \mathrm{N}$ segment it is distributed symmetrically within the axial valley [Grevemeyer et al., 2013]. This along-axis difference is interpreted by Grevemeyer et al. [2013] as resulting from local, active detachment faulting at the Logatchev OCC.

Thus, when comparing the TAG, Atlantis Massif, and Logatchev catalogs with our Rainbow catalog, we find that the lack of large events $\left(\mathrm{M}_{\mathrm{L}}>2\right)$ at Rainbow in combination with the diffuse pattern of seismicity further support the lack of active detachment faulting exhuming the Rainbow massif.

\subsection{Potential seismogenic mechanisms for the Rainbow Massif}

The inability of our seismic network to provide robust focal mechanism constraints limits our ability to constrain the nature of the source mechanism(s) for the observed seismicity. Nevertheless, we may use the size, location, and rate of the observed activity to evaluate the plausibility of the various potential source mechanisms that might be expected in this geological setting, including tectonic extension of the massif, thermal subsidence and cracking, and serpentinization-induced cracking.

Seismicity beneath the Rainbow massif exhibits a diffuse, dome-shaped pattern that roughly mimics the morphology of the massif itself (Fig. 2-4). Projecting the hypocenters onto cross-sections from the MCS profiles (Figure 2-11) shows that most are sandwiched in-between the seafloor and sub-horizontal reflectors in the MCS data, which have been interpreted to be magmatic sills intruded into ultramafic rock [Canales et al., 2017]. In addition, the majority of events occurred in host rock with relatively fast $P$ - 
wave velocities indicative of ultramafic material (Fig. 2-12). These observations, combined with the hydrogeological and tectonic setting of the massif, lead to the conclusion that the seismicity occurs in peridotite host rock that is being deformed by some combination of tectonic extension, thermal contraction, and serpentinization.

The conceptual model of McCaig et al. [2007] presents an idealized evolutionary model of an OCC in which hydrothermal activity is intimately related to activity along a detachment fault. In their model, slip along a detachment provides a mechanism to channelize high temperature hydrothermal fluids tapping heat from a partially molten zone at the ridge axis and/or within the detachment footwall. After the detachment becomes inactive, McCaig et al. [2007] model predicts that hydrothermal activity should evolve from a high- to a low-temperature system like Lost City. Our finding that Rainbow lacks significant seismicity associated with a detachment while at the same time high-temperature activity is sustained within the massif, provides a departure from the McCaig et al. [2007] model.

The volume of the seismically active region in our catalog is $\sim 412 \mathrm{~km}^{3}$, and with a total moment release of $3 \times 10^{21}$ dyne-cm over 9 months and assuming a shear modulus of $71 \mathrm{GPa}$ [Ben Ismail and Mainprice, 1998] we obtain a seismic strain rate [Ekstrom and England [1989] of $8.9 \times 10^{-9} \mathrm{yr}^{-1}$. If tectonic strain accommodates $80 \%$ [Paulatto et al., 2015] of the full spreading rate of $21.5 \mathrm{~mm} / \mathrm{yr}$ for this region [Le Douaran et al., 1982; Sloan and Patriat, 1992] across the $\sim 10 \mathrm{~km}$ width of the massif the tectonic strain rate is $1.72 \times 10^{-6} \mathrm{yr}^{-1}$. If the strain is accommodated over the entire axial valley $(\sim 13 \mathrm{~km})$ the tectonic strain rate is $1.3 \times 10^{-6} \mathrm{yr}^{-1}$. These estimates, combined with the best-constrained focal mechanism estimates of oblique extension (Figure 2-9) and the extensional faults 
that transect the massif, suggest that tectonic extension of the massif is a plausible source mechanism for the observed seismicity. However, the high b-value of 1.7 and the constant seismicity rates for our catalog are not consistent with expected values for tectonic events, which typically have catalog b-values of 1.0 and exhibit intermittent activity with mainshock-aftershock sequences.

Thermal strain from cooling of magmatic sills to generate hydrothermal convection is another potential source mechanism for the observed seismic activity. Following [Wilcock et al., 2002] the thermal strain rate for a volume of cooling crust is

$$
\dot{\varepsilon}_{H y}=\frac{Q \alpha_{l}}{V \rho c_{p}}
$$

where $Q$ is the hydrothermal heat flux $\left(0.5 \mathrm{GW}\right.$, [German et al., 2010]), $\alpha_{l}$ is the coefficient of thermal expansion $\left(5 \times 10^{-5} \mathrm{~K}^{-1}\right.$, [Liu and Lowell, 2009]), $V$ is the volume of the cooling sills $\left(6.1 \times 10^{9} \mathrm{~m}^{3}\right.$, [Canales et al., 2017]),$\rho$ is the crustal density $(2700$ $\mathrm{kg} / \mathrm{m}^{3},\left[\right.$ Hooft and Detrick, 1993]), and $c_{p}$ is the specific heat capacity of the sills (1400 J $\mathrm{kg}^{-1} \mathrm{~K}^{-1}$, [Liu and Lowell, 2009]). Using these parameters we obtain a thermal strain rate of $3.4 \times 10^{-5} \mathrm{yr}^{-1}$. We thus find that the thermal strain rate in the cooling magmatic sills is one or more orders of magnitude greater than the local tectonic strain rate. However, this thermal strain is occurring in the regions where the magma sills are imaged, which are essentially aseismic (Fig. 2-11) and where deformation may be accommodated by plastic, rather than brittle, processes (in cooling/crystallizing magma). Moreover, brittle deformation from subsidence induced by cooling at depth should generate discrete, graben-type faulting patterns in the overlying crust rather than the diffuse cloud of 
activity that we observed. These considerations lead us to conclude that while thermal strain from the contraction of cooling melt bodies driving hydrothermal circulation is likely an important process at the Rainbow massif, it is not consistent with the observed seismicity pattern.

It is clear from the composition of the hydrothermal fluids being discharged at the RHF [Charlou et al., 2002] and the rock samples acquired from the massif [Andreani et al., 2014] that the ultramafic massif is being actively serpentinized by hydrothermal circulation. The location of the microearthquake hypocenters in largely ultramafic rocks (Fig. 2-12) above the magmatic sills (Fig. 2-11) driving hydrothermal convection suggests that serpentinite alteration may play a role in generating the observed seismicity. Serpentinization of peridotite increases the solid volume of the rock, which can generate fractures either at the micro-scale due to intra-grain stresses [Kelemen and Hirth, 2012], or at the regional scale due to buoyant diapirism within the massif [Bonatti, 1976]. If the observed seismicity was generated by volume change in the host rock from serpentinization, then we can use the relationship of Mcgarr [1976] to relate the volume change to the moment release,

$$
\sum M_{o}=K \mu|\Delta V|
$$

where $K=1$ for a pure volume increase crack opening in one direction, $\mu$ is the modulus of rigidity ( $71 \mathrm{GPa}$ ), and $\Delta V$ is the total volume change associated with the event catalog. Using this equation we obtain a total volume change of $4 \times 10^{-6} \mathrm{~km}^{3}$ associated with our catalog, yielding a volumetric strain rate of $1.8 \times 10^{-8} \mathrm{yr}^{-1}$ when averaged over the seismogenic volume $\left(\sim 412 \mathrm{~km}^{3}\right)$. Given the age of the massif (39,000 yrs, [Paulatto et 
al., 2015]), the inferred volume of serpentine from seismic velocity $\left(280 \mathrm{~km}^{3}\right.$, [Canales et al., 2017]), and $40 \%$ volumetric expansion due to serpentinization the strain rate required to generate the current volume of serpentine is $1 \times 10^{-5} \mathrm{yr}^{-1}$, three orders of magnitude larger than our catalog. Therefore volumetric expansion due to serpentinization is a plausible mechanism for the observed seismicity.

Widespread serpentinization of the massif could provide some uplift of the massif through diapirism with buoyancy driven by the volume expansion and density decrease associated with serpentinization [e.g., Coleman, 1971], a mechanism based on the early ideas of Bonatti [1976] and proposed as responsible for part of the relief of other OCCs such as TAG [Germanovich et al., 2012] and Atlantis Massif [Blackman et al., 2008; Karson et al., 2006]. Serpentine diapirism could also explain the diffuse pattern of seismicity and the abundance of events at shallow depths, as uplift would result in extensional stress above the diapir.

The strain rates related to magmatic cooling and plate spreading, $3.4 \times 10^{-5} \mathrm{yr}^{-1}$ and $1.72 \times 10^{-6} \mathrm{yr}^{-1}$, respectively are orders of magnitude larger than the strain rates calculated from the total moment release in our catalog from crack opening, $1.8 \times 10^{-8} \mathrm{yr}^{-}$ ${ }^{1}$. Further, the total volume of serpentine present in the massif suggest that a volumetric strain rate of $1 \times 10^{-5} \mathrm{yr}^{-1}$ would be required if serpentinization took place at a constant rate for the lifetime of the massif.

\section{CONCLUSIONS}


From our analysis of microearthquake data acquired from the Rainbow massif we conclude that:

(1) Low-magnitude earthquakes at the Rainbow massif occur at an essentially constant rate with no swarm-like behavior and no mainshock-aftershock sequences. The events are distributed in a region sandwiched in-between magmatic sills imaged by MCS reflections and the seafloor, with no spatial patterns related to a fault surface, indicating that the detachment fault responsible for the exhumation of the massif is likely no longer active, consistent with seafloor geological observations. This a fundamental difference between the seismicity of Rainbow and that observed at other MAR OCCs such as TAG, Atlantis Massif, and Logatchev [Collins et al., 2012; deMartin et al., 2007; Grevemeyer et al., 2013].

(2) While we are unable to place robust constraints on the event focal mechanisms, the body of evidence suggests that the observed seismicity was generated by some combination of extension from tectonic stresses and volumetric strain from serpentinization of the massif.

(3) The lack of seismicity associated with active detachment faulting argues against models in which active detachment faults are needed to focus and sustain hightemperature hydrothermal activity within the footwall of OCCs [McCaig et al. [2007]. Instead, our results, combined with seismic imaging results [Canales et al., 2017], indicate that high-temperature hydrothermal discharge can be generated within inactive detachment faulting systems that contain magmatic intrusions in the footwall. 


\section{FIGURES}

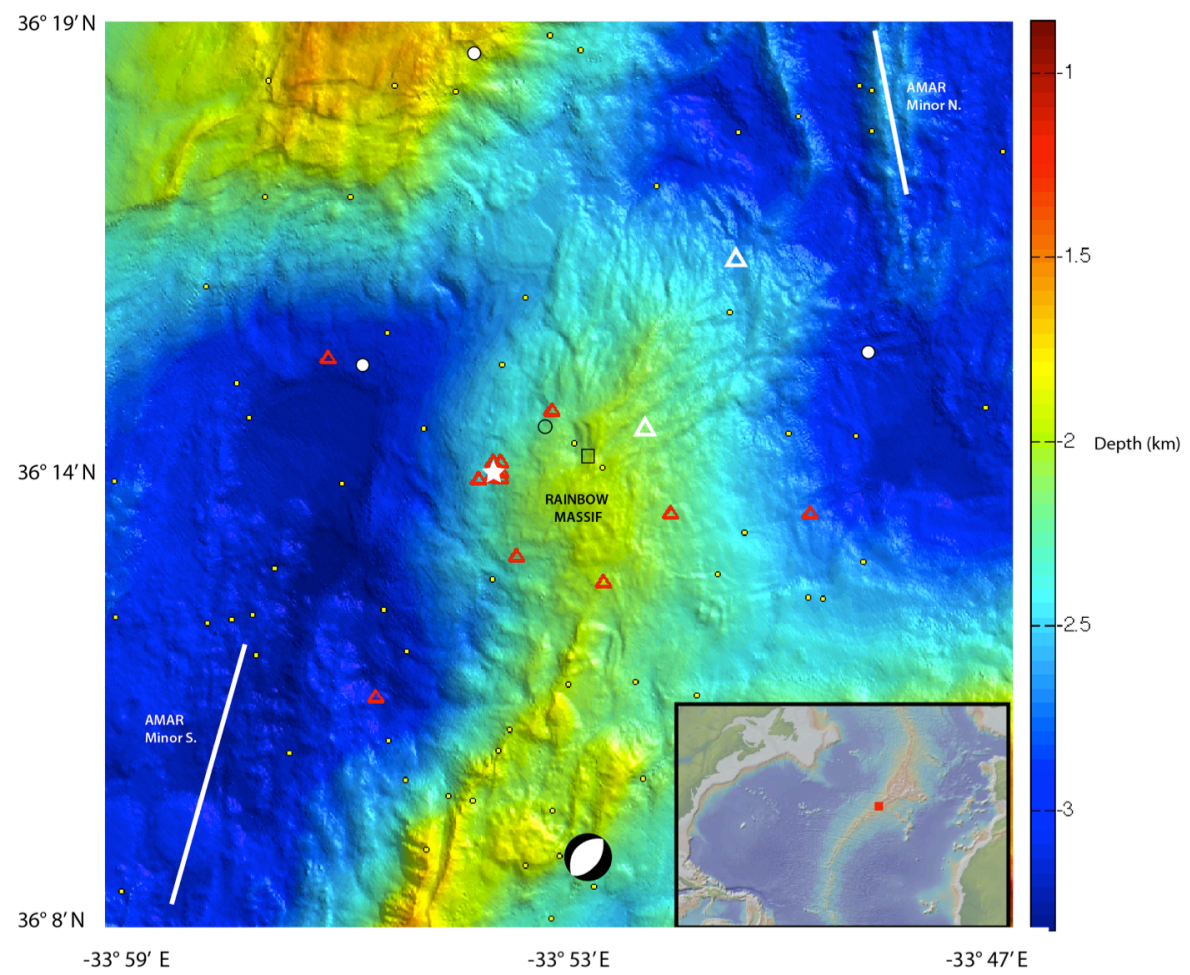

Figure 2-1. Bathymetry map of the Rainbow NTD [Paulatto et al., 2015]. The Rainbow massif is located between the AMAR minor N. and AMAR minor S spreading segments. The white star marks the location of active hydrothermal venting. The red triangles show the location of the 13 ocean bottom seismometers that returned useful data. Inset shows location of the study area along the MAR. Black outlined circle and square show fossil venting sites Ghost City and Clamstone respectively. Yellow dots are epicenter locations from the MARCHE hydrophone array. White circles show the location of teleseismic epicenters. Focal mechanism is from the GCMT catalog. 

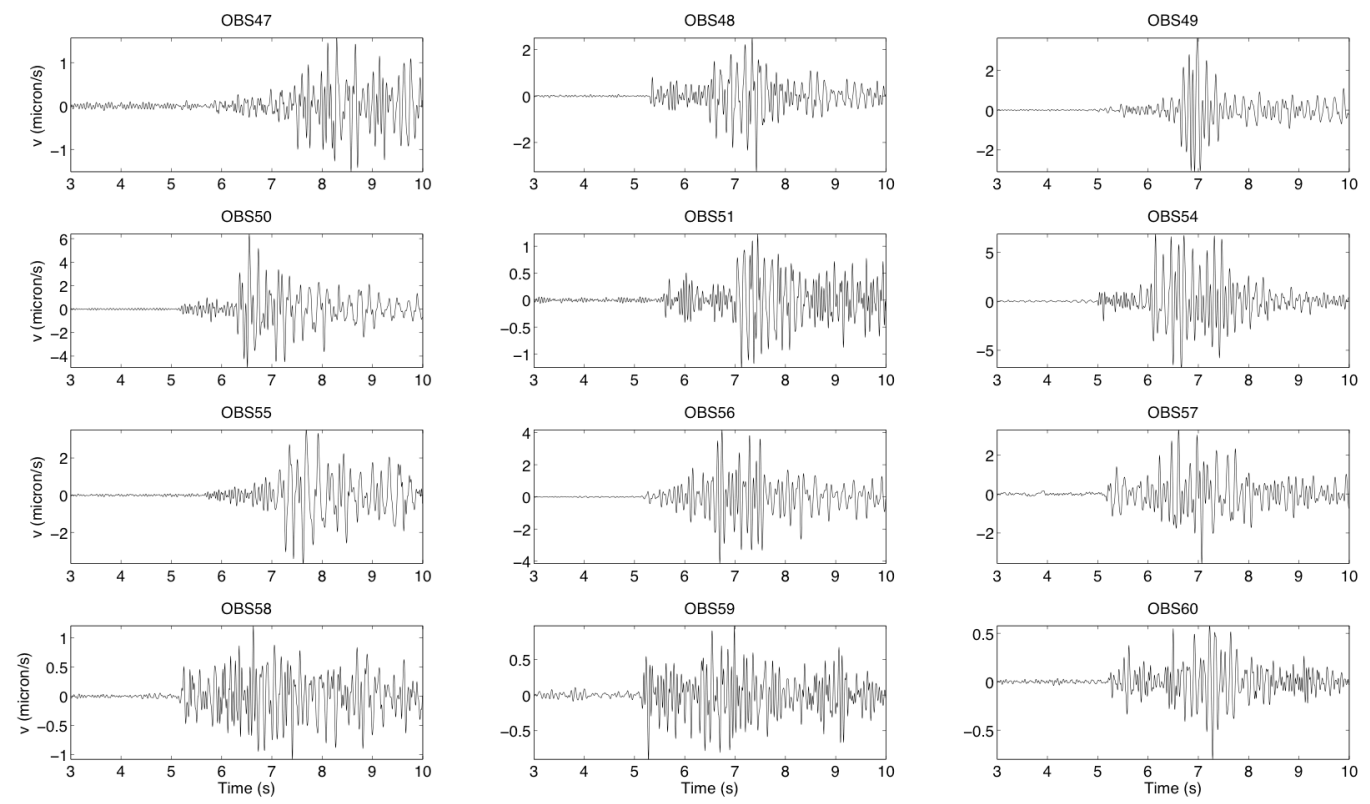

Figure 2-1. A sample of data for one event recorded on all of the vertical components for each of the 13 instruments. 


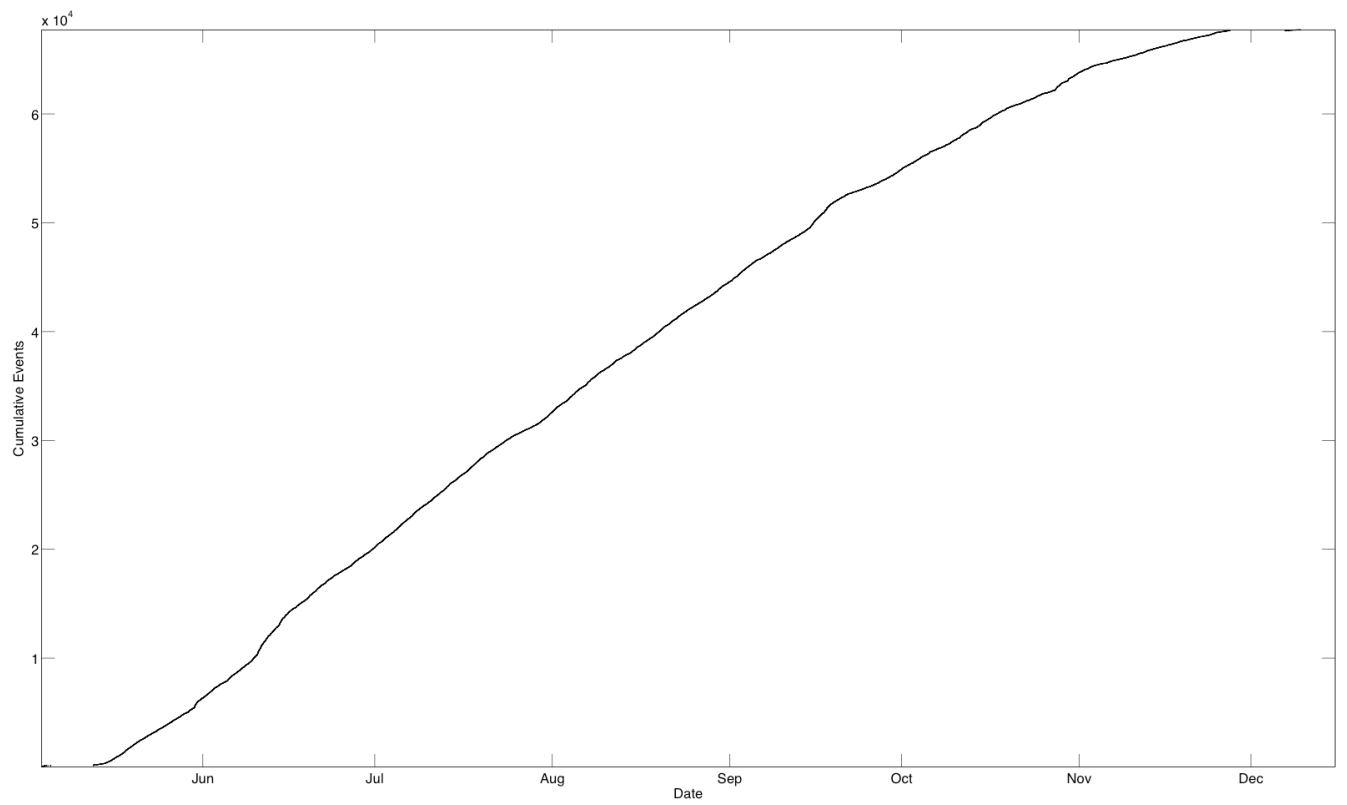

Figure 2-2. Cumulative Number of events recorded through time 
A.

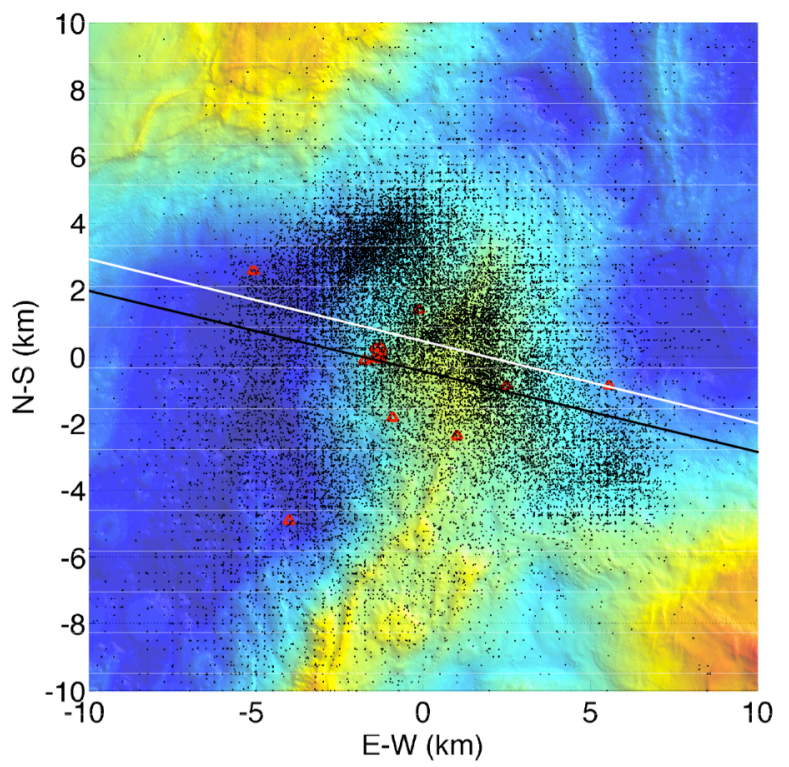

B.

$$
\text { E-W (km) }
$$

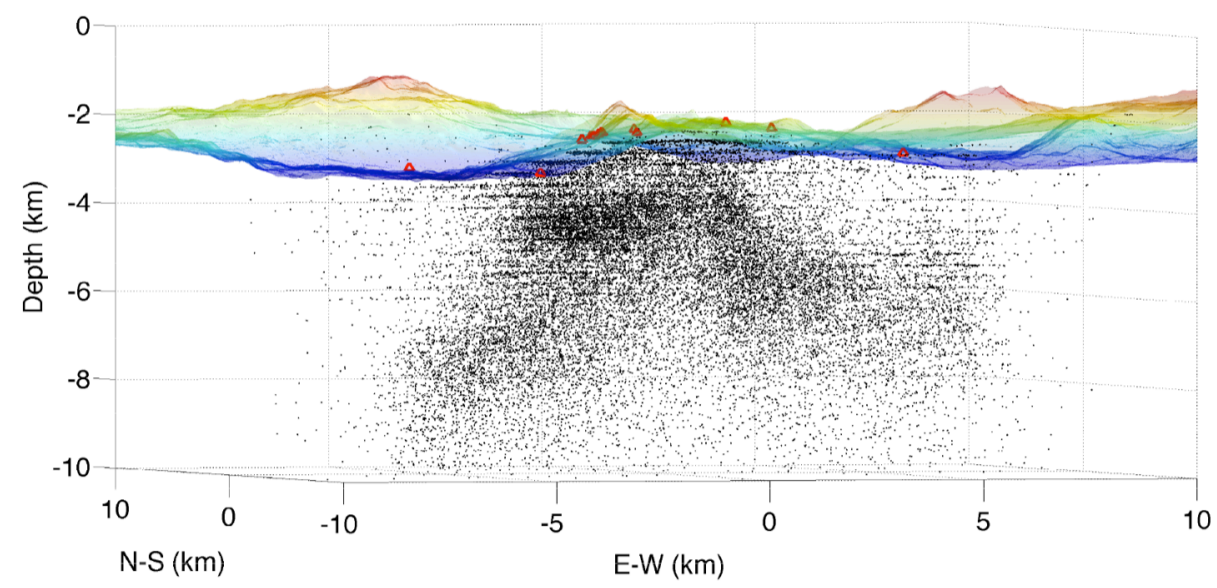

Figure 2-4. A. Epicenter locations for events with RMS $<200 \mathrm{~ms}$. Black line shows the location of MCS line 112 which transects the active venting site. White line shows the location of MCS line 114. B. Hypocenters within $1 \mathrm{~km}$ of line 112. B. Hypocenters located within $1 \mathrm{~km}$ of MCS line 112. View is looking Northeast perpendicular to line 112 . 

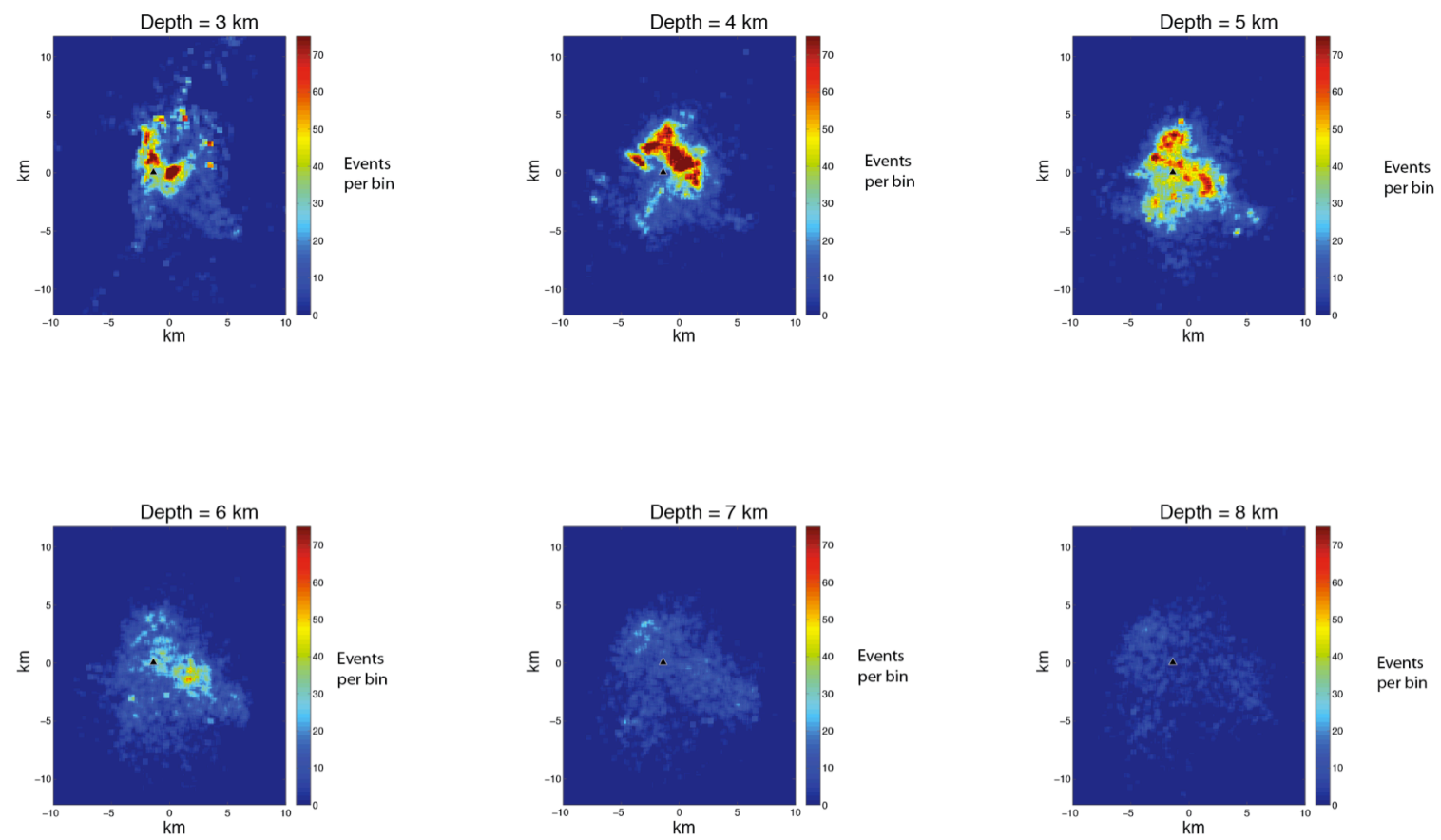

Figure 2-5. Density plot of events within a 500m grid spacing for multiple depths. Black triangle marks location of active hydrothermal venting 

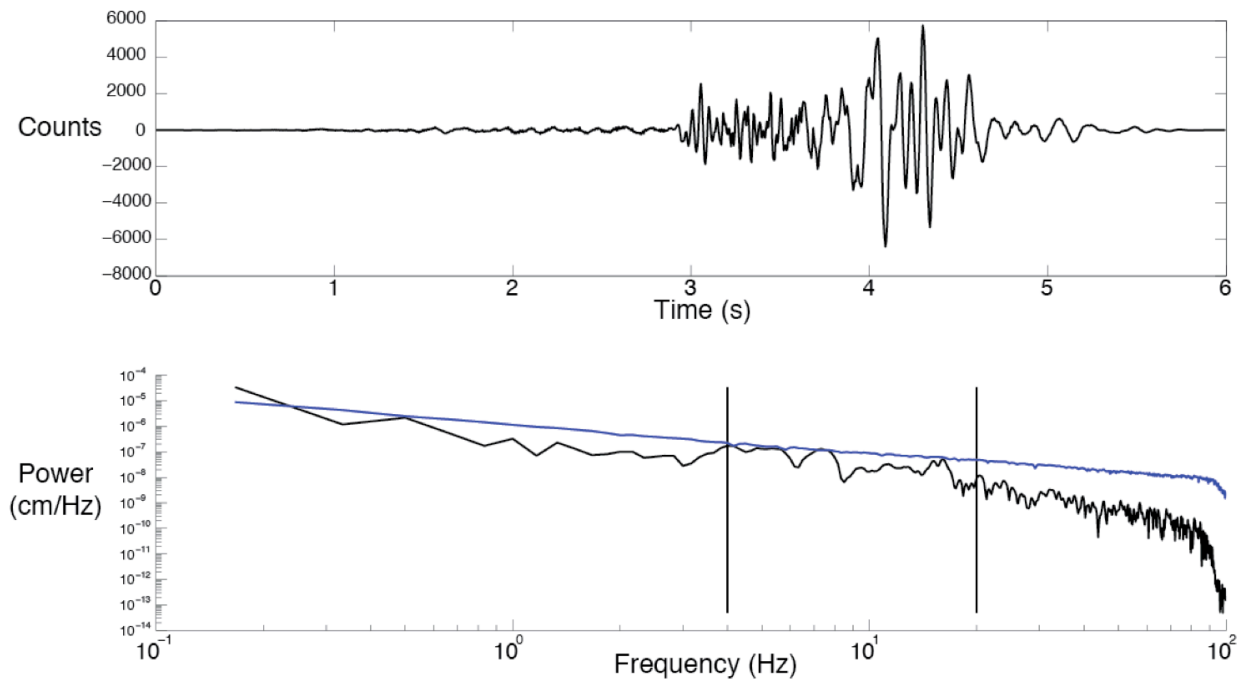

Figure 2-6. Waveform (top) and spectrogram (bottom) for one event. Black line on spectrogram represents vertical channel. Blue line is spectrogram for hydrophone. Vertical lines indicate the frequency range used for the power estimate $(4-20 \mathrm{~Hz})$. 


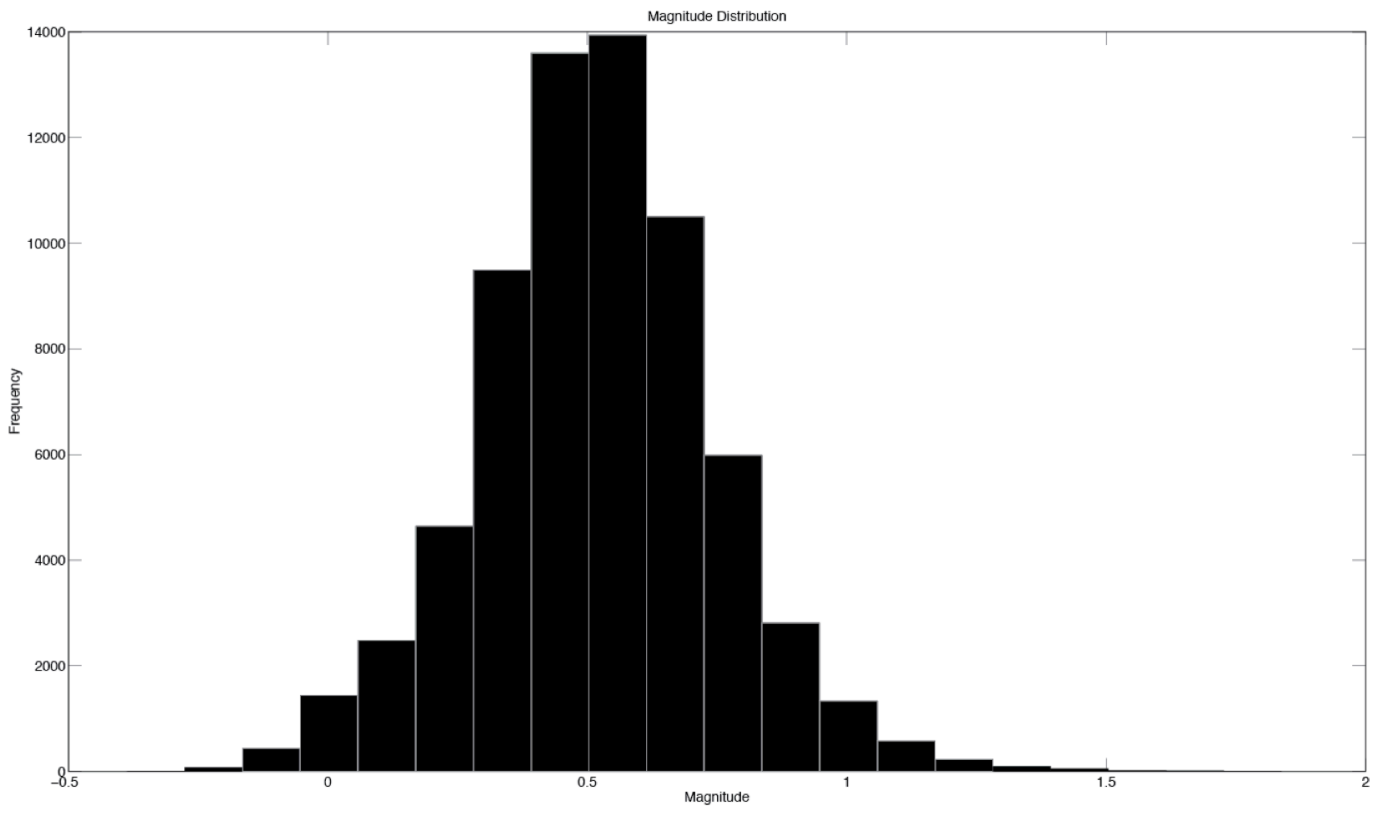

Figure 2-7. Distribution of moment magnitude for all events 


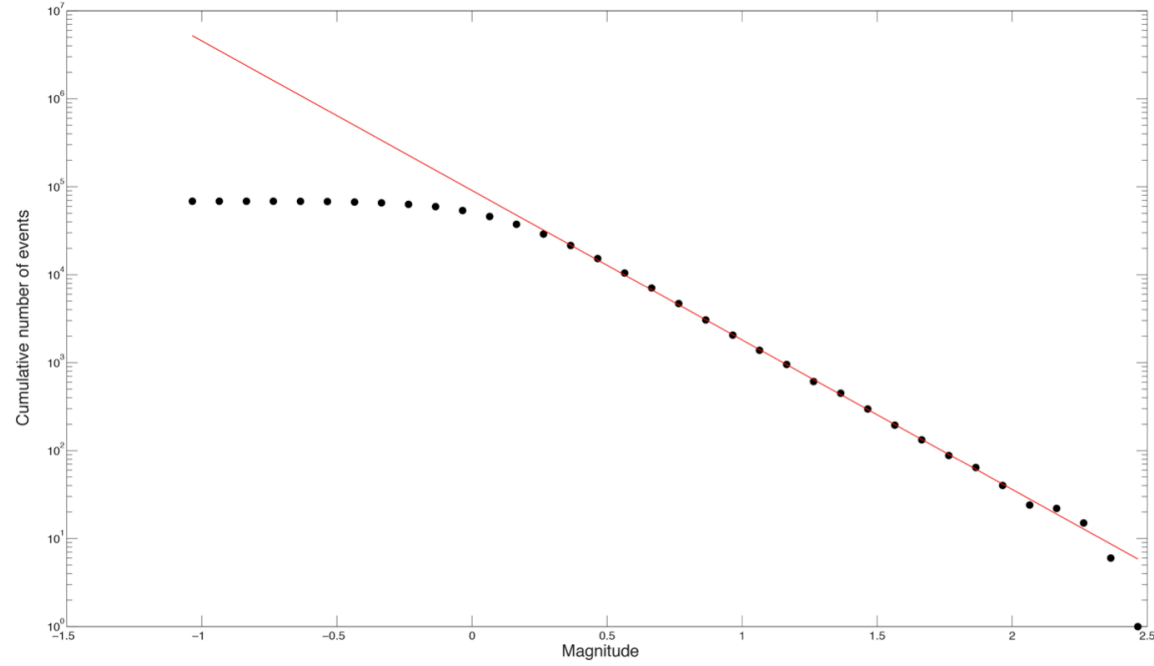

Figure 2-8. B-value plot. Black dots show cumulative number of events with respect to magntidue. The red line is the predicted value for a b-value of 1.7 which shows good fit to the data. 

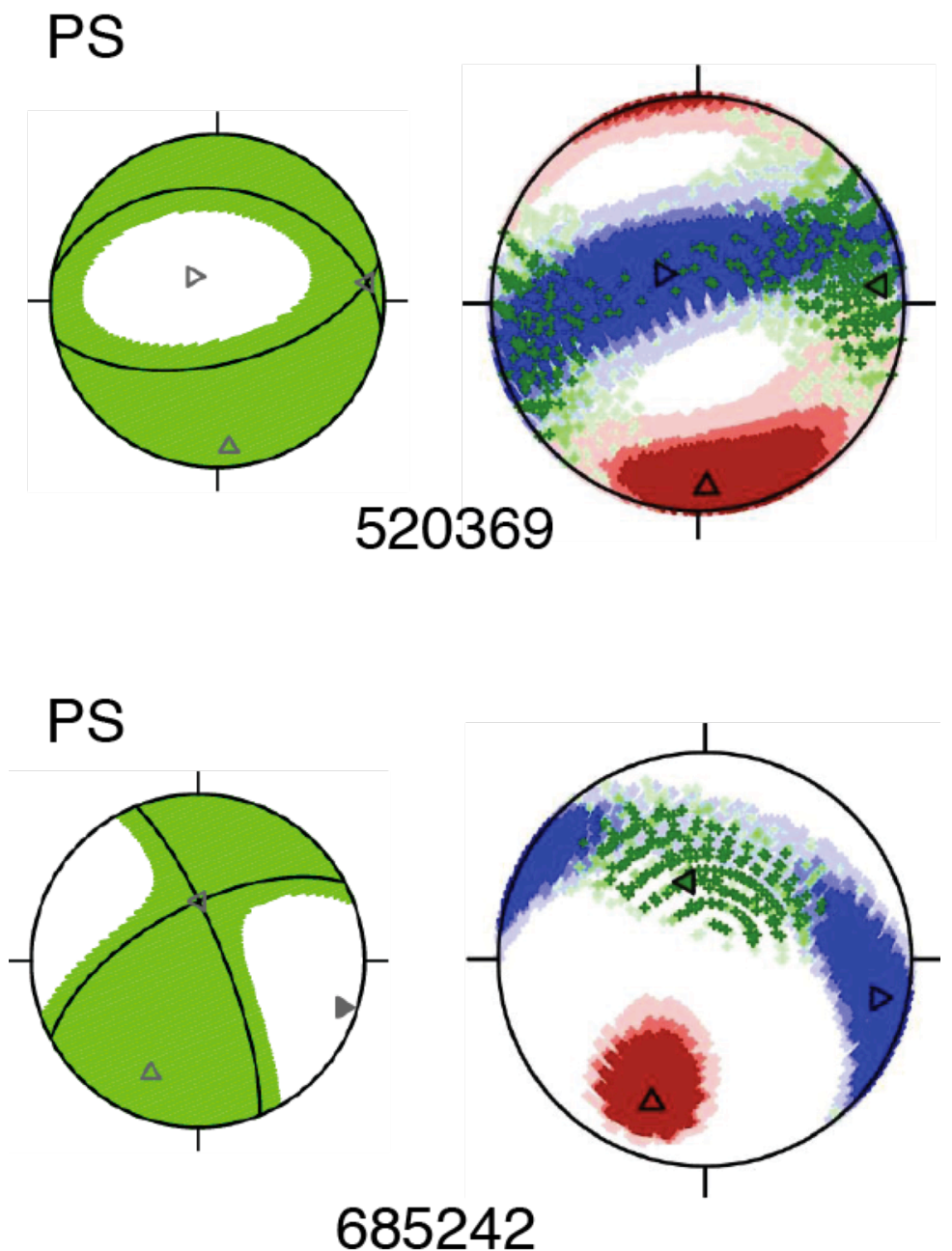

Figure 2-9. Focal mechanism plots for two well constrained events based on $\mathrm{P}$ and $\mathrm{S}$ wave picks. The left side shows the best fitting mechanism. The right side shows the uncertainty of each estimate of pole location. 


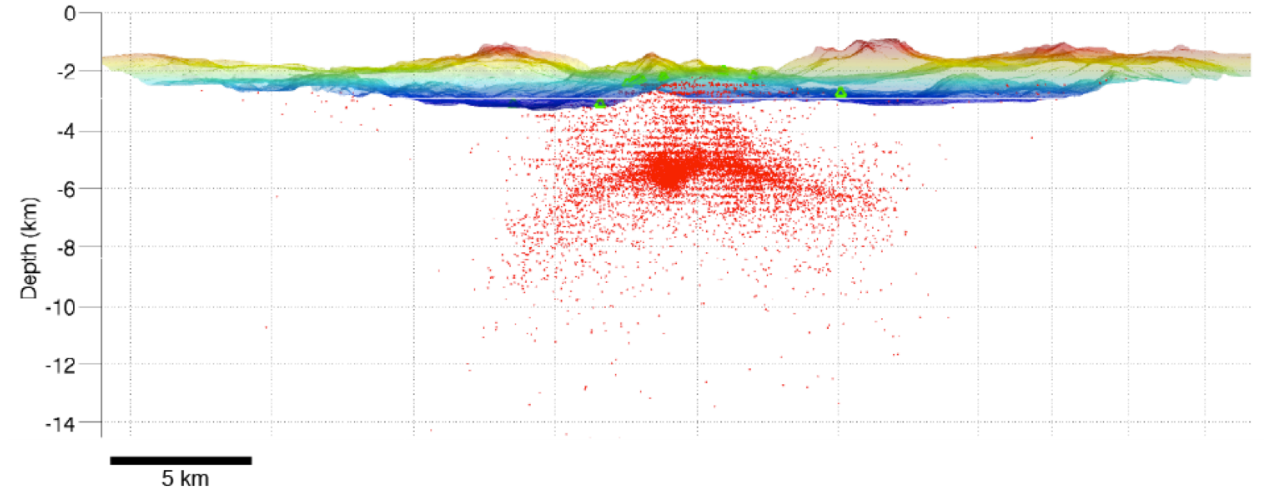

Figure 2-10. Event locations after the statistically based collapsing method. 
Line 114

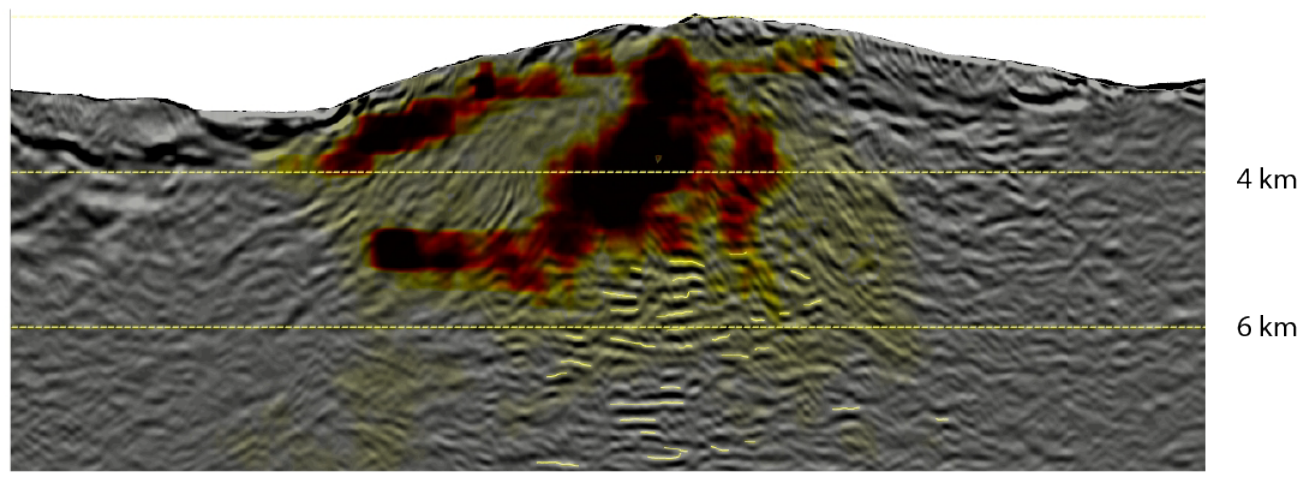

Line 112

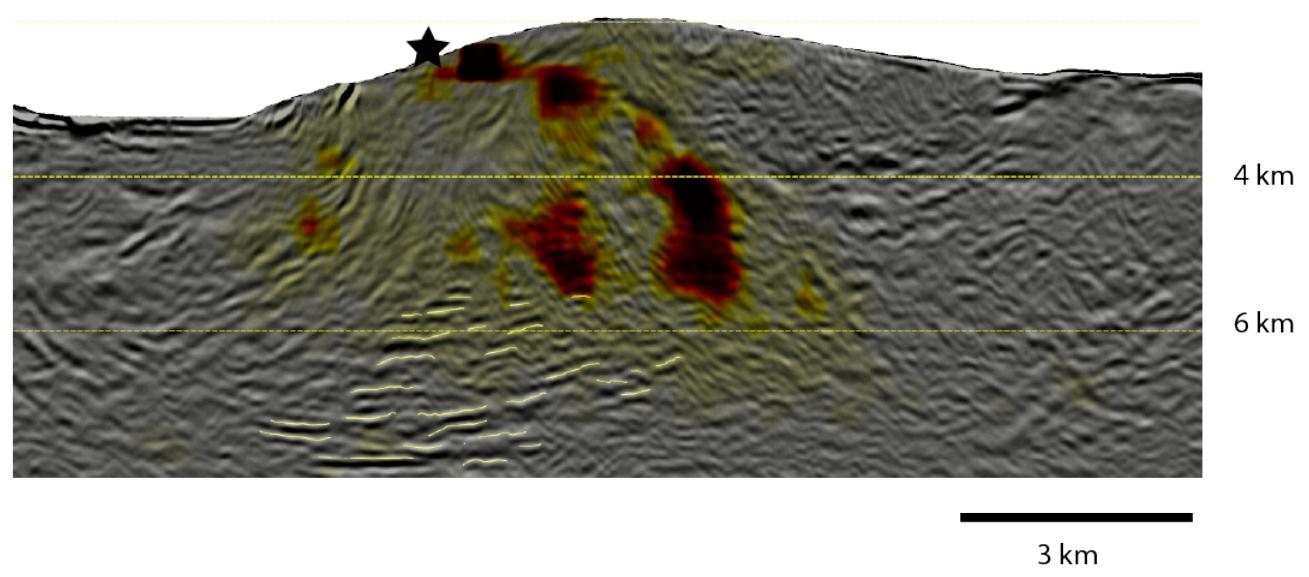

Figure 2-11. MCS reflection images from lines 114 and 112 with earthquakes density along respective lines. Darker colors indicate higher density of events. Yellow lines indicate identified magma lenses. 


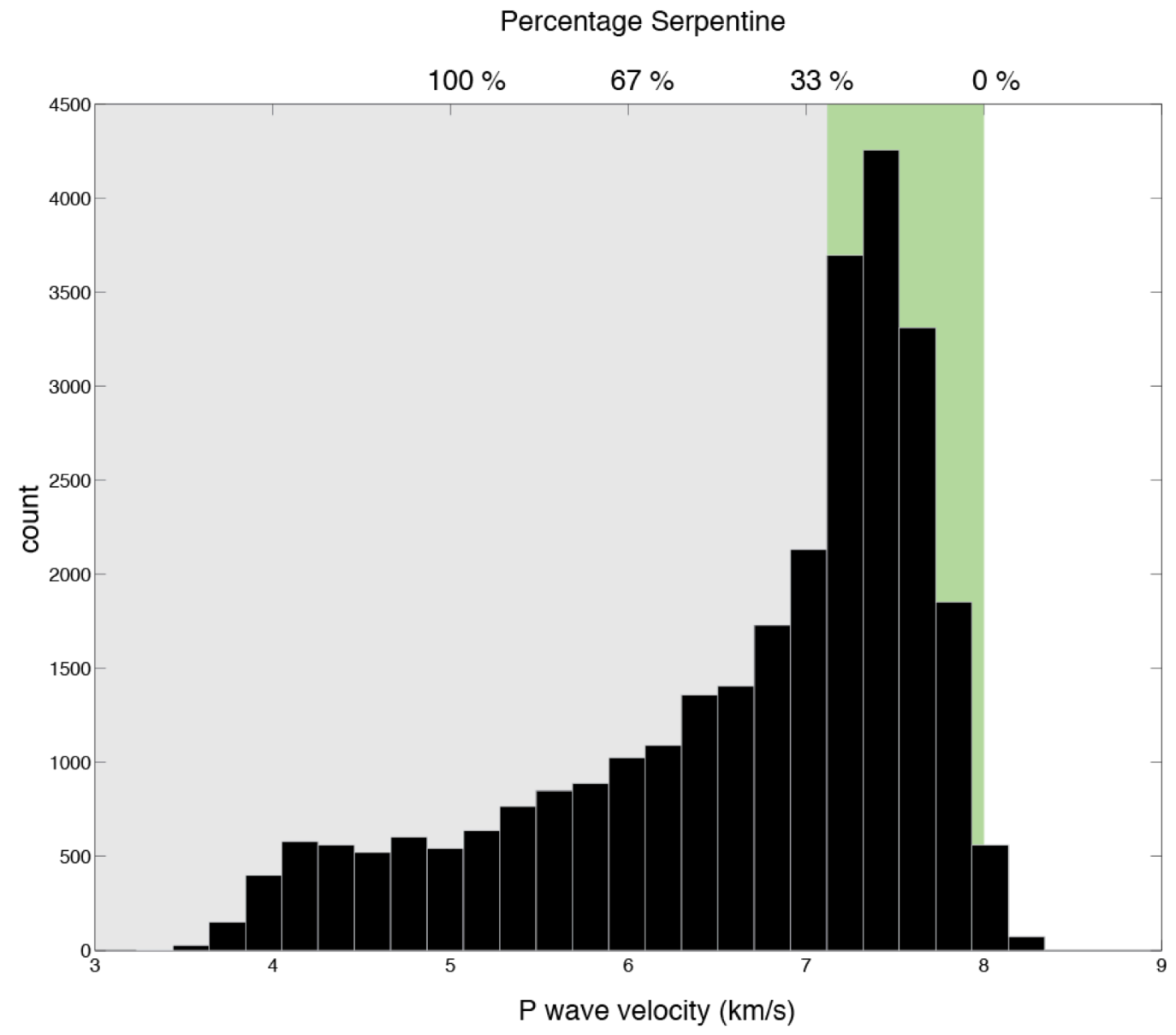

Figure 2-12. Histogram of $\mathrm{P}$-wave velocity at event locations with depth $>500 \mathrm{~m}$. Green zone shows Vp range corresponding to partially serpentinized peridotite. Gray region indicates $\mathrm{Vp}$ range that corresponds to multiple possible lithologies where $\mathrm{Vp}$ is no longer a clear indicator of alteration percentage. 


\title{
Chapter 3:
}

\section{A 2-D Tomographic Model of the Juan de Fuca Plate from Accretion at Axial Seamount to Subduction at the Cascadia Margin from an Active Source OBS survey ${ }^{1}$}

\begin{abstract}
We report results from a wide-angle controlled source seismic experiment across the Juan de Fuca plate designed to investigate the evolution of the plate from accretion at the Juan de Fuca Ridge to subduction at the Cascadia margin. A two-dimensional velocity model of the crust and upper mantle is derived from a joint reflection-refraction travel-time inversion. To interpret our tomography results, we first generate a plausible baseline velocity model, assuming a plate cooling model and realistic oceanic lithologies. We then use an effective medium theory to infer from our tomography results the extent of porosity, alteration, and water content that would be required to explain the departure from the baseline model. In crust of ages $>1 \mathrm{Ma}$ and away from propagator wakes and regions of faulting due to plate bending, we obtain estimates of upper crustal hydration of $0.5-2.1 \mathrm{wt} \%$ and find mostly dry lower crust and upper mantle. In sections of the crust affected by propagator wakes we find upper estimates of upper crustal, lower crustal, and upper mantle hydration of 3.1, 0.8, and $1.8 \mathrm{wt} \%$, respectively. At the Cascadia deformation front, we find that the amount of water stored at uppermost mantle levels in the downgoing $\mathrm{JdF}$ plate is very limited $(<0.3 \mathrm{wt} \%)$, with most of the water carried into the subduction zone being stored in the oceanic crust.
\end{abstract}

1 Published as: Horning, G., J. P. Canales, S. M. Carbotte, S. Han, H. Carton, M. Nedimović, and P. Keken (2016), A 2-D tomographic model of the Juan de Fuca plate from accretion at axial seamount to subduction at the Cascadia margin from an active source ocean bottom seismometer survey, J. Geophys. Res. Solid Earth, 121(8), 58595879. 


\section{INTRODUCTION}

Water incorporated into oceanic lithosphere prior to and with onset of subduction is the primary source of water transfer within the subduction zone [Rüpke et al., 2004]. As the plate descends, metamorphic dehydration reactions resulting from increasing pressure and temperature [van Keken et al., 2011] provide a mechanism for significant delivery of water at depth [Kawakatsu and Watada, 2007]. Free water and the presence of hydrous phases in the subducting slab both affect a number of subduction zone processes such as [Hacker et al., 2003]: (1) The presence of serpentine decreases the shear strength of peridotite [Escartín et al., 2001], affecting the rheology of the mantle wedge [Billen and Gurnis, 2001]; (2) Episodic tremor and slip (ETS) events have been linked to fluid overpressures at and above the plate interface [Obara, 2002; Rogers and Dragert, 2003]; (3) Dehydration embrittlement of the subducting slab may be responsible for intraslab seismicity [e.g., Hacker et al., 2003]; (4) By decreasing the solidus of the mantle, water plays an important role in the formation of magmas and active volcanic arcs [Tatsumi, 1989]. The total water content of an incoming plate can be considered as the sum of the free water in pore spaces in the sedimentary cover and highly porous upper crust (which is mostly lost in the shallow forearc region), chemically bound water in sediment clay minerals, chemically bound water in the upper and lower crust resulting from the precipitation of secondary hydrous alteration products, free water in fault zones, and bound water of hydrous minerals in the uppermost mantle resulting from serpentinization of peridotite. On the basis of modeling of global subduction zones, Hacker [2008] 
concludes that oceanic mantle, which is the least well constrained, is the primary source of water subducted to post-arc depths.

Hydration of oceanic crust begins in the near-axis region where fluid circulation along joints and cracks is driven by strong thermal gradients associated with crustal formation [Elderfield and Schulz, 1996]. At the axis both high-temperature focused flow and low-temperature diffuse drive hydration of the upper and perhaps middle crust through alteration of basaltic rocks and mineral precipitation in the pore space of the crust [Alt et al., 1986]. As the plate ages, hydration continues driven by low-temperature circulation associated with conductive plate cooling [Elderfield and Schulz, 1996]. Sediment blanketing of the oceanic crust and precipitation of hydrous phases in cracks and joints limit the open exchange of seawater within the crust, thus reducing the potential of the plate to incorporate more water as it ages. The "sealing age" of the plate is therefore dependent on both spreading and sedimentation rates [e.g., Nedimović et al., $2008]$.

Geochemical, petrological, and geophysical constraints suggest that the lower oceanic crust is dry prior to hydrothermal alteration [e.g., Hirth et al., 1998 and references therein]. The onset and extent of lower crustal hydrothermal alteration depends on the axial thermal structure and the distribution of permeable pathways and is a topic of ongoing debate. Cores drilled in exposed lower crustal rocks off the East Pacific Rise (EPR) reveal alteration along cracks through the precipitation of hydrous phases within 1 Myr of crustal accretion [Lécuyer and Reynard, 1996]. 
As the plate approaches a subduction zone, a secondary phase of hydration may occur because plate bending-related faulting creates a pervasive tectonic fabric throughout the crust and upper mantle [Peacock, 2001; Ranero et al., 2003]. Stresses created by the bending of the subducting slab result in subhydrostatic pressure gradients localized along faults which can penetrate tens of kilometers below the Moho, pumping fluids downward from the saturated upper crust to the dry lower crust and upper mantle [Faccenda et al., 2009].

The faulting of the oceanic lithosphere as it enters a subduction zone may lead to decreased seismic velocities through fracturing and increased porosity as well as subsequent hydration due to fluids migrating along those cracks. Low seismic velocities near the Chile and Nicaragua trenches have been used to estimate the extent of hydration of the incoming mantle [e.g., Contreras-Reyes et al., 2007; Ivandic et al., 2008; van Avendonk et al., 2011]. Offshore central Nicaragua, a velocity decrease of 5-7\% in the uppermost 3-4 km of the mantle was found seaward of the outer trench rise, indicating increasing crack density and/or systematic serpentinization of $12-17 \%(1.55-2.17 \mathrm{wt} \%$ water) [Ivandic et al., 2008]. On a trench parallel (15-20 km from the trench) profile over the Cocos plate, van Avendonk et al. [2011] estimate $\sim 1 \mathrm{wt} \%$ water content in the lower crust offshore Nicaragua, and uppermost mantle serpentinization of up to $30 \%$ (3.5 wt $\%$ water) offshore central and northwestern Nicaragua and $8-17 \%$ (1-2 wt $\%$ water) in the southeast. South-Central Chile similarly displays a decrease in upper mantle velocities in the trench and outer-rise area. There, the thick sedimentary cover is thought to impede hydration which is reflected in an upper-bound estimate of $9 \%$ serpentinization in the uppermost $2 \mathrm{~km}$ of the mantle [Contreras-Reyes et al., 2007]. In all of these cases the 
decrease in upper mantle seismic velocity coincides with the onset of bending-related faults observed in seafloor bathymetry.

At the Cascadia subduction zone, the state of hydration of the Juan de Fuca (JdF) plate is of particular interest because little hydration of the down-going plate is expected based on its young age and presumably warm state [e.g., Hyndman and Wang, 1993]. However, numerous observations consistent with slab dehydration suggest significant hydration of the down-going plate [e.g. Audet et al., 2009; Bostock et al., 2002; Hacker et al., 2003; Kao et al., 2005; Preston et al., 2003; Rogers and Dragert, 2003; Walowski et al., 2015]. Prior studies within the interior of the JdF plate provide evidence for hydration of the upper crust associated with ridge flank hydrothermal circulation and spatially correlated with local zones of ridge propagation [McClymont and Clowes, 2005; Nedimović et al., 2009; Nedimović et al., 2008; Newman et al., 2011] but the full extent of when and how water is incorporated into the lithosphere during the evolution of the JdF plate, and how water is distributed at depth within the plate prior to subduction remains unknown. To address this important question, we conducted in 2012 an activesource seismic study to characterize crustal and shallow mantle velocities and distribution of faulting along two ridge-perpendicular transects spanning the full width of the JdF plate, and a trench-parallel line to characterize along-margin variations in the architecture and velocity structure of the down-going plate [Carbotte et al., 2014; Han et al., 2016]. Here we present a P-wave seismic tomography model of the sediments, crust, and uppermost mantle along one of the plate transects extending from 0.7 Ma crust near Axial Volcano to the Cascadia margin offshore Central Oregon. We use the evolution of seismic velocities from the ridge to the deformation front as indicators of alteration and 
porosity changes at different levels, and provide an estimate of the water content of the plate under different plausible mineralogical assumptions. This work, based on wide angle ocean bottom seismometer (OBS) data, complements that of Han et al. [2016], who reported the results from analysis of multichannel seismic (MCS) data that document the distribution of faulting along both plate transects. Results from the remaining transects will be published elsewhere.

\section{TECTONIC SETTING}

\subsection{The Juan de Fuca Ridge}

The JdF plate is formed at the intermediate spreading $(25-33 \mathrm{~mm} / \mathrm{yr}$ half rate [Wilson, 1993]) JdF Ridge (JdFR). The JdFR is split into seven primary segments; Cleft, Vance, Axial, Coaxial, Northern Symmetric, Endeavour, and Middle/West Valley (Fig. 3-1). The JdFR has a northwesterly absolute motion that has recently ( $0.5 \mathrm{Ma})$ brought it into contact with the Cobb hot spot [Karsten and Delaney, 1989], currently located beneath Axial Seamount. In addition to Axial seamount, a broad plateau centered on the Cleft segment associated with $0.7-1.0 \mathrm{~km}$ thicker crust is thought to be the result of increased crustal production in the last 0.5 Ma related to the Cobb hot spot combined with a preferential southward channeling of melt supply [Carbotte et al., 2008]. Similarly, the Endeavour segment has a large plateau related to increased crustal thickness as a result of interaction with the Heckle melt anomaly [Carbotte et al., 2008]. Morphology of the ridge is characterized by axial summit grabens created by dikeinduced faulting [Carbotte et al., 2006] and their large sensitivity to small fluctuations in magma supply at this spreading rate [Canales et al., 2005]. The depth to the seismically imaged axial melt lenses generally increases to the north from $2.1 \mathrm{~km}$ at Cleft to $2.6 \mathrm{~km}$ 
at Endeavour [Carbotte et al., 2006]. An exception to this trend is Axial seamount, where the depth to the top of the magma reservoir varies between 1.1 and $2.3 \mathrm{~km}$ [Arnulf et al., 2014].

\subsection{The Juan de Fuca Plate Interior}

The JdF plate is crosscut by a number of 'pseudo-faults' or propagator wakes, which result from the growth or "propagation" of one spreading ridge segment across a small ridge offset into pre-existing crust formed at an adjacent "dying" ridge segment [Wilson, 1988] (Fig. 3-1). As a result of propagation, crust transferred from one plate to another results in plate age reversals along the spreading direction [Hey et al., 1980]. Propagation also rotates and shears the crust within its wake [Hey et al., 1980] resulting in higher porosity and alteration, as has been inferred from seismic studies on the flanks of the EPR [e.g., Canales et al., 2003] and JdFR [e.g., McClymont and Clowes, 2005; Nedimović et al., 2008]. As a result of this shearing and alteration, propagator wakes are potential areas of enhanced fluid flow [Nedimović et al., 2008]. On the basis of velocitydensity relationships and gravity anomalies, McClymont and Clowes [2005] further propose that propagator wakes are locations of partial upper-mantle serpentinization. Nine major events of ridge propagation at the JdFR have occurred during the last $18 \mathrm{Ma}$ [Wilson, 1988; Wilson, 1993]. Using gravity and seismic data Marjanović et al. [2011] find thinner and/or more dense crust within these propagator wakes. Additionally they find the presence of 10-20 km wide zones of thicker crust located on the young crust side of the propagators at distances up to $10 \mathrm{~km}$ from the edge of the wake. Within these wide zones of thicker crust Nedimović et al. [2005] imaged bright subhorizontal to shallowly 
ridgeward-dipping seismic reflectors in the mantle which they interpreted as frozen subcrustal magma chambers related to the propagation of the ridge axis.

In the interior of the plate, hydration of the upper crust is inferred from observations of increasing P-wave velocities within seismic layer 2A and 2B with increasing crustal age and sediment cover [Nedimović et al., 2008; Newman et al., 2011]. The thickness of the sedimentary cover varies in the N-S direction across the JdF plate with full burial of the oceanic crust at younger ages in the north decreasing strongly to the south. Compared to regions with limited sedimentary cover, larger increases in velocities at young crustal ages are found in regions of full sediment burial near the ridge axis [Nedimović et al. 2008]. This is a consequence of fluid circulation in a high-permeability JdF upper crust [Davis et al., 1997] that results in alteration and mineral precipitation increasing with sedimentary cover [Hunter et al., 1999; Nedimović et al., 2008]. The documented spatial variations in crustal velocities therefore imply greater extents of hydration in the upper crust in the north than farther south along the plate.

\subsection{The Cascadia Subduction Margin}

The structure of the Cascadia forearc region varies significantly along strike in response to changes in thickness (or absence) of the accreted oceanic Siletz terrane [Tréhu et al., 1994]. Thickness of the terrane reaches a maximum value of $25-35 \mathrm{~km}$ beneath the Oregon Coast Range. This area is considered to be the region of greatest strength of the forearc crust which is reflected in low rates of forearc seismicity, the narrowest subduction complex width, and a region of smaller but more mafic arc volcanic activity [Tréhu et al., 1994]. To the north of the Oregon Coast Range, the Siletz terrane thickness decreases with a minimum value of $6 \mathrm{~km}$ offshore Vancouver Island. South of 
the Oregon Coast Range the Siletz terrane is absent, with the forearc instead mostly supported by the Klamath block [McCrory and Wilson, 2013]. The regions of thin or absent Siletz terrane are areas of increased forearc seismicity, increased subduction complex width and more silicic and voluminous volcanic activity [Tréhu et al., 1994] . The seismic investigation of Gerdom et al. [2000] of the internal structure of the Cascadia accretionary prism offshore Oregon found that the dip of the subducting Juan de Fuca plate increases from $1.5^{\circ}$ to $6.5^{\circ}$ to $16^{\circ}$ as it moves from the trench to beneath the accretionary complex to east of the coast. Additionally, Gerdom et al. [2000] find that the base of the Siletz terrane seems to be in contact with the subducting oceanic crust, which would suggest that no large volume of sediment is subducted to greater depth offshore Oregon.

Hydration of the lower crust and upper mantle just seaward of the deformation front is expected to be limited due to the young age (5-9 Ma [Wilson, 1988; Wilson, 2002], Fig. 3-1) and warm thermal regime of the JdF plate [Hyndman and Wang, 1993; Wada and Wang, 2009]. Previous reflection studies revealed pervasive faulting in the sedimentary section blanketing the Juan de Fuca plate starting $\sim 200 \mathrm{~km}$ west of the deformation front but whether there is any significant crustal hydration associated with this faulting was unknown [Nedimović et al., 2009]. The new seismic reflection images of Han et al. [2016] reveal faults closer to the deformation front that cut the crust and reach down to and beneath Moho levels offshore Oregon. Offshore Washington, faults are slightly steeper, dominantly dip seaward, and do not extend into the lower crust or upper mantle. Based on these differences in the extent of crustal/mantle faulting near the deformation front, Han et al. [2016] infer that the oceanic plate offshore Oregon has a 
higher potential for crustal alteration and mantle serpentinization than offshore Washington.

Within the Cascadia subduction zone, numerous observations suggest significant hydration of the lower crust and upper mantle of the down-going JdF plate. Episodic nonvolcanic tremors [Rogers and Dragert, 2003] associated with slow slip along the subduction interface [Dragert et al. [2001] are abundant in the Cascadia subduction zone, and their occurrence is thought to be facilitated by slab-derived fluids based on the location of the tremor in close proximity to strong seismic reflectors above the plate interface [Kao et al., 2005]. Intraslab seismicity located at intermediate depths is generally thought to arise from dehydration reactions [Kao et al., 2008; Preston et al., 2003]. Reflection banding is also present above the megathrust and is likely related to fluids given the high electrical conductivity associated with this zone [Nedimovic et al., 2003]. Low shear wave velocities in the forearc mantle from teleseismic waveform inversions suggest that the forearc region is highly hydrated and serpentinized due to fluids released from the slab as the subducting crust undergoes eclogitization [Bostock et al., 2002].

\section{DATA ACQUISITION}

In June-July 2012 a two-ship seismic experiment was conducted using the $R / V$ Oceanus (cruise OC1206A) and the R/V Marcus G. Langseth (cruise MGL1211) with the main objective of understanding the state of hydration of the JdF plate from ridge to trench as well as along strike of the subduction zone to inform the interpretation of alongstrike variation in subduction zone processes. Active source 2D MCS reflection profiles 
were collected by the $R / V$ Marcus G. Langseth along three main lines (Fig. 3-1): two plate transects from the JdFR to the Cascadia margin (Line 1, from Axial Volcano to offshore central Oregon, and Line 2 from Endeavour segment to offshore central Washington), and a margin-parallel profile (Line 3) connecting the plate transects and located $\sim 10 \mathrm{~km}$ seaward from the Cascadia deformation front. MCS acquisition parameters are given in Han et al. [2016]. Wide-angle reflection/refraction data were collected along the same profiles, which were instrumented with short-period OBSs from the OBSIP instrument pool (obsip.org). OBS deployments and recoveries were conducted from $R V$ Oceanus. OBS seafloor locations were determined by shipboard acoustic surveying or by direct wave arrival travel time relocation. OBS sample rate was $200 \mathrm{~Hz}$ for four channels ( 3 channel seismometer and hydrophone). The OBSs recorded airgun shots from the Langseth's 6,600 cu.in. airgun array, which was triggered every $37.5 \mathrm{~m}$ for MCS profiling and every $500 \mathrm{~m}$ for the wide-angle survey. The highly-dense spatial data sampling of the MCS shots allow for detailed identification of near-offset, shallow arrivals (i.e., sediments and upper crust) in the OBS records (Fig. 3-2), while OBS recordings of the large shot spacing result in records with high signal-to-noise ratio at large offsets appropriate for identifying crustal and mantle arrivals (Fig. 3-3).

Here we report observations and results obtained along Line 1, which included 29 OBSs at $16 \mathrm{~km}$ inter-instrument spacing (Fig. 3-1). Our analysis of Line 1 data includes minimal processing of the MCS data to image igneous basement and measure sediment thickness, and detailed traveltime tomography of the OBS data to determine the $P$-wave velocity structure of the sediments, crust, and upper mantle. An in-depth analysis of Line 1 and 2 MCS data is presented by Han et al. [2016]; OBS results from the other profiles 
will be presented elsewhere. Source data used for this study are archived through IRIS (OBS data [Canales and Carbotte, 2012]) and the MGDS (MCS data [Carbotte et al., 2014]).

\section{DATA PROCESSING}

\subsection{MCS Data}

For the purposes of this paper we processed the MCS data up to a post-stack migrated section, focusing on imaging the igneous basement to be used as a constraint on the tomographic inversions. Imaging crustal and mantle reflectivity from these data is presented in Han et al. [2016]. Our processing consisted of: (1) Common-Midpoint (CMP) geometry definition and gathering; (2) Stacking velocity analysis; (3) Spherical divergence correction; (4) Surface-consistent amplitude balancing; (5) 3-60 Hz bandpass filtering; (6) Normal-moveout correction; (7) CMP stacking; (8) mute seafloor multiple; (9) Post-stack F-K domain time migration. The seafloor-to-basement two-way travel time along Line 1 was digitized from the migrated image.

\subsection{OBS Data}

The OBS data were used to derive a $P$-wave velocity model based on the arrival times of the following phases: sediment refractions $(P s)$; sub-basement crustal refractions $(P g)$; Moho wide-angle reflections (PmP); and sub-Moho refractions $(P n)$.

OBS data were filtered between 5 and $20 \mathrm{~Hz}$ for phase interpretation and travel time picking. Predictive deconvolution to minimize reverberations from the source bubble and suppress internal multiples was performed on the OBS records of large shot 
spacing to improve imaging of the $P m P$ triplication. Details of picking for each phase are given in Table 1. Examples of typical OBS records and the corresponding travel time picks are presented in Figures 3-2 and 3-3. Record sections for all the OBS for both large and small shot spacing are included in the Supplementary Materials.

\section{VELOCITY MODELING}

The 2D tomographic velocity model inversion and ray tracing was performed using the joint refraction/reflection method Tomo2D [Korenaga et al. 2000]. Tomo2D uses a 2D starting model and travel time picks to solve the forward problem and invert for a new velocity model and depth to a floating reflector. The model space is parameterized as a sheared grid of variable spacing, hung from the bathymetric profile. Horizontal node spacing was set to a constant $250 \mathrm{~m}$ while vertical node spacing was set to $100 \mathrm{~m}$ for the first $2 \mathrm{~km}, 200 \mathrm{~m}$ to $4 \mathrm{~km}, 300 \mathrm{~m}$ to $7 \mathrm{~km}$, and $500 \mathrm{~m}$ to the bottom of the model. Overall dimensions of the model are 2090 nodes along the profile in X direction and 107 nodes in depth or $\mathrm{Z}$ direction. Bathymetry along the profile was constructed from multibeam data from the $R V$ Langseth EM-122 echosounder. The forward problem is solved using a hybrid of the graph and ray bending methods [Korenaga et al., 2000; van Avendonk et al., 1998]. The inverse problem uses the sparse matrix solver LSQR to solve a regularized linear system with model parameters including $P$-wave velocity at each model node and depth to reflector weighted by smoothing and damping parameters [Korenaga et al., 2000]. Trade-off between perturbations in velocity vs. reflector depth is controlled by a depth kernel weighting parameter $w$ [Korenaga et al., 2000]. Smoothing is imposed by a parameter $\lambda$ that controls the relative importance of smoothing constraints with respect to the data resolution [Korenaga et al., 2000]. 
Damping constraints are also placed on the model to decrease the amplitude of model parameter perturbations when starting with a model with large misfit.

We followed a top-down modeling approach, starting with the sedimentary layer, then the crust, and finally the mantle. At each stage, the structure of the overlaying layers obtained from the previous stage was kept fixed during the inversion. This was accomplished by imposing large damping values to model parameters located above a pre-determined interface: the basement for the Stage 2 inversions (crust), and the Moho reflector for the Stage 3 inversion (mantle). This strategy ensures that velocity perturbations at each stage occur only below the pre-determined interface.

Rather than using a single starting model at each stage, we followed the Monte Carlo approach described in Korenaga et al. [2000]. This approach allows estimating the model uncertainty arising from the dependence of inversion results on the initial assumptions. At each stage we computed 100 solutions starting from random initial models (details of models in supplementary text). Each Monte Carlo solution was obtained after several inversions, starting with a large $\lambda$ value to obtain a longwavelength structure and then continued to lower $\lambda$ values to allow shorter-wavelength perturbations to the model as required by the data. The preferred solution for each stage was then calculated as the average of the 100 Monte Carlo solutions, and the model uncertainty estimate as the standard deviation of the 100 Monte Carlo solutions.

The quality of the data fit was evaluated using the root mean square (RMS) value of the difference between the predicted and observed travel times and the $\chi^{2}$ (RMS misfit normalized by pick error). Data fit convergence was deemed adequate when the $\chi^{2}$ 
reached unity. Data fit statistics for the preferred solutions after each inversion stage are given in Table 1.

\subsection{Stage 1: Sediments}

For simplicity we refer to "sediments" as the layer above the igneous JdF plate oceanic basement everywhere along our model, including the continental shelf east of the deformation front. Thus, our sedimentary layer represents the pelagic and turbiditic sediments west of the deformation front, as well as the accretionary wedge and subducting sediments, and the western edge of the igneous Siletz terrane [Gerdom et al., 2000; Tréhu et al., 1994] east of the deformation front. We refer to refractions within any of these units collectively as $P s$ arrivals. Only data from 12 instruments (50-65, Fig. 3-1) were used at this stage, as sediments beyond $140 \mathrm{~km}$ west of the deformation front are too thin to produce usable $P s$ arrivals in the OBSs.

Using the Monte Carlo approach described above during this first stage resulted, in the following stage, in highly uncertain crustal velocities beneath the continental shelf due to the lack of deep-penetrating $P$ s rays that sample zones of high sedimentary $P$-wave velocity and the western edge of the Siletz terrane [Gerdom et al., 2000; Tréhu et al., 1994]. Therefore, we modeled the sediment layer in two separates parts: one covering the model section seaward from the deformation front using the Monte Carlo approach described above, and a second one covering the landward part of the model in which a single 2D starting model from Gerdom et al. [2000] was used. To compensate for the lack of deep-penetrating $P s$ rays beneath the continental shelf, inversion of the landward part of the model also included vertical-incidence basement traveltimes derived from the 
MCS data [Han et al., 2016], thus increasing the ray coverage in a region of the model with sparse coverage from the OBS data. Both solutions were then merged into a single model and further refined to provide one internally consistent solution to all $P \mathrm{~s}$ travel times.

The OBS records of the MCS shots show clear reflections from the basement (PbP, Fig. 3-2). Although this information could be used to constrain sediment thickness, we did not include this phase in our modeling because sediment thickness derived from the MCS images is more accurate and has higher lateral resolution. To determine the thickness of the sedimentary cover, the two-way travel-time difference between the seafloor and basement reflectors on the MCS profile was used in conjunction with the velocity model obtained in Stage 1.

The Stage 1 results (shown as part of the final model in Figure 3-4) have no or very thin sedimentary cover from the seaward end of the profile until $\sim 250 \mathrm{~km}$ west of the deformation front where there is a small basin bounded on the east by a narrow (10 $\mathrm{km}$ wide) basement high. Sedimentary thickness then begins to gradually increase landward starting at $200 \mathrm{~km}$ west of the deformation front and reaching $3.1-3.2 \mathrm{~km}$ at the trench. Sediment velocities start at $\sim 1.7 \mathrm{~km} / \mathrm{s}$ at the seafloor with a vertical gradient of $0.6 \mathrm{~s}^{-1}$ through the sediment section. The sedimentary velocity model shows only a small variation from a 1D reference velocity model. Our experimental setup provided ray coverage in the eastern portion of the sedimentary sequence $(<140 \mathrm{~km}$ west of the deformation front) where the sedimentary thickness is significant (Fig. 3-4A). Due to the expected small lateral variation in sedimentary velocities the extrapolation of the model to the west $(>140 \mathrm{~km})$ based on results obtained within areas with ray coverage is 
justified. Furthermore, due to the decreasing sedimentary thickness to the west any velocity inaccuracy from this extrapolation will result in very small errors in sediment thickness.

\subsection{Stage 2: Crust and Moho}

A new set of Monte-Carlo initial models were constructed using the sedimentary velocity model and basement depth of Stage 1 and randomized 1D crustal structure (see supplementary text) hung beneath the crust-sediment interface. For this stage we used $P g$ and $P m P$ arrivals observed in the OBS records of large shot spacing. In order to keep the sedimentary layer structure constant, we imposed a large damping value to grid points above the basement interface. This strategy ensures that any velocity perturbations from the inversion of crustal phases occur in the crustal layer of the model. The trade off between velocity perturbations within the crust and Moho depth is controlled in the inversion through a depth kernel weighting factor, $w$. A value of 1 representing equal weighting was used. Sensitivity of the results to this parameter was evaluated using a range of larger values of $w$. Generally, increasing $w$ leads to larger deviations of the inverted reflector depth from the starting model as well as larger model misfit. Thus the choice of equal weighting seems appropriate.

The Stage 2 model shows ray coverage from $P g$ and $P m P$ phases that extends $350 \mathrm{~km}$ west of the deformation front to $40 \mathrm{~km}$ east for the full thickness of the crust (Fig. 3-4). Velocities at the top of the crust gradually increase from $3.1 \pm 0.1 \mathrm{~km} / \mathrm{s}$ at 360 $\mathrm{km}$ west of the deformation front to $4.3 \pm 0.8 \mathrm{~km} / \mathrm{s}$ beneath the trench. Lower crustal velocities drop from 7.1-7.3 $\pm 0.15 \mathrm{~km} / \mathrm{s}$ to $6.9-7.0 \pm 0.1 \mathrm{~km} / \mathrm{s}$ beginning $\sim 100 \mathrm{~km}$ west of 
the deformation front. Crustal thickness along the line has a maximum of $6.3 \pm 0.3 \mathrm{~km}$ at $300 \mathrm{~km}$ from the deformation front. Crustal thickness shows a slight decreasing trend toward the trench reaching $6.1 \pm 0.5 \mathrm{~km}$ at the trench.

\subsection{Stage 3: Mantle}

Following a satisfactory inversion for $\operatorname{Pg}$ and $\operatorname{PmP}\left(\chi^{2} \sim 1\right.$, Table 1$)$, the mantle phases $P n$ were included in the inversion. A new set of initial models was constructed by using the sedimentary and crustal velocity model of Stages 1 and 2, and randomized 1D mantle structure (see supplementary text) hung beneath the Moho interface. The sedimentary and crustal structures were held constant by imposing large damping values to model parameters above the Moho interface.

The Stage 3 model has ray coverage in the uppermost mantle with a range of penetration of 0.5 to $4 \mathrm{~km}$ below Moho (Fig. 3-S1). Velocities in the upper mantle are generally 7.9-8.1 $\pm 0.1 \mathrm{~km} / \mathrm{s}$. Two large low velocity anomalies are present; one wide zone is located at $170-220 \mathrm{~km}$ west of the deformation front and one narrow zone $40-50 \mathrm{~km}$ west of the deformation front. These two low velocity zones have values as low as $6.9 \pm 0.4 \mathrm{~km} / \mathrm{s}$ and are spatially correlated with the location of propagator wakes.

\subsection{Monte Carlo Uncertainty Estimation}

A measure of the uncertainty of the models arising from the dependence of inversion results on the initial assumptions was estimated by calculating the standard deviation of all the Monte Carlo realizations at each stage. The uncertainty estimates for all individual layers were combined into a single matrix and are shown in Figure 3-S1B. 
The uncertainty of the model beneath the Oregon continental shelf could not be estimated because here we used only one starting model (see Section 5.1).

Uncertainty in the crust in the outer portion of the plate $(>150 \mathrm{~km}$ west of the deformation front) is low with values between 0 and $0.2 \mathrm{~km} / \mathrm{s}$ generally increasing with depth. Beginning from $150 \mathrm{~km}$ west of the deformation front moving landward the uncertainty of a thin zone (100-500 m) located at the top of the crust gradually increases to $0.5-0.7 \mathrm{~km} / \mathrm{s}$ while values in the lower crust remain around $0-0.2 \mathrm{~km} / \mathrm{s}$ (Fig. $3-\mathrm{S} 1)$. East of the deformation front the zone of high uncertainty in the upper crust expands to a 1.5 $\mathrm{km}$ thickness and uncertainties in the lower crust increase to $0.1-0.4 \mathrm{~km} / \mathrm{s}$. In the mantle, uncertainties are generally $0.1 \mathrm{~km} / \mathrm{s}$ with the exception of the two low velocity zones that have values up to $0.4 \mathrm{~km} / \mathrm{s}$ due to the lower ray coverage inherent in low velocity zones.

\section{ANALYSIS AND INTERPRETATION OF THE VELOCITY MODEL}

In order to interpret our velocity results, we first generated a plausible baseline velocity model based upon a plate cooling model and realistic oceanic lithologies. We then use effective medium theory (with elastic parameters from expected lithologies and alteration products) [Kuster and Toksöz, 1974] to infer from our tomography results the amount of porosity, alteration, and water content required to reconcile our results with the baseline model.

\subsection{Thermal Modeling}

To construct a thermal model for the JdF plate along our model line we first used SEDTEM [Wang and Davis, 1992] to calculate the thermal structure west of the 
deformation front. SEDTEM is a one-dimensional finite element model that accounts for the role of sedimentation on plate cooling. Input parameters appropriate for the JdF plate sediments are taken from [Hyndman and Wang, 1993] (their table A1). Sedimentation rate was estimated from MCS derived sedimentary thickness. In order to account for the more complicated thermal structure of the accretionary prism and continental margin, we used a 2D numerical thermal model with kinematic slab and dynamic wedge, following Syracuse et al. [2010]. The model incorporates constraints appropriate for our profile: sediment thickness, crustal thickness, crustal age, convergence speed, and the oceanic geotherm derived from SEDTEM at $30 \mathrm{~km}$ west of the deformation front. The resulting 2D temperature model is presented in Figure 3-5.

\subsection{Predicting $V p$ as a Function of Crustal Age and Lithology}

We use the temperature dependence of velocity for basalt, gabbro, and peridotite [Christensen, 1979] to calculate the predicted age-dependent $V p$ along our profile at three representative depth intervals: the upper crust $(0.5-1.5 \mathrm{~km}$ below basement, within the dike section), lower crust (2.5-0.5 km above Moho), and upper mantle (0.5-1.5 km below Moho). For each depth interval temperatures were vertically averaged. As reference values for $V p$ for unaltered lithologies at room temperature, we use $6.7 \mathrm{~km} / \mathrm{s}$ for diabase [Carlson, 2014], $7.35 \mathrm{~km} / \mathrm{s}$ for gabbro [Miller and Christensen, 1997], and $8.5 \mathrm{~km} / \mathrm{s}$ for peridotite [Ben Ismail and Mainprice, 1998]. The predicted Vp for each lithology as a function of distance along Line 1 are shown in Figure 3-6, for comparison with the tomography results vertically averaged within each of the depth intervals considered. Differences between the predicted $V p$ and the tomography results are discussed in detail in Section 7. 


\subsection{Water Content Estimates}

Porosity in the plate results in reduced seismic wave speeds compared to a nonporous matrix [Wilkens et al., 1991]. We assume that all of the differences in $V p$ between the depth-averaged tomography results and the baseline velocities derived from the thermal model are due to porosity (inherited from accretion at the ridge and/or faulting induced), with cracks and pore space filled with either water or hydrous alteration products. We consider that any potential effects due to changes in anisotropic fabric along the profile, or along-profile changes in dominant lithology at each depth interval are negligible. We an use effective medium theory as formulated by Kuster and Töksoz, [1974] to explore the effect on $V p$ of two end-member scenarios: free water and alteration-mineral filled porosity. The effective $V p$ of a two-phase medium $\left(V p{ }^{*}\right.$, i.e., our tomographically derived $\mathrm{Vp}$ ) is a function of the elastic constants of the hydrated porosity medium (infilling alteration products) and that of the dry matrix, the porosity fraction $c$

and the crack aspect ratio $\alpha: V p^{*}=f\left(K, K^{\prime}, \mu, \mu^{\prime}, \rho, \rho^{\prime}, c, \alpha\right)$, where $K, \mu$, and $\rho$ are bulk modulus, shear modulus, and density, respectively, and 'denotes porosity medium. Thus, assuming that the elastic constants of the porosity infilling material, the crack aspect ratio, and its water $\mathrm{wt} \%$ are known, one can derive porosity fraction $c$ by comparing our tomographically derived $P$-wave velocities with the predicted baseline $V p$, and from $c$ the bulk water content of the two-phase medium.

\subsubsection{Upper crust}

In the upper crust we only consider the case of porosity in the form of free water filling cracks. We do not consider the case of porosity occupied by alteration minerals 
because common alteration minerals found in the upper crust such as quartz, epidote, sulfides, zeolites, calcite, and prehnite have elastic constants very similar to those of diabase, thus making $V p$ insensitive to the amount of alteration in diabase [Alt et al., 1986]. Therefore our water content estimates for the upper crust should be viewed as lower bounds. The aspect ratio of cracks has a strong influence on the effect of porosity on $V p$. Aspect ratios of 1 correspond to perfectly spherical inclusions and 0.01 to thin cracks. Using the elastic constant for diabase and brine listed in Table 2 and the formulation of [Kuster and Toksöz, 1974] we find that the observed Vp in the upper crust can be explained by $0.3-0.8 \mathrm{wt} \%$ to $0.8-4.0 \mathrm{wt} \%$ water, for crack aspect ratios of 0.01 and 0.1 , respectively (Fig. 3-7A).

\subsubsection{Lower crust}

For the lower crust we consider the case of porosity both in the form of infilling alteration and free water. Where gabbro is exposed to seawater at elevated temperatures there are several possibilities for plausible alteration mineral assemblages. We use the thermodynamic models of [McCollom and Shock, 1998] to define an assemblage of alteration minerals for olivine gabbro at temperatures and pressures appropriate for the lower crust along our profile (Fig. 3-5). At $400{ }^{\circ} \mathrm{C}$ modeled assemblage MA1 consists of plagioclase (34\%), amphibole (45\%), clinopyroxene (12\%), and epidote (9\%) (Table 1), while at $500{ }^{\circ} \mathrm{C}$ modeled assemblage MA2 is plagioclase (40\%), amphibole (43\%) and clinopyroxene (17\%) (Table 1) [McCollom and Shock, 1998]. Elastic parameters for the alteration mineral assemblages at the appropriate pressure and temperatures were calculated using the workbook of Hacker and Abers [2004] (Table 2). 
Inferred water content in the lower crust derived from our velocity model has a range of $0.0-1.1 \mathrm{wt} \%$ water depending on the alteration mineral assemblage considered (Fig. 3-7B). In some instances, modeled velocities in the lower crust are lower than the theoretical velocity of the porosity material. In those cases a maximum value of $w \mathrm{t} \%$ water equal to the water content of the alteration assemblage is given, as if the protolith had been completely replaced with alteration products. The estimated total amount of water in the plate differs for the two mineral assemblages considered but the trends of water content are the same for both cases, and are discussed in Section 7. As an endmember case, we also calculate water contents for the lower crust for the case of porosity in the form of free water filling cracks (Fig. 3-7B), which yields a lower bound for the amount of water that can be stored in the lower crust based on our seismic velocity model.

\subsubsection{Uppermost mantle}

At pressures above $2 \mathrm{kbar}$ and temperatures over $400^{\circ} \mathrm{C}$ serpentine (antigorite) and talc are the expected dominant alteration minerals in a water-saturated average mantle peridotite [e.g. Schmidt and Poli, 1998]. For the expected pressures in the uppermost mantle along our transect $(<2.5 \mathrm{kbar}$ west of the deformation front $)$ serpentine is stable to $\sim 500{ }^{\circ} \mathrm{C}$. At higher temperatures serpentine is converted into forsterite and talc [Ulmer and Trommsdorff, 1995]. As estimated temperatures below the Moho along our line are generally $400-500^{\circ} \mathrm{C}$ reaching a maximum of $550{ }^{\circ} \mathrm{C}$ at the deformation front (Fig. 3-5), it is likely that the alteration minerals present in the upper mantle are a combination of serpentine and talc and we therefore calculate potential water contents for each. Water is predicted to be driven to mantle levels in the outer rise region by sub- 
hydrostatic vertical pressure gradients along brittle normal faults [Faccenda et al., 2009]; thus we also calculate free water contents as an end-member case (Fig. 3-7C).

\section{DISCUSSION}

Our plate-scale seismic velocity model for the Juan de Fuca plate (Fig. 3-4A) bears the imprint of a complex suite of the structure inherited from crustal formation, intra-plate stresses, sedimentary loading, off-axis low temperature hydrothermal alteration, subduction-related bending faulting and associated alteration. In the following sections, we discuss the velocity variations found at upper crustal, lower crustal, and upper mantle levels, as well as our inferred water content estimates and implications for structure of the plate interior structure away from propagator wakes and away from the region of subduction bending (7.1); implications for the influence of propagator wakes on plate structure and hydration (7.2); implications for the extent of hydration associated with plate deformation inferred from seismic reflection imaging of crustal and mantle faults (7.3); and the mantle hydration of a young, hot subducting oceanic plate (7.4).

\subsection{Plate Structure Away From Propagator Anomalies and Away From Bending-Related}

\section{Processes}

Our velocities for the upper crust are averaged for a depth interval that encompasses most of seismic layer 2B within the dike section of the oceanic crust, and that excludes the uppermost lowest velocity layer of the crust (seismic Layer 2A). Velocities within this upper crustal layer at young ages $(<1 \mathrm{Ma})$ show the largest deviation from the across-plate predicted $V p$ for diabase, $(\Delta V p \sim-1.7 \mathrm{~km} / \mathrm{s})$, indicating that for such young ages upper crustal velocity is largely controlled by porosity with water 
contents of up to $\sim 4 \mathrm{wt} \%$ (Fig. 3-6 and 3-7). Between crustal ages of 1.0 and 1.3 Ma $(\sim 350 \mathrm{~km}$ from the deformation front) velocities increase and free water contents decrease which we attribute to infilling of intrinsic porosity inherited from crustal formation by alteration minerals. For crustal ages of 1.3-6.0 Ma $(\sim 350-180 \mathrm{~km})$, the average $V p$ is $\sim 5.6 \mathrm{~km} / \mathrm{s}$ (Fig. 3-6A), which is similar to the nearly constant $5.4-5.6 \mathrm{~km} / \mathrm{s}$ velocity found at the top of layer $2 \mathrm{~B}$ in $0.5-8.3 \mathrm{Ma}$ crust in the super-fast spreading southern EPR [Grevemeyer et al., 1998]. A previous study across the flanks of the JdFR [Newman et al., 2011] found that upper layer $2 \mathrm{~B}$ reaches a mature $V p$ value of $\sim 5.2 \mathrm{~km} / \mathrm{s}$ within $0.5 \mathrm{Myr}$, and remains relatively constant afterwards out to at least $\sim 3.5 \mathrm{Ma}$. Our results are consistent with this (note that our upper crustal values represent the average within the dike section, while Newman et al. [2011] reported values only for the uppermost part of this layer), and show that within the sedimented JdF plate interior upper crustal structure remains constant beyond $1 \mathrm{Myr}$ in the absence of subduction bending effects (i.e., $>150 \mathrm{~km}$ from the deformation front) (Fig. 3-6A). The estimated amount of free water stored in this mature, unperturbed upper crust ranges between 0.5 $2.4 \mathrm{wt} \%$ (Fig. 3-7A) depending on the aspect ratio of cracks. The observation that layer 2B velocities remain $\sim 1.1 \mathrm{~km} / \mathrm{s}$ lower than expected in the dike section to at least until 6 Ma (Fig. 3-6A) and without any apparent correlation with sediment burial (as opposed to the shallower, more porous layer 2A [Nedimović et al., 2008]) is consistent with the previous observations of Newman et al. [2011]. These authors concluded that layer 2B structure is more dependent on processes occurring at or shortly after accretion than on the evolution of the low-temperature, sediment-controlled shallow hydrothermal system. Exceptions to this are found at basement highs outcropping above the sediments. For 
example, a local upper crustal velocity low ( $V \mathrm{p}=5 \mathrm{~km} / \mathrm{s}, 4 \mathrm{wt} \%$ water $)$ at $\sim 245 \mathrm{~km}$ from the deformation front occurs at a basement high where sedimentary thickness is near zero (Fig. 3-6A). These basement highs may provide permeable pathways for outflow zones for diffuse off-axis hydrothermal circulation [Fisher et al., 1990; Newman et al., 2011].

The velocity in the lower crust closely matches that predicted by our thermal modeling from 360 to $\sim 140 \mathrm{~km}$ west of the deformation front, with the exception of moderately reduced values $(-0.2 \mathrm{~km} / \mathrm{s})$ across the mid-plate propagator wake crust (Fig. 3-6B). This indicates that little porosity in the lower crust is inherited at the ridge, and that the lower crust remains dry (or locally hydrated below the levels detectable with our data) outside of the propagator wakes or the region of subduction bending (Fig. 3-7B). This result is in agreement with studies from the southern EPR where no significant age dependent velocity variations are found in the lower crust between 0.5 and $8.3 \mathrm{Ma}$, in contrast to velocities at upper crustal and upper mantle depths [Grevemeyer et al., 1998]. Within the first $\sim 4.6 \mathrm{Myr}$ ( $>250 \mathrm{~km}$ from the deformation front) velocities in the upper mantle follow predicted velocities (indicating a mostly dry mantle, Figure 3-7C), after which the influence of propagator wakes (where present) dominates the mantle structure (Fig. 3-6C) and velocities in general are lower than predicted values.

\subsection{Influence of Propagator Wakes}

Propagator wakes in the interior of the JdF plate are spatially correlated with intraplate seismicity [Nedimović et al. [2009]. Nedimović et al. [2009] suggest that increased seismicity is due to locally decreased strength inherited from rift propagation caused by the combined weakening effects of more fracturing and fracture-facilitated 
alteration. Our results support this interpretation: the two propagator wakes transected by our seismic profile are associated with significant velocity and, by inference, hydration anomalies at lower crustal and upper mantle levels, and to a lesser extent in the upper crust (Fig. 3-6, 3-7). Near the ridge axis, the wakes of ridge axial discontinuities are known to be associated with prominent negative $P$-wave velocity anomalies throughout the crust that reflect greater fracturing within the inner pseudofault than in the surrounding crust [e.g., Canales et al., 2003; Weekly et al., 2014]. We find upper crustal (layer $2 \mathrm{~B}$ ) velocities within the propagator wakes are only slightly reduced relative to neighboring crust, suggesting more modest fracturing and/or alteration (Fig. 3-6A). This observation is consistent with the findings of Newman et al. [2011] of moderate upper layer 2B velocity decreases within propagator wakes that coincide with increased lower layer $2 \mathrm{~A}$ velocities interpreted as the result of enhanced fluid flow and mineral precipitation [Nedimović et al., 2008]. Our results predict upper crust within propagator wakes that is only moderately more hydrated than unperturbed crust of similar age (Fig. 3-7A).

In the lower crust, however, broad regions of small velocity anomalies of -0.1 $\mathrm{km} / \mathrm{s}$ are found in our model (Fig. 3-6B). The anomalies in the lower crust are less localized to the propagator wake zones, compared with the anomalies in the uppermost mantle, extending some $20 \mathrm{~km}$ beyond the boundaries of the propagator wake. An anomaly of $-0.1 \mathrm{~km} / \mathrm{s}$ corresponds to estimated chemically bounded water contents of 0.25-0.8 $\mathrm{wt} \%$ (depending on the alteration mineral assemblage assumed, Table 2), or alternatively to less than $0.1 \mathrm{wt} . \%$ if we assume all water is stored as a free phase in the pore spaces (Fig. 3-7B). 
At mantle levels the propagator wakes are associated with the lowest mantle velocities found anywhere along our plate transect $(\Delta V p<-1 \mathrm{~km} / \mathrm{s}$, Figure $3-6 \mathrm{C})$. This is consistent with findings of low $V p(7-7.2 \mathrm{~km} / \mathrm{s})$ across other propagator wakes in the northern part of the JdF plate [McClymont and Clowes, 2005], and indicates significant local alteration and hydration of the mantle. While the lateral extents of the two propagator wakes transected by our profile are significantly different (50 km vs. $10 \mathrm{~km}$ ) the magnitudes of the velocity anomalies are similar. Interestingly, seismic reflection imaging [Han et al., 2016] indicates that Moho reflections are weak to absent within the zone of the larger propagator wake. This difficulty in imaging Moho indicates a very low velocity gradient across the crust/mantle transition that is consistent with the local low $V p$ values found in the mantle (Fig, 3-6C).

The very weak (or absence of) Moho reflections in the MCS data is also consistent with our OBS data that show markedly different $P g-P m P-P n$ triplications for waves sampling the propagator wakes compared with those from waves sampling normal crust. For example, record sections from instruments 70 and 71 (Fig. 3-S30-S31) located near the western edge of the propagator wake (Figure 3-4A) display very well defined triplications with high-amplitude $P m P$ (which suggests sharp velocity contrast at the Moho) for shots to the west of the OBSs that sample normal crust ( $\sim 20-60 \mathrm{~km}$ negative ranges). In contrast to this, shots to the east of the OBSs that sample propagator crust ( 20-60 km positive ranges) display weak $P m P$ and less defined triplications, suggesting a more gradual velocity increase through the Moho. The same pattern is observed on instruments 67 and 68 (Fig. 3-S27-S28) located near the eastern edge of the propagator (Figure 3-4A): well defined triplications for shots to the east of the instrument (positive 
ranges), but weaker $P m P$ and less defined triplication for shots to the west of the instruments (negative ranges). Data from instrument 69 (Fig. 3-S29), which is located near the center of the propagator wake (Figure 3-4A), have low amplitude $P m P$ arrivals and lack clear triplication for shots both to the east and west of the OBS. All of these observations are consistent with the subdued velocity contrast at the crust/mantle transition in the propagator wake zones in our final velocity model (Figure 3-4A).

If we assume serpentinization is the alteration process, the JdF plate mantle could be locally hydrated with up to $1.8 \mathrm{wt} \%$ water beneath propagator wakes (Fig. 3-7C), which corresponds to a $15 \%$ maximum value of serpentinization. However our thermal model predicts sub-Moho temperatures that are too high $\left(>400{ }^{\circ} \mathrm{C}\right)$ for significant serpentine formation, but within the stability field of other hydrated minerals such as talc. If talc is the dominant hydration mineral, then water contents could be lower $(0.9 \mathrm{wt} \%$, Figure 3-7C). Alternatively, the extensive fracturing and shearing of the crust at propagating ridge offsets [Hey et al., 1980; Wilson et al., 1988] may enhance convective cooling, resulting in locally cooler mantle within the propagator wakes than predicted by our plate thermal model, thus facilitating mantle serpentinization. In addition to chemically bounded water, open fractures at sub-Moho levels may contain free water. Under this assumption, propagator wakes may contain up to $0.1-0.3 \mathrm{wt} \%$ water in open fractures (Fig. 3-7C). However, the same assumption yields a lower amount of free water in the lower crust $(<0.1 \mathrm{wt} \%$, Fig. 3-7B), and it is difficult to explain how more water could be retained in open fractures at mantle levels than at lower crustal levels. Thus, we conclude that the large negative velocity anomalies present at both propagator wakes in 
the uppermost mantle are, at least in part, due to serpentinization of the mantle and/or presence of other hydrated minerals such as talc.

\subsection{Deformation Effects in Plate Seismic Structure}

Previous studies have revealed faults within the sediment section blanketing the $\mathrm{JdF}$ plate at distances of up to $200 \mathrm{~km}$ west of the deformation front (Fig. 3-4C) and one region of crustal-scale faulting [e.g. Nedimović et al., 2009]. Reflection images derived from the collocated MCS data acquired along our Oregon transect presented in Han et al. [2016], reveal faults within the sediments and faint fault reflections in the upper crust at distances up to $320 \mathrm{~km}$ seaward of the deformation front. Sediment and crustal faults are sparse and heterogeneous in distribution west of $130-140 \mathrm{~km}$ from the deformation front, but increase in density at closer distances, with numerous faults within the sediments and crust at distances $<130 \mathrm{~km}$, as well as a prominent group of ridgeward-dipping lower crustal reflectors (LCRs) found 70-150 km from the deformation front (Fig. 3-4C). Plate bending due to the combined effects of sediment loading and subduction begins at 145$150 \mathrm{~km}$ west of the deformation front, as inferred from residual basement topography after correcting for plate cooling [Han et. al., 2016]. Removing the predicted effects of sediment loading from the basement topography, bending due to subduction is inferred to initiate $\sim 75-80 \mathrm{~km}$ from the deformation front. Within $40 \mathrm{~km}$ from the deformation front, sediment fault throws increase, and reflective faults that transect the entire crust and extend 6-7 km into the upper mantle are observed (Fig. 3-4C). From these observations

Han et al. [2016] conclude that most deformation associated with plate bending occurs at distances $<40 \mathrm{~km}$ from the deformation front. 
Our plate-scale velocity model reveals significant changes in structure within this same distance range. Some of this variability can be associated with the onset of plate deformation due to subduction bending and sediment loading, while other structures may have been inherited from ridge accretionary processes.

\subsubsection{Upper crust}

At $\sim 150 \mathrm{~km}$ from the deformation front, upper crustal velocities increase rapidly from $5.6 \mathrm{~km} / \mathrm{s}$ found in 1.3-6.0 Ma crust to quite uniform values of $\sim 6.1 \mathrm{~km} / \mathrm{s}$ in $6.3-7.8$ Ma crust (Fig. 3-6A). This change in upper crustal structure is spatially coincident with changes in crustal reflectivity and sediment fault distribution [Han et al., 2016] including: (1) the presence of LCRs in 6-8 Ma crust; and (2) a transition from sparsely distributed sediment faults to high sediment fault density at $140 \mathrm{~km}$ from the deformation front (Fig. 3-4C). LCRs are mid-to-lower crustal low angle reflections interpreted as shear zones formed at the ridge crest during periods of buoyant mantle flow that is faster than plate motion [Bécel et al., 2015; Han et al., 2016; Kodaira et al., 2014; Han et al., submitted]. The spatial correlation of the zone of high upper crustal $V p$ with the LCRs suggests that the anomalous upper crustal structure could also be inherited from such period of anomalous crustal formation. Although the origin of LCRs is unclear, it is possible that an upper crust with lower porosity and hence higher $V p$ was formed along with them. An argument against this hypothesis is that in the only other region where these features have been observed and seismic velocity information is available, there is no evidence for similar increased upper crustal velocities [Kodaira et al., 2014].

Alternatively, the coincident increase in both the upper crustal $V p$ at 6.0-6.3 Ma crust (Fig. 3-6A) and the sediment fault density suggests that processes related to or 
controlled by the deformation of the plate may play a role. The earlier study of Nedimović et al. [2008] from the JdF plate interior indicates that hydrothermal circulation and precipitation of alteration minerals infilling porosity inherited from accretion at the ridge axis in the uppermost crust is ongoing to the end of their study area at $150 \mathrm{~km}$ from the spreading ridge. At this distance from the ridge axis, Layer 2A velocities are still significantly below $4.0 \mathrm{~km} / \mathrm{s}$ [Nedimović et al, 2008] and hence less than the expected mature Layer 2A velocity of $\sim 4.3 \mathrm{~km} / \mathrm{s}$ [Grevemeyer et al., 1999] within the discussed area of increased fault density. With the higher sediment fault density beginning in $\sim 6$ Ma crust, perhaps faulting and fracturing reach deeper into the dike section leading to deeper penetrating ridge flank hydrothermal circulation and clogging of intrinsic porosity with mineral precipitation. Closer to the deformation front upper crustal velocities decrease to values comparable to and in places, slightly lower than found in younger pre $6 \mathrm{Ma}$ crust. Here, the landward reduction in $V p$ may be a consequence of the documented increased faulting in this region due to plate bending, with the effects of faulting in velocity canceling and outpacing any velocity increase due to mineral precipitation processes.

Approaching the deformation front $V p$ uncertainty increases significantly (Fig. 3$6 \mathrm{~A})$; however immediately to the east of the deformation front two narrow upper crustal anomalies $(V p>6 \mathrm{~km} / \mathrm{s})$ with low water content (Fig. 3-7A) could indicate localized zones of dehydration of the downgoing plate, perhaps contributing to the abundant fluid production in the accretionary prism at Hydrate Ridge [Trehu et al., 2004].

\subsubsection{Lower crust}


From near the ridge axis to $135-145 \mathrm{~km}$ from the deformation front and just east of the wide propagator wake, lower crustal velocities have values indicating dry gabbros (Fig. 3-6B). Starting from $130 \mathrm{~km}$ west of the deformation front, $P$-wave velocities in the lower crust show a long-wavelength decreasing trend (Fig. 3-6B), which is coincident with the initiation of plate deformation due to sediment loading and subduction bending around $145 \mathrm{~km}$, and with the development of faint possible trenchward-dipping faulting in the lower crust (Fig. 3-4C) [Han et al., 2016]. Although the onset of this decreasing lower crustal $V p$ is also spatially coincident with the appearance of LCRs, the large-scale decreasing trend in $V p$ is continuous to the deformation front, well east of the LCR crust (Fig. 3-6B). We attribute the progressive decrease in velocities in the lower crust to increased porosity caused by sediment loading and bending-related strain that initially produces fractures and fault zones that are too small or close to the limit of what can be resolved with the MCS data. Hydration of the lower crust after the onset of bendingrelated faulting can be up to $1 \mathrm{wt} \%$ in chemically bounded water, or as little $0.2 \mathrm{wt} \%$ if all water is stored as a free fluid phase in pore spaces (Fig. 3-7B).

\subsubsection{Upper mantle}

Between 150-50 km west of the deformation front, mantle velocities are relatively low $(0.25-0.50 \mathrm{~km} / \mathrm{s})$ with respect to predicted values, suggesting greater fracturing and hydration in this region (Fig. 3-6C). Along this section of the profile, a cluster of landward dipping events are imaged from $\sim 110-130 \mathrm{~km}$ attributed to mantle shears associated with LCR formation, but no reflections interpreted as through-crust faults penetrating into the mantle are imaged in the reflection data (Fig. 3-4C) [Han et al., 2016]. The reduced mantle velocities could be due to local anisotropy anomalies induced 
by mantle shears, or alternatively, due to faulting at scales smaller than can be detected given the resolution of the reflection imaging. If the latter, then some mantle hydration at this location can be inferred form the seismic velocities. Modeled temperatures at the Moho along this section are $\sim 450{ }^{\circ} \mathrm{C}$ (Fig. 3-5), indicating that talc rather than serpentine is probably the primary mode of hydration in this part of the system. In the case of talc alteration, the moderate decrease in mantle velocity is consistent with only $<0.2 \mathrm{wt} \%$ water at upper mantle levels as a consequence of plate bending processes.

Closer to the deformation front (at distances between 34 and $13 \mathrm{~km}$ ) deeply penetrating faults extending 6-7 km into the upper mantle are clearly imaged immediately east of the small propagator wake (Fig. 3-4C) [Han et al., 2016]. As discussed above, a prominent mantle velocity anomaly is associated with the propagator wake, with a low centered at $40 \mathrm{~km}$ and rapid eastward increase, reaching (or exceeding) normal 'dry' mantle velocities locally $\sim 10 \mathrm{~km}$ seaward of the trench (Fig. 3-6C). The zone of deep penetrating faults falls within the region of increasing mantle velocities immediately to the east of the small propagator. Mantle water contents of $<1 \mathrm{wt} \%$ (Fig. 3-7C) are estimated for this region, consistent with values reported by Han et al. [2016] based on estimates of the volume of the imaged fault zones. There is no clear explanation for why, within $15 \mathrm{~km}$ of the deformation front, our mantle velocities reach predicted dry values (Fig. 3-6C). Mantle reflectivity is also absent within $14 \mathrm{~km}$ of the deformation front consistent with less deep fracturing and alteration [Han et al., 2016]. In addition, seismic data from a fan profile recorded at this location during our experiment shows a complex mantle anisotropic signature that cannot be explained by simple olivine alignment along the spreading direction [Canales et al., 2014]. It is possible that the elevated mantle 
velocities we find immediately west of the deformation front may be partly associated with an anomalous mantle anisotropic structure in the paleosegment east of the 8.2-8.8 Ma propagator. Regardless of this, the mantle velocities approaching and across the deformation front suggest that the oceanic mantle of the paleosegment currently being, and about to be subducted beneath the Cascadia deformation front at this latitude is only very mildly hydrated (Fig. 3-7C).

\subsection{Mantle Hydration of a Young, Hot Subducting Oceanic Plate}

Active-source experiments at other subduction zones have found values of upper mantle hydration in the incoming plate at the onset of subduction of up to $3.5 \mathrm{wt} \%$ water off central and NW Nicaragua [van Avendonk et al., 2011], 1-2 wt\% water off SE Nicaragua [Ivandic et al., 2008; van Avendonk et al., 2011], and 0-3 wt\% water off southcentral Chile [Contreras-Reyes et al., 2007]. Along our transect of the JdF plate, the inferred extent of mantle hydration is somewhat lower and locally variable with values between 0 and $1.8 \mathrm{wt} \%$ (Fig. 3-7C) and we expect water delivery to the deep portions of the Cascadia subduction zone to be highly variable both spatially and through time. Directly west of the deformation front a local mantle velocity high is found (Fig. 3-6C) consistent with predicted values for dry upper mantle. However, pronounced velocity anomaly lows indicating locally enhanced hydration of the uppermost mantle are associated with the propagator wakes located further west (Fig. 3-6C). As they subduct, these hydration anomalies will result in local zones of increased water delivery. Nedimović et al. [2009] relate the increased seismicity beneath the Olympic peninsula in part to the presence of a subducted propagator wake. In Cascadia the pressuretemperature conditions in the uppermost mantle are at the edge of the stability zone for 
serpentine, but are suitable for the formation of other hydrated alteration minerals such as talc. However even if talc is the primary style of mantle hydration of the incoming plate beneath Cascadia, the amount of water stored at mantle levels in the downgoing JdF plate is very limited, with most of the water likely carried down at crustal levels.

\section{CONCLUSIONS}

We have used wide-angle seismic data to obtain a $2 \mathrm{D} P$-wave tomography model of the Juan de Fuca Plate along a profile extending from the flank of Axial seamount to offshore Central Oregon. Our results show variations in crustal and upper mantle structure that we interpret as resulting from variations in porosity and extent of hydration of the oceanic plate prior to subduction beneath the Cascadia forearc. We conclude that:

(1) Within the plate interior, away from the influence of plate bending processes, the JdF crust (below seismic layer 2A) and mantle acquire a mature structure within $1 \mathrm{Myr}$ after accretion. This mature structure is characterized by an upper crust with average velocity of $5.6 \mathrm{~km} / \mathrm{s}$ within the dike section (layer 2B), from which we infer a water content of $0.5-2.1 \mathrm{wt} \%$ (depending on the dominant shape of water-filled pores assumed); and a lower crust and uppermost mantle with seismic velocities consistent with dry gabbro and peridotite, respectively, at the temperatures expected from a cooling plate model.

(2) Our profile crosses the wakes of two propagators formed at the paleo JdFR, which are associated with velocity and hydration anomalies at lower crustal and upper mantle levels, and to a lesser extent in the upper crust. Within the lower crust, we estimate water contents of $0.25-0.8 \mathrm{wt} \%$ if we assume that water is chemically bound in alteration mineral assemblages, or as little as $<0.1 \mathrm{wt} \%$ if water is stored as a fluid phase in pore 
spaces. We find large low-velocity anomalies in the mantle (at $0.5-1.5 \mathrm{~km}$ below basement) at the location of the propagators, which we interpret as resulting from local mantle hydration (up to $0.9-1.8 \mathrm{wt} \%$ if mantle hydration occurs in the form of talc or serpentine, respectively, or as little as $0.2 \mathrm{wt} \%$ of free water). Thus, paleosegment boundaries (i.e., propagator wakes) are zones of enhanced hydration that may at least locally affect subduction zone processes.

(3) At a distance of $\sim 150 \mathrm{~km}$ from the Cascadia deformation front, we find changes in upper crustal velocity structure that correlate spatially with both the onset of plate deformation due to the combined effects of subduction bending and sediment loading, as well as with the location of lower crustal reflectivity interpreted as inherited from a period of anomalous ridge accretionary processes [Han et al., 2016]. The observed increase in upper crustal velocity could be an intrinsic feature related to the formation of this lower crustal reflectivity, or alternatively, could be related to changes in the midplate hydrothermal system triggered by onset of plate-bending related deformation.

(4) The onset of bending-related faulting results in progressive decrease in lower crustal seismic velocities towards the deformation front. We estimate that this velocity decrease can be explained by hydration of the lower crust, with up to $1 \mathrm{wt} \%$ if water is chemically bounded in alteration mineral assemblages, or as little as $0.2 \mathrm{wt} \%$ of free water.

(5) Within 150-50 km west of the deformation front, away from a small propagator wake zone, mantle velocities are slightly lower than predicted for dry upper mantle compositions, consistent with limited alteration of the mantle. In the vicinity of the deformation front at distances $15-30 \mathrm{~km}$ where deep-penetrating faults are imaged in 
MCS data, less than $1 \mathrm{wt} \%$ mantle hydration in the uppermost $1-2 \mathrm{~km}$ is found. In the region of the deformation front mantle hydration is both spatially heterogeneous and very limited with values between 0 and $0.3 \mathrm{wt} \%$ water.

(6) All our observations lead us to conclude that the paleosegment currently being subducted beneath the Cascadia deformation front offshore Central Oregon is very mildly hydrated, if not dry, at mantle levels, with most of the water that is supplied into the subduction system being stored at crustal levels.

\section{TABLES}

Table 1. Data fit statistics.

\begin{tabular}{cccccccc}
\hline Stage & Phase & $N$ & $\lambda$ & $L_{H}(\mathrm{~km})$ & $L_{Z}(\mathrm{~km})$ & RMS & $\chi^{2}$ \\
I & $P S$ & 1388 & 15 & 3 & 0.3 & 17 & 0.25 \\
II & $P g$ & 2414 & 15 & 3 & 0.3 & 17 & 0.76 \\
II & $P m P$ & 2695 & 15 & 6 & 0.3 & 30 & 1.5 \\
III & $P n$ & 2602 & 150 & 6 & 1 & 25 & 0.97 \\
\hline
\end{tabular}

$N$ is number of picks. $\lambda$ is a smoothing weight, $L_{H}$ and $L_{Z}$ are horizontal and vertical correlation lengths, respectively, and $\chi^{2}$ is the RMS normalized by the pick uncertainty.

Table 2. Elastic parameters and water content for water, alteration phases, and protoliths.

\begin{tabular}{lcccccccc}
\hline & $K(\mathrm{Gpa})$ & $\begin{array}{c}\mu \\
(\mathrm{Gpa})\end{array}$ & $\begin{array}{c}\rho \\
\left(\mathrm{g} \mathrm{cm}^{-3}\right)\end{array}$ & $\begin{array}{c}\text { Water } \\
(\mathrm{wt} \%)\end{array}$ & $\begin{array}{c}V p \\
(\mathrm{~km} / \mathrm{s})\end{array}$ & $\begin{array}{c}V s \\
(\mathrm{~km} / \mathrm{s})\end{array}$ & $\begin{array}{c}\text { Aspect } \\
\text { ratio }\end{array}$ & $\begin{array}{c}d V p / d T \\
\left(\mathrm{~km} \mathrm{~s}^{-1} \mathrm{~K}^{-1}\right)\end{array}$ \\
Brine & $2.4^{\mathrm{a}}$ & 0 & $1.03^{\mathrm{a}}$ & 100 & 1.50 & - & 0.01, & - \\
MA1 & 87 & 47 & 3.04 & 1.1 & 7.00 & 3.9 & 0.01 & - \\
MA2 & 85 & 44 & 2.98 & 0.8 & 6.94 & 3.8 & 0.01 & - \\
Serpentine & 43.5 & $14.5^{\mathrm{d}}$ & $2.52^{\mathrm{d}}$ & $12.3^{\mathrm{c}}$ & $5^{\mathrm{b}}$ & $2.4^{\mathrm{b}}$ & 0.01 & - \\
Talc & $41.5^{\mathrm{d}}$ & $22.6^{\mathrm{d}}$ & $2.58^{\mathrm{d}}$ & $4.7^{\mathrm{c}}$ & 5.30 & 3.0 & 0.01 & - \\
Diabase & $78.3^{\mathrm{e}}$ & $41^{\mathrm{e}}$ & $2.93^{\mathrm{e}}$ & - & 6.70 & 3.7 & - & -0.00039 \\
Gabbro & $96.7^{\mathrm{b}}$ & $46.3^{\mathrm{b}}$ & $2.94^{\mathrm{b}}$ & - & 7.35 & 4.0 & - & -0.00057 \\
Peridotite & $142.5^{\mathrm{f}}$ & $70.7^{\mathrm{f}}$ & 3.30 & - & 8.50 & 4.6 & - & -0.00056 \\
\hline
\end{tabular}

$K$ is bulk modulus, $\mu$ is shear modulus, $r$ is density, and $T$ is temperature.

MA1, modeled assemblage one contains plagioclase, amphibole, clinopyroxene, and epidote. MA2, modeled assemblage two contains plagioclase, amphibole, and cpx.

a:Toksöz [1976]; b: Miller and Christensen [1997]; c: Schmidt and Poli [1998] d: Bailey and Holloway [2000]; e: Carlson [2014]; f: Ismail and Mainprice [1998]. 


\section{FIGURES}

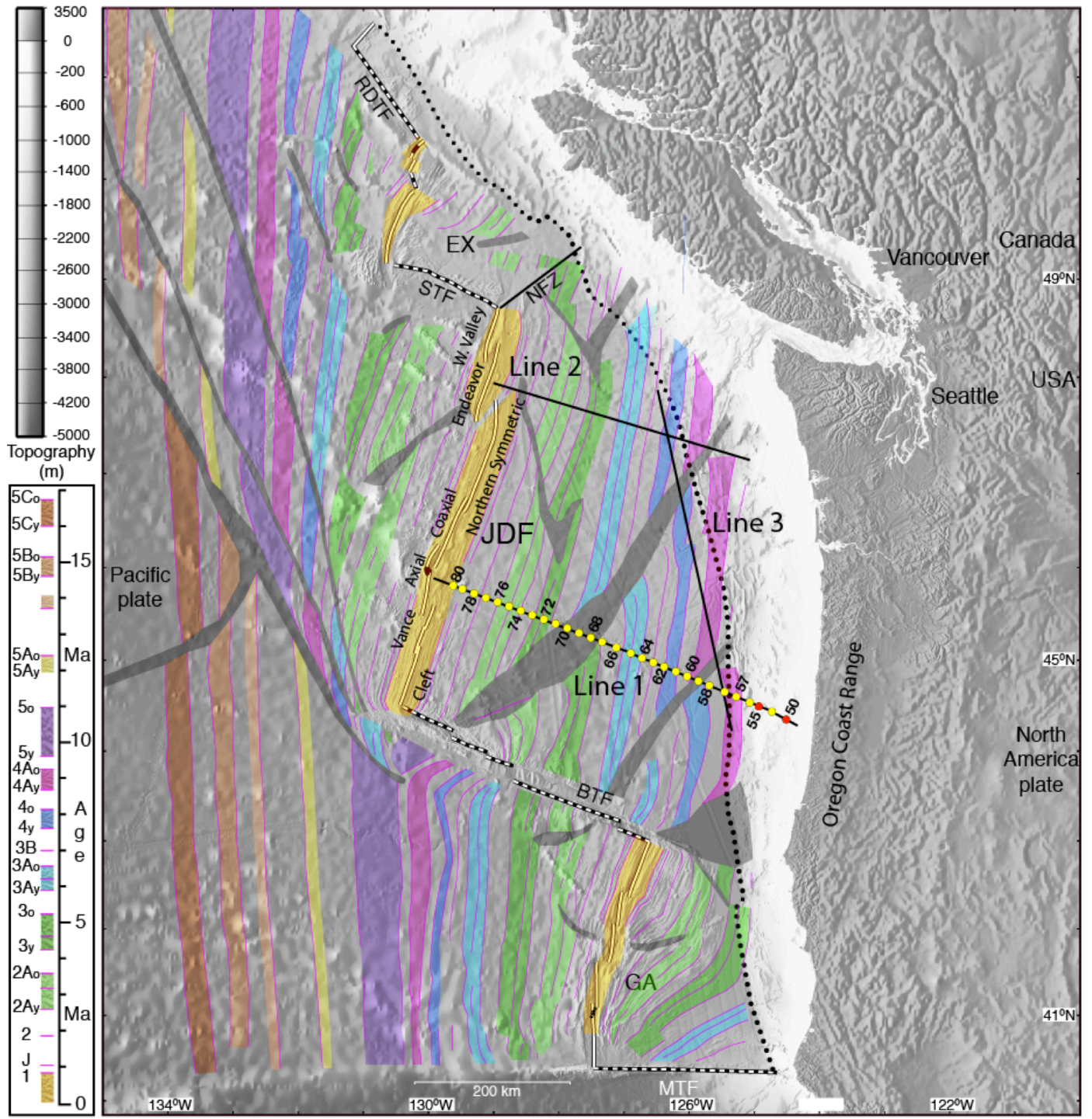

Figure 3-1. Location of the Juan de Fuca Ridge-to-Trench seismic profiles Line 1, 2, and 3. OBS positions for Line 1 are marked with yellow circles (some of them numbered; red for instruments that did not return data or were not used). Color bands correspond to magnetic isochrones from Wilson [2002]. Dark gray shaded regions correspond to propagator wakes. Dotted black line is the Cascadia deformation front. Ridge axis is shown in yellow lines, and fracture zones in black-white lines. JDF-Juan de Fuca plate; EX-Explorer plate; GA-Gorda deformation zone; RDTF-Revere-Dellwood transform fault; STF-Sovanco transform fault; NF-Nootka fault zone; BTF-Blanco transform fault; MTFMendocino transform fault. Figure modified from Nedimović et al. [2009]. 

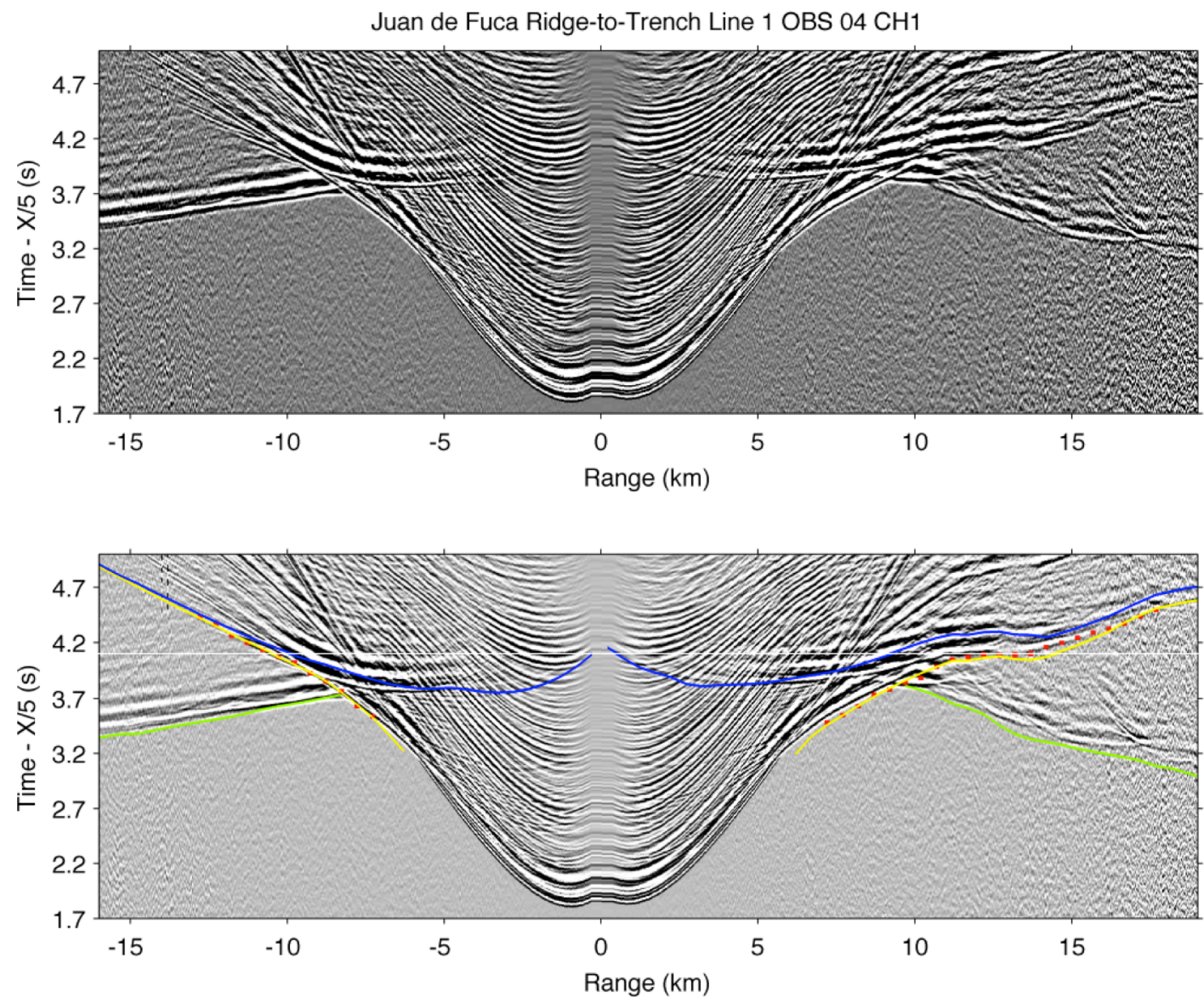

Figure 3-2. OBS data from instrument 57 with intershot spacing of $37.5 \mathrm{~m}$. Clear sediment refraction $(P s)$ and sub-basement crustal refraction $(P g)$ arrivals are present. Picked arrival times for $P S$ (red) are plotted with predicted arrival times from forward modeling of final model in yellow, light green and dark blue for $P s, P g$, and basement reflection $(P b P)$ respectively (lower panel). 

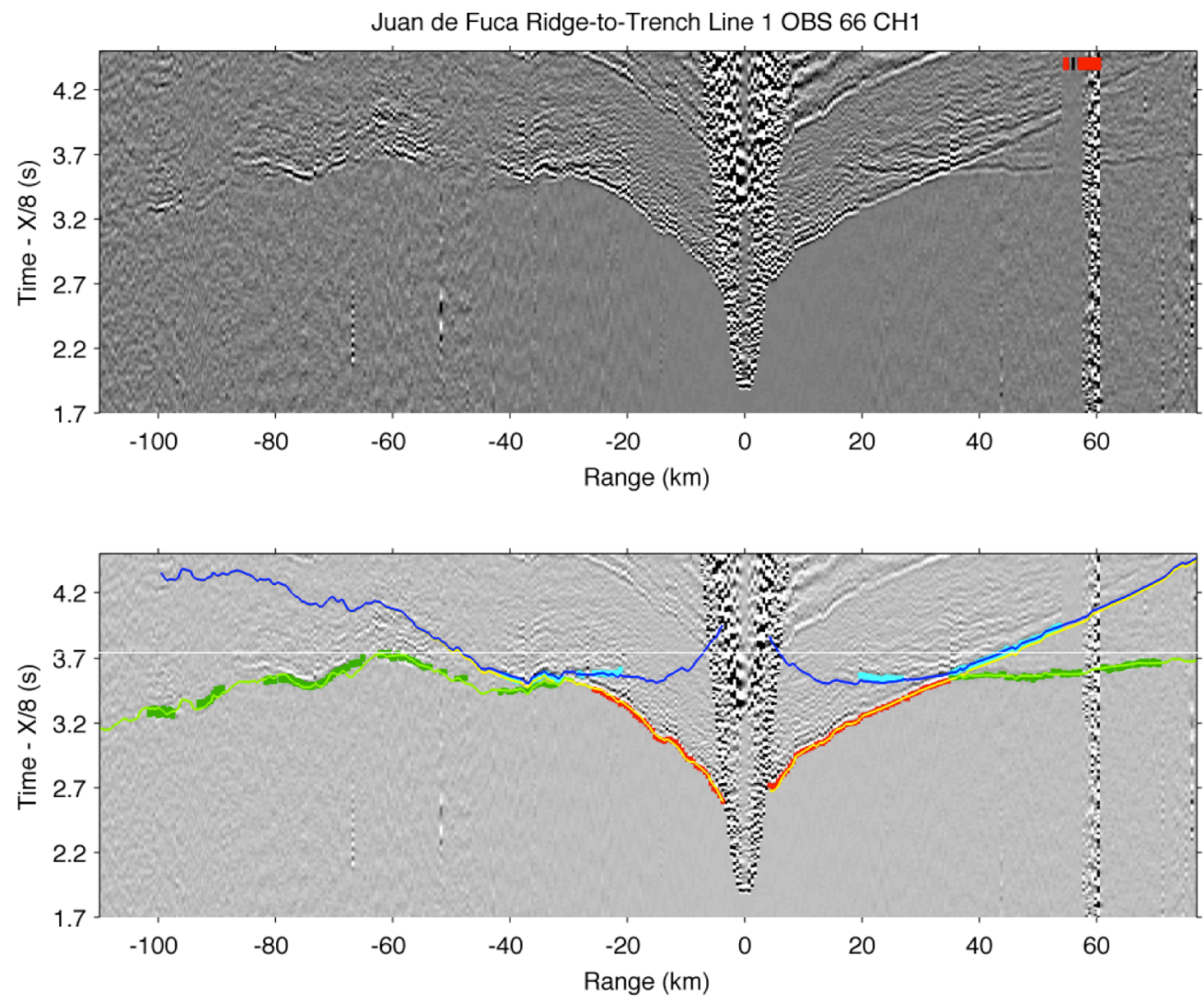

Figure 3-3. OBS data from instrument 66 with intershot spacing of $500 \mathrm{~m}$. Clear $P g, P m P$, and $P n$ arrivals are present. Data gaps from mitigation shooting (red bars) or skipped shots (black bar) are indicated for the ranges affected (upper panel). Picked arrival times for $P g$ (red), $P m P$ (light blue), and $P n$ (dark green) are plotted with predicted arrival times from forward modeling of final model in yellow, light green and dark blue for $P g, P m P$, and $P n$ respectively (lower panel). 
A

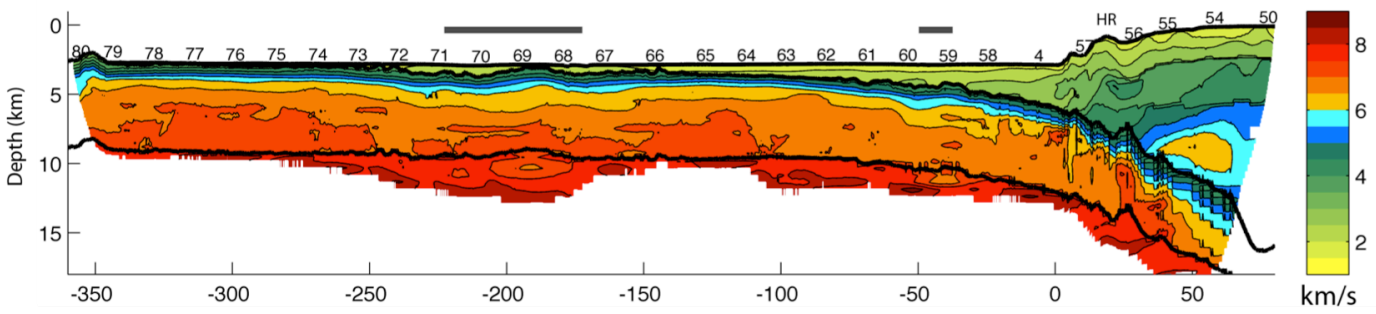

B
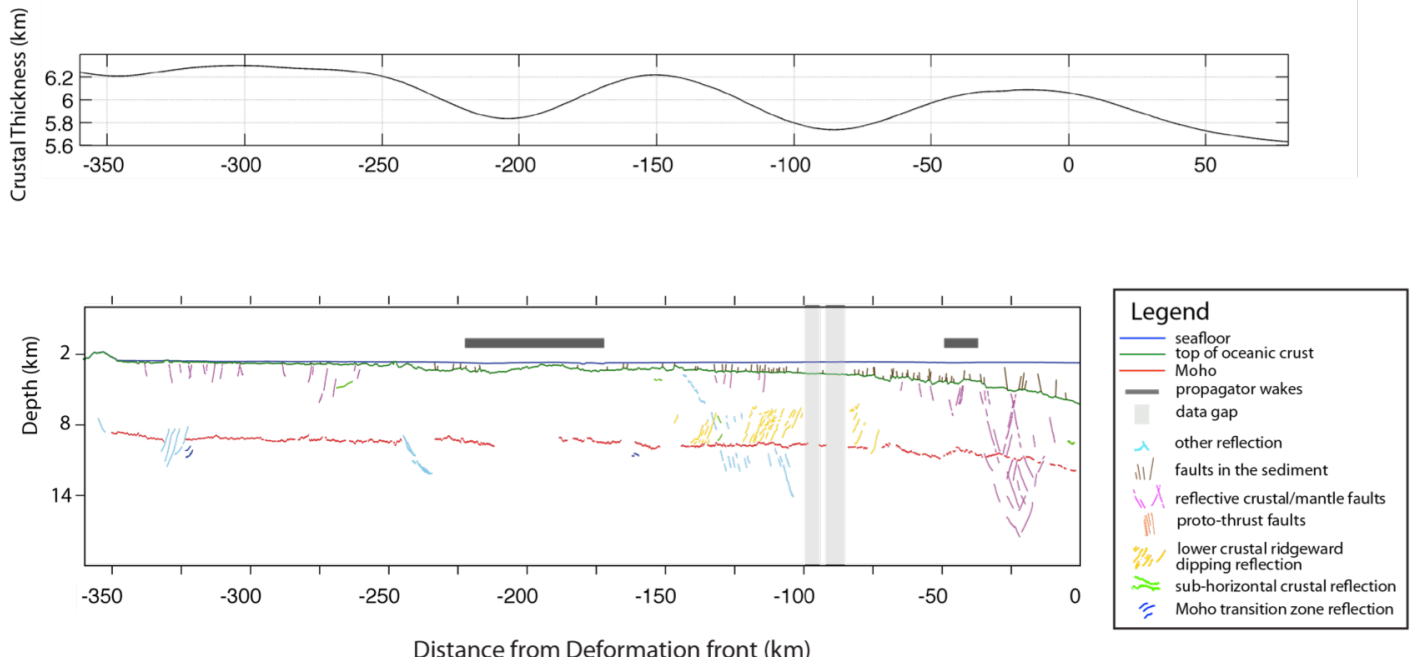

Figure 3-4. (A) Final 2D velocity model. Thick gray bars indicate location of propagator wakes. OBS numbers (see Fig. 1) are shown at the top. 'HR' denotes location of Hydrate Ridge between OBSs 56 and 57. (B) Crustal thickness along line. (C) Interpretation of prestack time migrated (PSTM) multichannel seismic (MCS) images of the Oregon transect from Han et al., 2016. Features are annotated in the legend table. Vertical exaggeration is $\sim 7 \mathrm{x}$. 


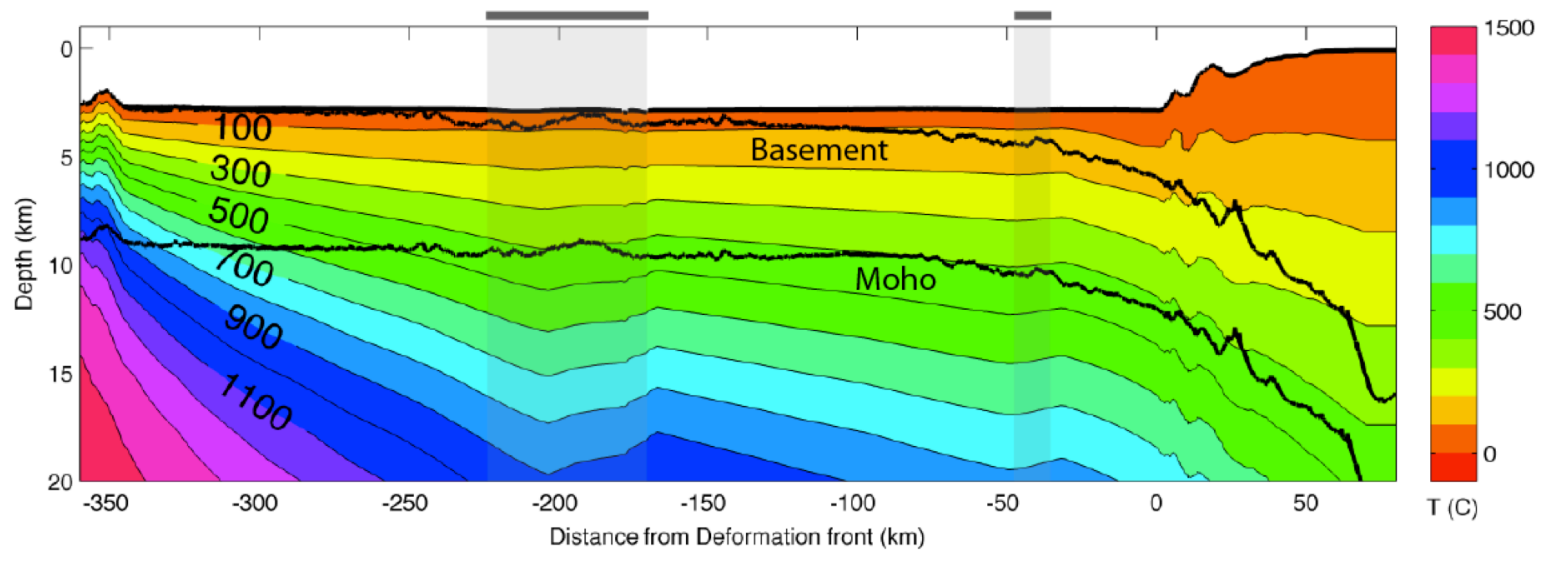

Figure 3-5. Predicted plate temperature. Gray bars mark locations of propagator wakes. Depth to basement and Moho are shown with bold black lines. The small-scale "bumps" in the isotherms eastward of the deformation front are purely an artifact produced by conforming the thermal structure to the seafloor topography for display purposes. 

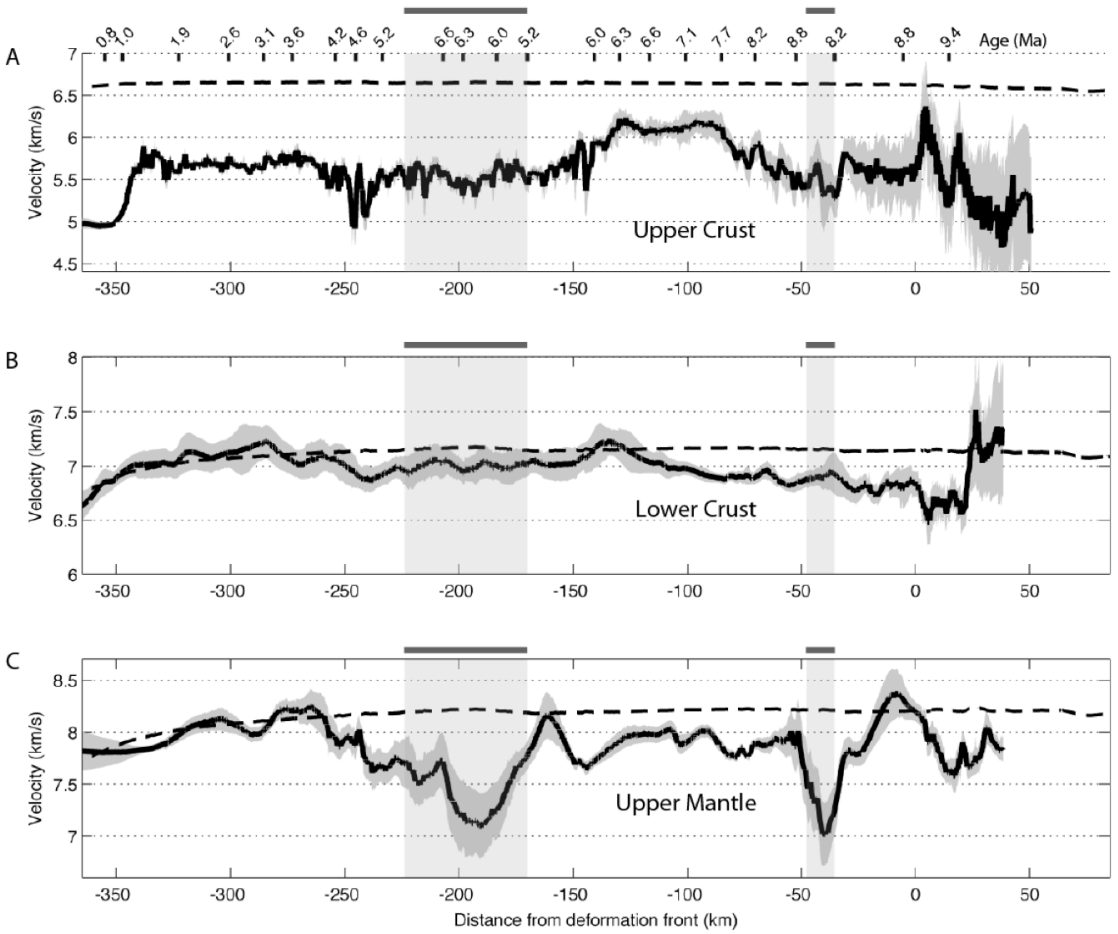

Figure 3-6. Along line velocity extracted from tomography model (Fig. 4) (solid black line) with error bounds (dark gray shaded region) at three depth intervals: (A) upper crust $(0.5-1.5 \mathrm{~km}$ below basement), (B) lower crust (2.5$0.5 \mathrm{~km}$ above Moho), (C) upper mantle (0.5-1.5 km below Moho) compared to thermal model predicted velocities (dashed lines) for the same depth ranges and an assumed lithology (see text). Gray bars mark locations of propagator wakes. Vertical tick marks in top panel indicate plate age in Ma. 

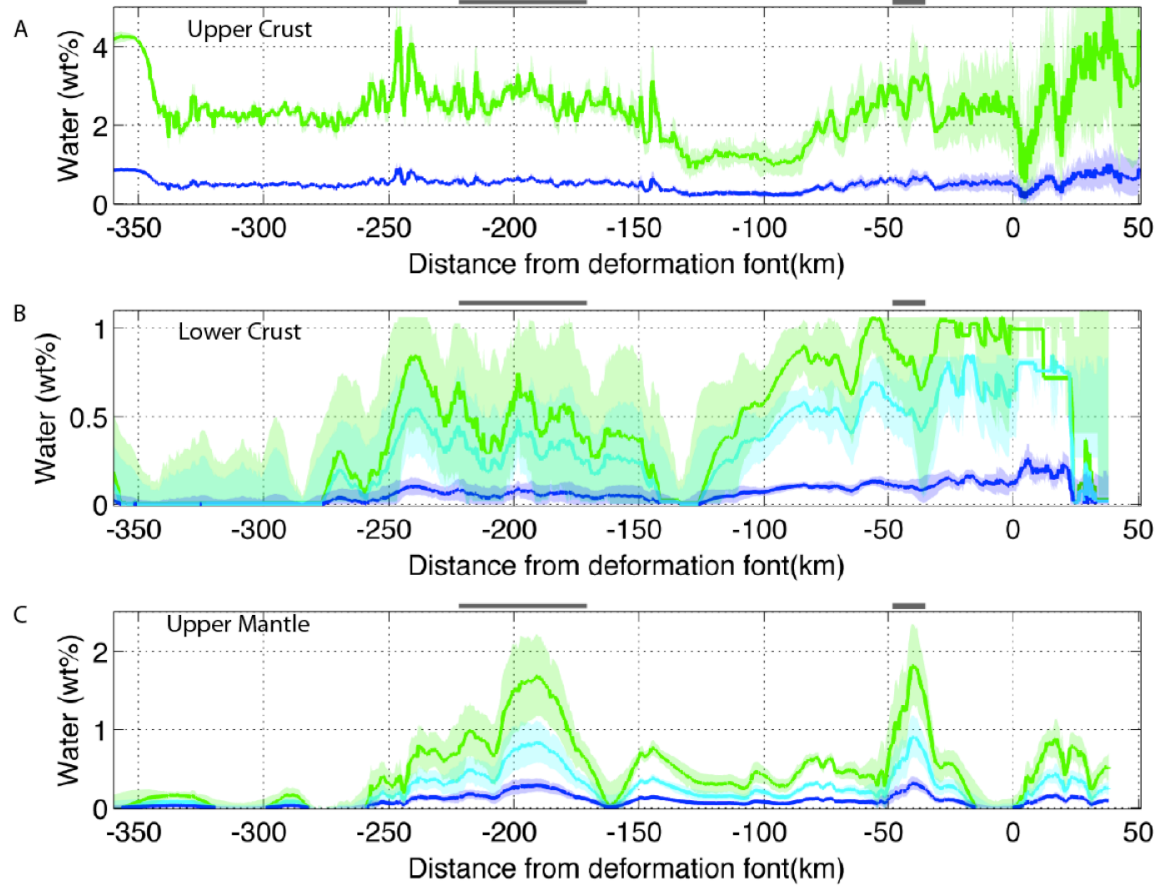

Figure 3-7. Calculated water content for the three depth intervals. (A) Upper crust $(0.5-1.5 \mathrm{~km}$ below basement) water content for cracks filled with free water with crack aspect ratios of 0.01 , dark blue line, and 0.1 , green line, with shaded region corresponding to range of values arising from uncertainty in the velocity model. (B) Lower crust (2.5-0.5 km above Moho) water content for cracks filled with free water (dark blue), mineral assemblage 1 (green), and mineral assemblage 2 (cyan). (C) Upper mantle (0.5-1.5km below Moho) water content for cracks filled with free water (dark blue), serpentine (green), and talc (cyan). Shaded regions correspond to range of values arising from uncertainty in the velocity model. Gray bars indicate location of propagator wakes. 


\title{
Chapter 4:
}

\section{Geochemical Investigation of Cretaceous Age Serpentinites from the Puerto Rico Trench}

\begin{abstract}
Exposure of mantle peridotite and its interactions with seawater to form serpentinite are integral parts of seafloor spreading, and play a key role in affecting the rheology, chemistry, and microbial habitability of the oceanic lithosphere at slow- and ultra-slow spreading ridges. Here we present results of a petrographic and spectroscopic study of altered rocks recovered from the from the north wall of the trench Puerto Rico Trench (PRT). The PRT represents one of two subduction zones worldwide where slow spreading oceanic lithosphere is presently subducted, and where serpentinized peridotite has been directly evidenced by seafloor sampling. The PRT provides a rare tectonic window into the interior of oceanic crust, due to its orientation parallel to seafloor spreading, which is currently poorly sampled and under constrained. Thin section petrography, XRF analysis, electron microprobe analysis, and confocal Raman spectroscopy reveal that the peridotite, which in all likelihood originated at the MidAtlantic Ridge during the early Cretaceous, was virtually completely serpentinized under static conditions (as it is evidenced by the preserved mesh texture after olivine and bastite after orthopyroxene), and underwent subsequent seafloor weathering during the following 100Ma. Our results suggest that the material presently subducted in the PRT is not simply composed of serpentine, magnetite, and brucite; it is rather a complex disequilibrium assemblage of minerals including serpentine, brucite, chlorite, talc, magnetite, hematite and goethite. In addition to these mineralogical shifts, bulk chemical analysis indicates that these samples are depleted in $\mathrm{MgO}$ while being enriched in $\mathrm{SiO}_{2}$ and $\mathrm{Fe}_{2} \mathrm{O}_{3}$. when compared to analogous serpentinites from the MAR. We propose that poorly constrained off-axis alteration and weathering processes evident here may be an important factor in the elemental mass-balance between the oceans and crust.
\end{abstract}




\section{INTRODUCTION}

Alteration of oceanic crust, through interaction with high and low temperature hydrothermal fluids as well as off-axis weathering, results in significant shifts in bulk chemistry, mineralogical assemblage, density, and rheological properties. The types of changes that occur in the oceanic crust depend on the structure and mineralogy of the plate, which are heavily dependent on spreading rate. Plate formation at slow-spreading ridges occurs through a sequence of asymmetric accretion at long-lived detachment faults and sporadic periods of magmatism resulting in symmetric crustal accretion [Escartín et al., 2008; Olive et al., 2010]. These two modes of accretion result in an oceanic crust with highly variable composition. It is estimated that $0-12.5 \%$ of the crust formed at the slow spreading MAR is of ultramafic composition[Carlson, 2001]. Slow-spreading crust is a large proportion of the global ridge system [Müller et al., 2008] which makes the mass balance of exchange between seawater and slow spread crust an important term in the global geochemical cycle.

In order to create a quantitative inventory of the chemical and mineralogical composition of the oceanic crust representative samples which span the range of crustal accretion modes are needed. Sampling of the interior of the oceanic crust is possible only through drilling or when a tectonic window, such as a detachment fault or fracture zone, exposes the interior of a plate at the seafloor. This difficulty fundamentally biases the sampling of ultramafic lithologies to those of very young in age as well as those exposed in areas with exceptionally thin crust [Prince and Forsyth, 1988] and where fluid-rock interaction should be more extensive. These problems result in a non-representative sampling of the highly heterogeneous slow-spreading oceanic crust. 
The north wall of the Puerto Rico Trench serves as a unique location wherein a 'tectonic window' into the interior of presumably typical slow-spread crust has been created by the highly oblique subduction of the North American Plate beneath the Caribbean plate [ten Brink, 2005; ten Brink et al., 2004] (Fig. 4-1). The north wall is marked by numerous scarps which are thought to expose the interior of the plate through large offset normal faults (Fig. 4-2) [Bowin et al., 1966]. During Cruise Chain 11 a camera lowing returned images of a veined dark rock with no sedimentary cover on the main scarp (Fig. 4-2). The dark rock was thought to be peridotite and led to two followup cruises to dredge for samples along these scarps [Bowin et al., 1966]. Dredging returned sedimentary rocks, variably altered basalt, and highly altered peridotite (serpentinite).

Serpentinization of peridotite results in large changes in rock density, strength, bulk chemistry, mineralogy, and texture. Seawater reacts with olivine (+-pyroxene) creating serpentine, magnetite, and brucite (+- talc, chlorite, Ni-Fe sulfides). Reaction pathways are dependent on temperature, fluid chemistry (silica activity, $\mathrm{pH}$ ), and waterrock ratio [Klein et al., 2009]. Examining the resulting mineral assemblages, pseudomorphic textures, and elemental partitioning in serpentinized peridotites can thus provide constraints on the conditions under which the rock formed. Serpentinites collected from the MAR provide the young end-member of compositions present in the oceanic crust. Samples collected in the PRT represent some of the oldest serpentinites ever recovered and a unique opportunity to evaluate the role of $\sim 100 \mathrm{Ma}$ of off-axis alteration and weathering on the under-constrained ultramafic component of oceanic crust. 


\section{METHODS}

\subsection{Sample Collection}

The rocks of the Puerto Rico Trench were sampled through dredging operations conducted in 1961 and 1962 during Cruises 19 and 34 on R/V Chain. Cruise 19 had three successful dredges, D2, D3, and D10. R/V Chain Cruise 34 also had three successful dredges, D2, D3, and D4. Of these dredges ultramafic lithologies were present only in the samples collected near 66 30'W from the north wall during Chain Cruise 19, Dredges 2 and 10 . Sedimentary rocks and variably altered basalt comprise the remainder of the dredged samples. Ten hand-specimen samples of serpentinized peridotite from Chain 19, Dredge 10 were selected for analysis.

\subsection{Sample Preparation}

Rocks chips for thin section preparation were cut and sent out to High Mesa Petrographics. High Mesa created 30um polished unstained uncovered thin sections suitable for petrographic and spectrographic analyses from the 10 selected samples. 20 gram powdered samples for X-Ray Fluorescence (XRF) analysis were created using an agate motorized motor and pestle. XRF analysis for bulk chemistry was performed at the GeoAnalytical Lab (Washington State University). A Li-tetraborate fused bead technique by X-ray fluorescence was used for analysis for 27 major and trace elements. Additionally volatile content was analyzed with Loss-on-ignition (LOI).

\subsection{Petrography}


The alteration mineralogy and replacement textures were examined in reflected and transmitted light under parallel and crossed polarizers. High resolution mosaic images of all thin sections were created using an automated Zeiss Axio Imager 2 petrographic microscope.

\subsection{Scanning Electron Microscopy}

A Hitachi TM 3000 table-top scanning electron microscope (SEM) was used for detailed petrographic examination of uncoated thin sections. Back-scattered electron images and qualitative chemical analyses from Energy-Dispersive X-ray Spectroscopy (EDS) were used to provide a 'road-map' of areas of interest for quantitative electron microprobe analysis. Cathodoluminescence (CL) images were separately obtained to distinguish the zircon as magmatic or hydrothermal in origin.

\subsection{Electron Microprobe}

The Electron Microprobe Analysis (EMPA) facility at Yale University was used investigate representative thin sections in detail. Samples were chosen to cover the entire range of mineralogical content and pseudomorphic textures. Samples were coated in conductive carbon using an Emitech carbon evaporator. The EMPA is a JEOL JXA$8530 \mathrm{~F}$, typical operating conditions were $15 \mathrm{kV}, 10$ nanoamps current, 5 micron beam size, and 300-400s count times.

\subsection{Confocal Raman Spectroscopy}

To aid in mineral phase identification the thin sections were analyzed with a Horiba LabRAM HR confocal Raman Spectrometer equipped with a 633nm laser. Typical operating conditions were $300 \mathrm{um}$ aperture, $600 \mathrm{~nm}$ grate, and window of 100- 
$1200 \mathrm{~cm}^{-1}$. LabSpec software was used to analyze spectra which were then compared to a database of raman spectra for phase determination.

\subsection{Magnetics}

The magnetic susceptibility and density of rock chips corresponding to the 10 chosen samples were analyzed with a Bartington MS2B magnetic susceptibility meter and an Accupyc II 1340 gas pycnometer. Multiple measurements were made with varying orientations to evaluate the importance of magnetic anisotropy on measured values.

\section{RESULTS}

\subsection{Mineralogy}

A combination of thin section petrography, SEM-EDS analysis, Raman confocal spectroscopy, and EMPA was used to determine mineralogical composition. With the exception of a singular olivine grain (Fo 90) in D10-3 found as an inclusion in spinel (Fig. 4-3), all of the samples are completely serpentinized peridotite. Serpentine occurs in both bastite and mesh psuedomorphic textures, replacing orthopyroxene and olivine respectively, forming the bulk of the samples (Fig. 4-4). Serpentine in mesh-texture is predominantly lizardite with an average $\mathrm{X}_{\mathrm{Mg}}\left(\mathrm{X}_{\mathrm{Mg}}=\mathrm{MgO} /(\mathrm{MgO}+\mathrm{FeO})\right)$ of 0.95 (Fig. 45). The bastite texture lizardite was more iron rich with an $X_{M g}$ of 0.91 . Given the apparent absence of either primary or pseudomorphic clinopyroxene and the relative proportion of bastite to mesh texture these samples most likely represent a harzburgite protolith. Minor talc and chlorite $\left(\mathrm{X}_{\mathrm{Mg}}=0.92\right)$ are found in bastite grain centers while magnetite is notably absent (Fig. 4-5). Magnetite is found spread throughout the mesh 
texture serpentine with some samples showing replacement of magnetite by goethite. Minor fine-grained $(<1 \mathrm{~mm}) \mathrm{Cr}$-spinel is the only relict phase. Rare veins of chlorite are present in a few samples. In one case (D10-9) a large chlorite vein hosts anhedral zircon grains up to $150 \mu \mathrm{m}$ in size as well as anhedral apatite (Fig. 4-6). In addition to the mesh and bastite texture serpentine, each sample contains at least one generation of crosscutting chrysotile veins (Fig. 4-4).

\subsection{X-ray Fluorescence}

X-ray fluorescence analyses of major and selected trace elements as well as loss on ignition (LOI) data are presented in table 1. With the assumption that these samples were completely serpentinized in the near-axis region of the MAR in the Cretaceous then the difference between their bulk chemistry and equivalent modern samples from the MAR should reflect $\sim 100$ Ma of off-axis weathering and alteration. Figure 4-7 displays the mass loss or gain of major elements when compared to samples of abyssal peridotites from the MAR [Paulick et al., 2006]. The method of Gresens (1967) was used to determine the elemental gains/losses. An assumption of constant volume necessitates the comparison of rocks with similar density and mineralogic makeup (talc-altered rocks and partially serpentinized samples (LOI $<13 \mathrm{wt} \%$ ) are not included).

\section{$\underline{3.4 \text { Magnetics }}$}

Magnetic susceptibility and density is presented in figure 4-8 with typical ranges for various ultramafic rocks. Magnetic susceptibility is within expected values for completely serpentinized peridotites from mid-ocean ridge settings reflecting an increase in magnetic susceptibility due to the formation of magnetite. The measured magnetic susceptibility may have been partly compromised by the oxidation of magnetite to 
hematite and goethite. The decrease in density results from precipitation of hydrous phases.

\section{DISCUSSION}

The mineral assemblage and textures present in these samples represent multiple phases of extensive alteration from high temperature hydrothermal alteration at the MAR

to low-temperature oxidative weathering. The high $\mathrm{X}_{\mathrm{Mg}}(0.95)$ of lizardite in mesh texture and the presence magnetite suggests that serpentinization occurred at relatively high temperatures $\left(>200^{\circ} \mathrm{C}\right)$ [Klein et al., 2009] in the near axis region of the MAR. Serpentinization of a harzburgite at moderate to high temperatures should include the formation of abundant brucite. In fact, minor brucite is found in samples of serpentinite from the MAR. The absence of brucite in samples from the PRT suggests that brucite is weathered during transport to the subduction zone [Snow and Dick, 1995]. This weathering may provide a pathway for increasing porosity and explain the porous bastite grain centers we encountered during electron microprobe analysis. Many of the samples also showed evidence for alteration of magnetite to hematite $\left(\mathrm{Fe}_{2} \mathrm{O}_{3}\right)$ and goethite $(\mathrm{FeO}(\mathrm{OH}))($ Fig. 4-9). These weathering processes may provide a partial explanation for the bulk chemistry differences between the PRT and MAR serpentinites (Fig. 4-7). The dissolution of brucite $\left(\mathrm{Mg}(\mathrm{OH})_{2}\right)$ could account for the relatively large loss in $\mathrm{MgO}$ of 3.1 $\mathrm{g} \mathrm{MgO} / 100 \mathrm{~g}$ rock. The reasons for the increase in $\mathrm{SiO}_{2}$ and $\mathrm{Fe}_{2} \mathrm{O}_{3}$ are not as readily apparent but may be explained by the choice of protolith composition. Zircon of sample D10-9 hosted in the chlorite vein reveals a number of intriguing features (Fig. 4-6a). Distinguishing between magmatic and hydrothermal zircon grains is 
difficult with petrographic techniques but the differences are readily apparent using cathodoluminescence (CL) images (Fig. 4-6 d,e). Hydrothermal zircons have a 'mottled' appearance in contrast to the regular zonation of magmatic zircon [Fu et al., 2009]. A CL image of the largest zircon grain clearly indicates its hydrothermal origin (Fig. 4-6 b). Hydrothermal zircon is known to form at temperatures of $\sim 270-300{ }^{\circ} \mathrm{C}[$ Dubinska et al., 2004] further supporting alteration of these rocks at moderate to high temperatures. U-Pb dating of this zircon gives an age of alteration at 114.7-115.3 Ma (Klein et al., unpublished.). Considering the high temperatures required for this alteration this age probably closely matches the time of mantle exhumation at the MAR.

\section{CONCLUSIONS}

The ten samples presented here represent a preliminary investigation and while they are not by themselves sufficient to make interpretations about the specific processes at work in the $\sim 100 \mathrm{Ma}$ of time between serpentinization and exposure in the Puerto Rico Trench they indicate that a number of alteration processes are active during the transport of crust to the subduction zone. Heat flow data have provided evidence that hydrothermal circulation can occur in the basement of old crust (106 Ma) in the absence of advective heat loss [Fisher and Von Herzen, 2005]. Weathering processes are also readily apparent in the oxidation of magnetite to goethite and hematite (Fig. 4-9). The loss of magnesium which we see in our bulk chemistry comparison (Fig. 4-7) was described in other serpentinites by Snow and Dick [1995]. There are two pathways through which $\mathrm{Mg}$ is lost during the alteration of peridotite; the dissolution of brucite created during serpentinization and the direct dissolution of olivine and enstatite (Snow 
and Dick, 1995). With a relatively low (\%10) estimate of ultramafic abundance in the crust the $\mathrm{Mg}$ loss is equivalent to $3.2 \%$ of river $\mathrm{Mg}$ input (Snow and Dick, 1995). By comparing completely serpentinized peridotites (without olivine or enstatite) we can prescribe the loss of $\mathrm{Mg}$ in our samples to the dissolution of brucite $\left(\mathrm{Mg}(\mathrm{OH})_{2}\right)$. The enrichments in $\mathrm{SiO}_{2}$ and $\mathrm{Fe}_{2} \mathrm{O}_{3}$ which are concomitant with the depletion of $\mathrm{Mg}$, while unknown in source, may be similarly important as sinks for those elements in the crust. These trends demonstrate that off-axis alteration and weathering can cause significant shifts in bulk chemistry of altered ultramafic slow-spreading crust. More extensive sampling will be needed to verify the consistency of these effects and determine if they are significant enough to affect mass balance calculations of oceanic crust with seawater.

\section{TABLES}

Table 1: Unnormalized Major Elements (Weight \%)

\begin{tabular}{|c|c|c|c|c|c|c|c|c|c|c|c|c|}
\hline & D10-1 & D10-3 & D10-4 & D10-7 & D10-8 & D10-9 & D10-10 & D10-12 & D10-15 & D10-16 & D10-3 & AVG \\
\hline $\mathrm{SiO} 2$ & 39.74 & 39.54 & 39.63 & 39.48 & 38.56 & 40.10 & 37.88 & 39.27 & 40.42 & 39.18 & 39.54 & 39.38 \\
\hline $\mathrm{TiO} 2$ & 0.014 & 0.024 & 0.018 & 0.025 & 0.014 & 0.067 & 0.026 & 0.028 & 0.034 & 0.021 & 0.024 & 0.03 \\
\hline $\mathrm{Al} 2 \mathrm{O} 3$ & 1.05 & 0.69 & 0.99 & 1.17 & 1.03 & 1.28 & 1.36 & 0.55 & 0.74 & 1.42 & 0.69 & 1.03 \\
\hline $\mathrm{FeO}^{*}$ & 7.93 & 8.32 & 8.87 & 7.95 & 9.51 & 10.07 & 8.24 & 9.41 & 9.22 & 9.20 & 8.32 & 8.87 \\
\hline $\mathrm{MnO}$ & 0.060 & 0.084 & 0.076 & 0.092 & 0.098 & 0.106 & 0.098 & 0.087 & 0.085 & 0.087 & 0.084 & 0.09 \\
\hline $\mathrm{MgO}$ & 36.44 & 36.71 & 36.07 & 37.40 & 36.49 & 34.60 & 35.25 & 36.74 & 36.57 & 36.37 & 36.71 & 36.26 \\
\hline $\mathrm{CaO}$ & 0.04 & 0.02 & 0.09 & 0.03 & 0.03 & 0.17 & 0.46 & 0.03 & 0.08 & 0.04 & 0.02 & 0.10 \\
\hline $\mathrm{Na2O}$ & 0.18 & 0.17 & 0.17 & 0.18 & 0.22 & 0.17 & 0.43 & 0.07 & 0.11 & 0.29 & 0.17 & 0.20 \\
\hline K2O & 0.04 & 0.02 & 0.04 & 0.03 & 0.02 & 0.03 & 0.05 & 0.01 & 0.02 & 0.04 & 0.02 & 0.03 \\
\hline P2O5 & 0.015 & 0.012 & 0.016 & 0.009 & 0.009 & 0.024 & 0.010 & 0.019 & 0.014 & 0.011 & 0.012 & 0.01 \\
\hline Sum & 85.53 & 85.60 & 85.97 & 86.35 & 85.99 & 86.61 & 83.80 & 86.22 & 87.29 & 86.66 & 85.60 & 86.00 \\
\hline LOI (\%) & 13.88 & 13.35 & 13.17 & 12.71 & 13.14 & 12.31 & 15.96 & 12.56 & 12.52 & 12.71 & 13.35 & 13.23 \\
\hline Sum & 99.41 & 98.95 & 99.14 & 99.06 & 99.12 & 98.91 & 99.76 & 98.77 & 99.81 & 99.37 & 98.95 & 99.23 \\
\hline
\end{tabular}




\section{FIGURES}

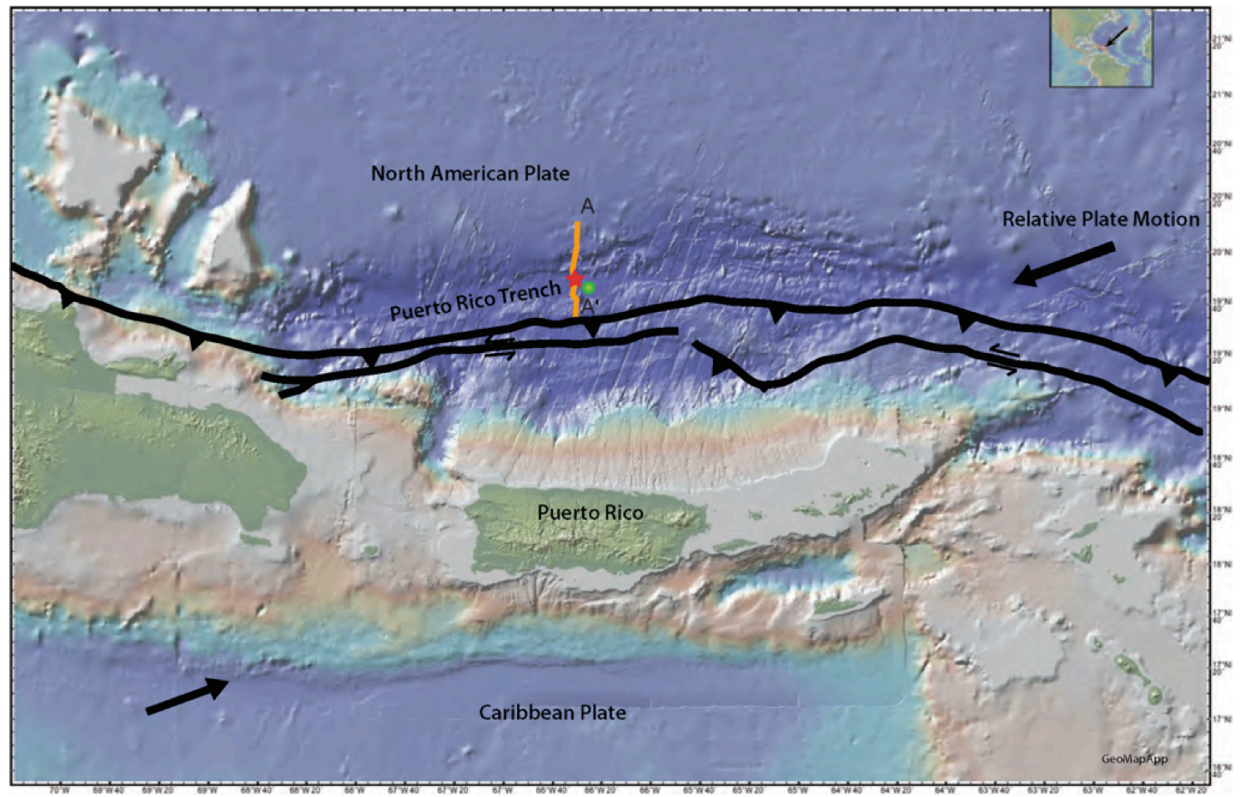

Figure 4-1. Location of sample collection and seismic reflection profile.

Structural interpretation from Ten Brink [2005]. Red star indicates the location of Chain 19, Dredge 10. Orange line indicates location of seismic reflection profile. Green circle indicates location of camera lowering. 

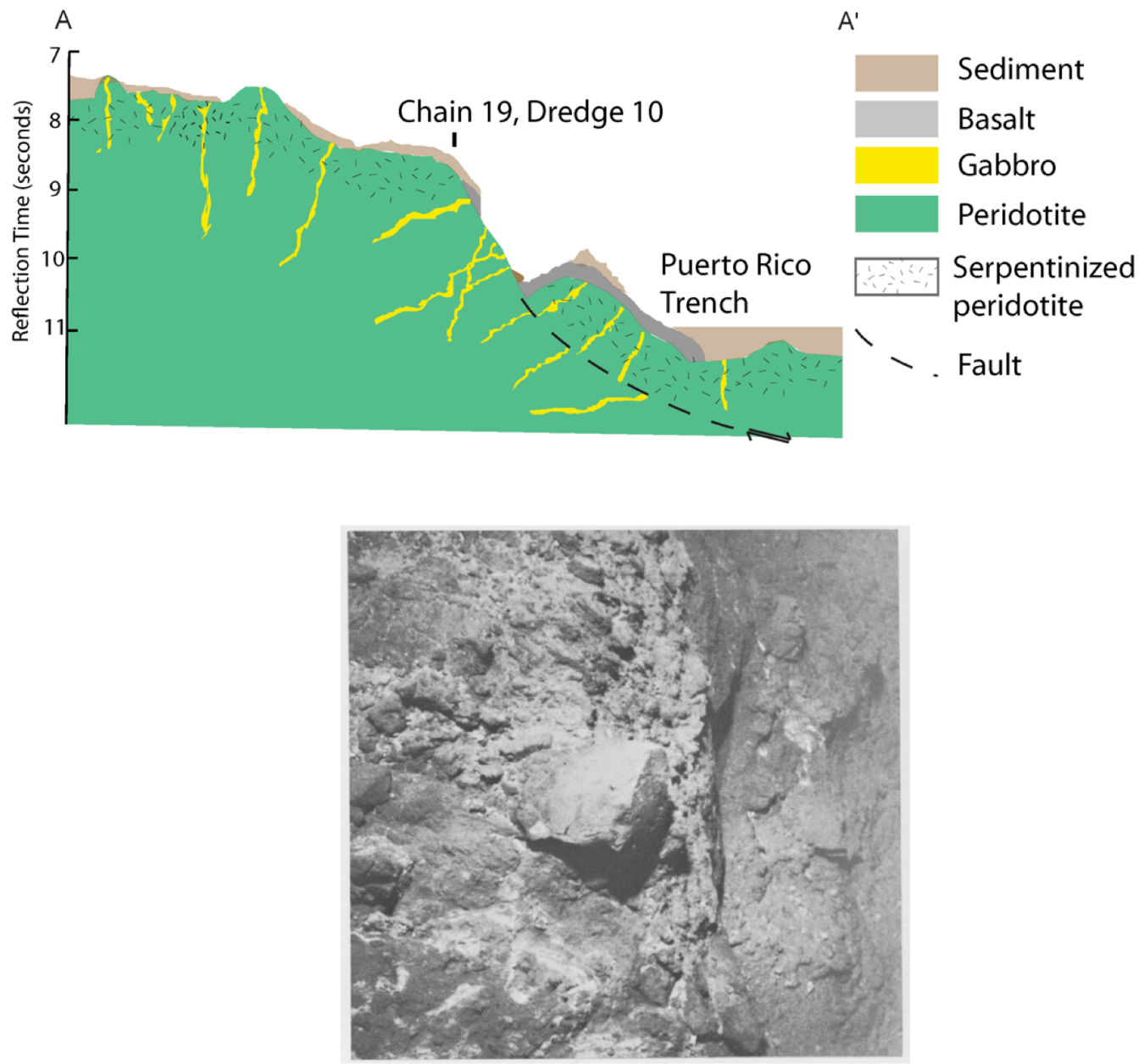

Figure 4-2. top: Speculative cartoon of structure based on a continuous seismic refelction profile [Bowin et al., 1996] along $66^{\circ} 31^{\prime} \mathrm{W}$. bottom: Picture of dark veined rock from camera lowering on cruise Chain 11 


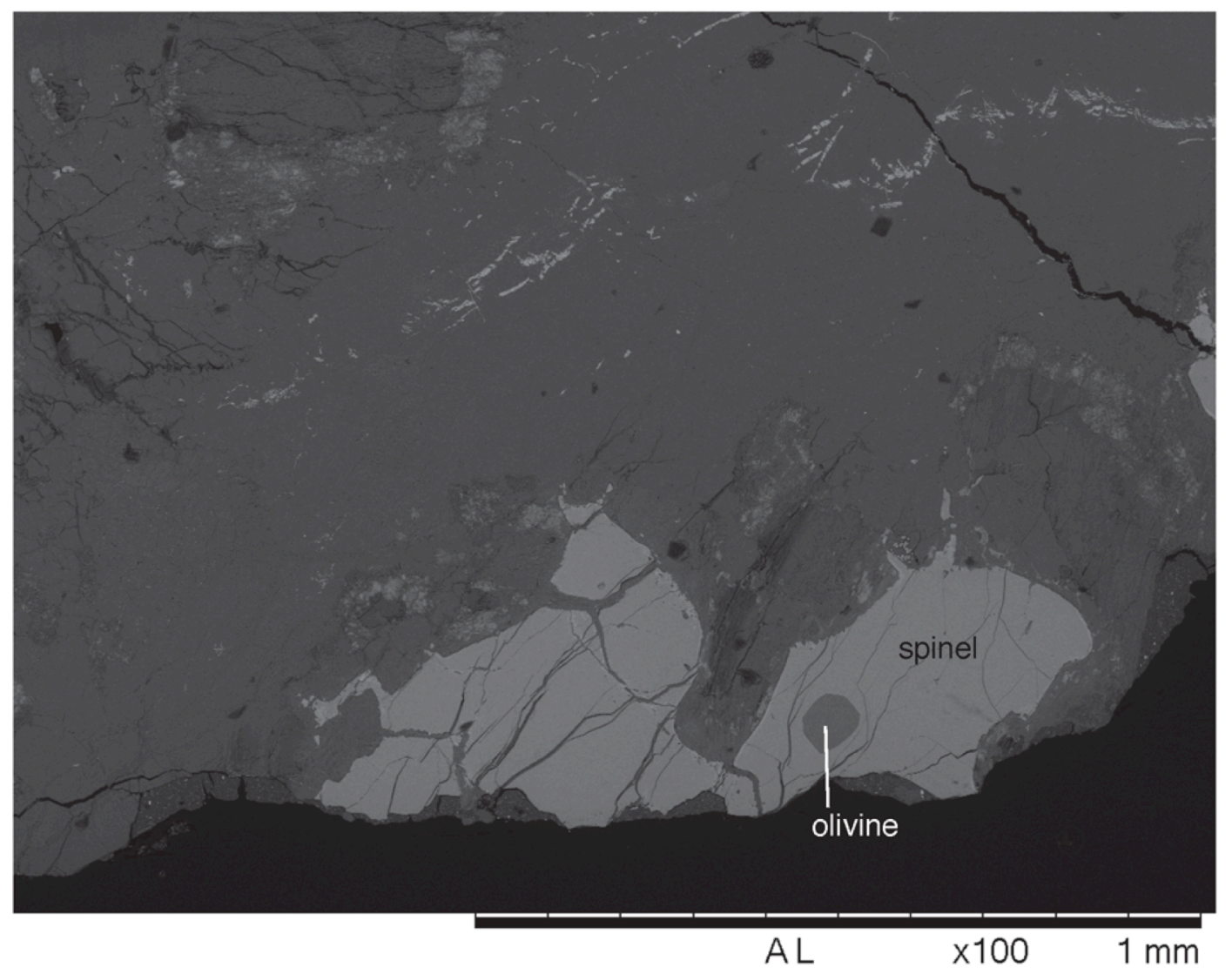

Figure 4-3. Electron backscatter image of olivine inclusion in spinel from sample D10-3 

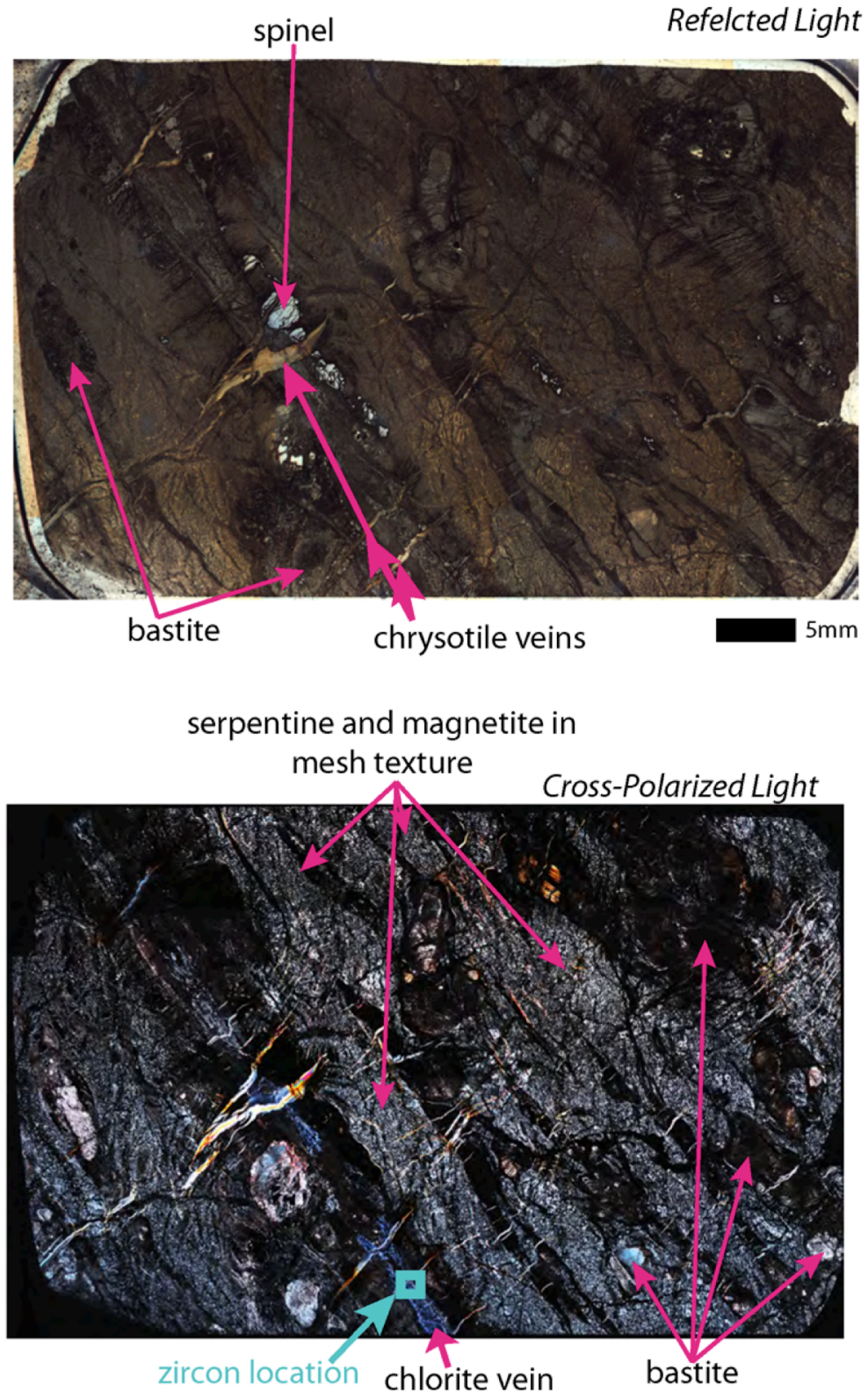

Figure 4-4. Reflected and cross-polarized light images of sample D10-9 


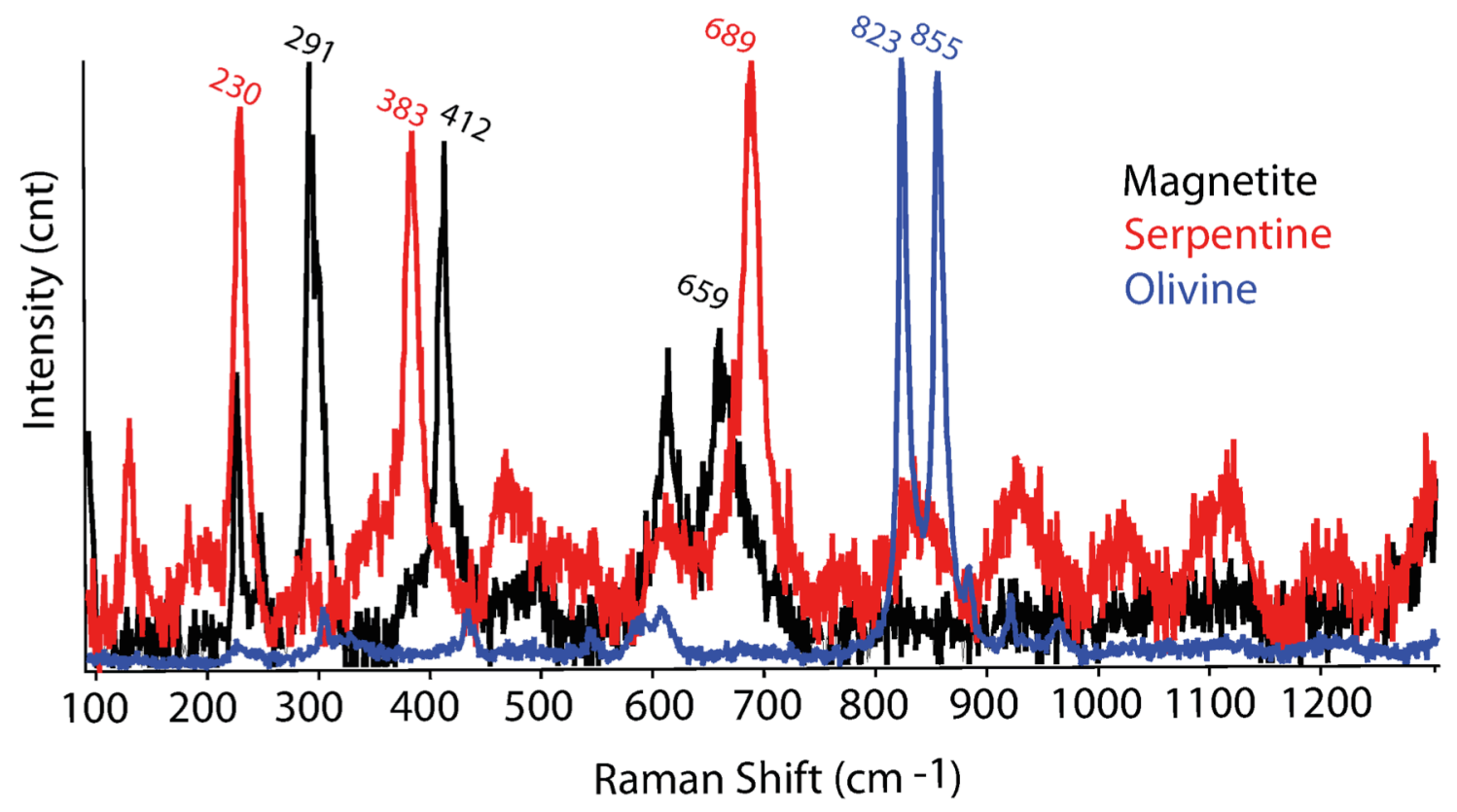

Figure 4-5. Raman spectra with diagnostic peaks labeled for magnetite, serpentine, and olivine. 

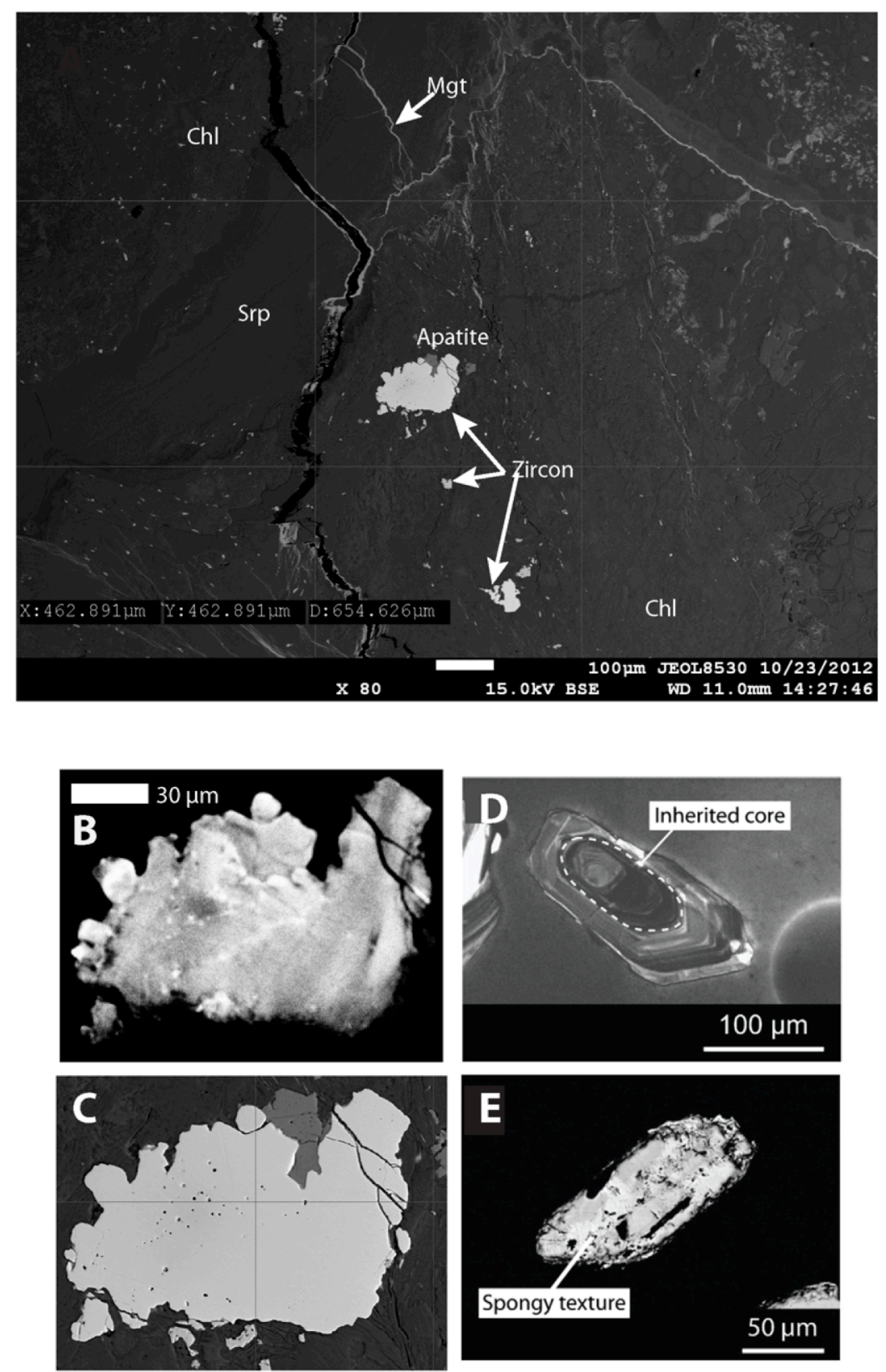

Figure 4-6. A: zircon grains in chlorite vein from sample D10-9 B: CL image of zircon grain from D10-9 C. Backscatter image of zircon grain from D10-9 D. CL image of magmatic zircon [Pelleter et al., 2007] E. CL image of hydrothermal zircon with mottled appearance [Pelleter et al., 2007]. 


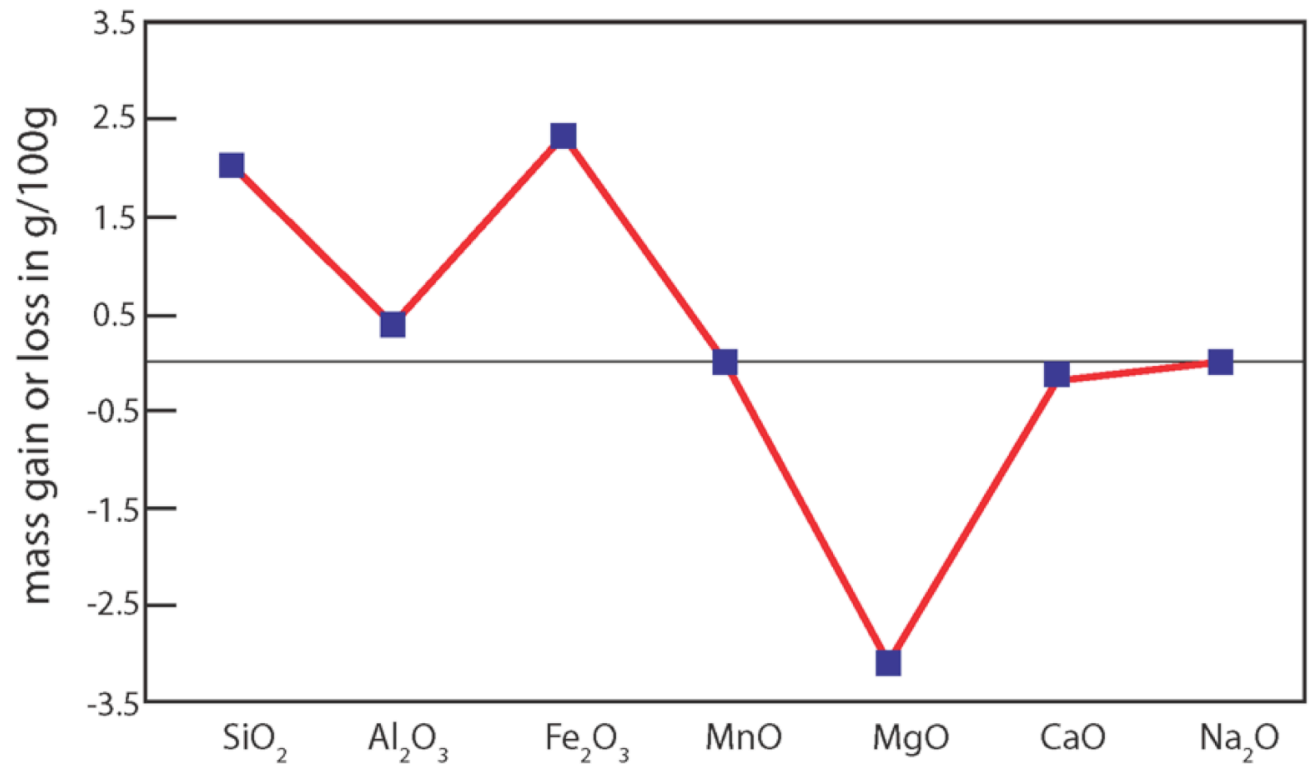

Figure 4-7. Mass gain/loss of selected elements in completely serpentinized PRTNW harzburgite compared with a completely serpentinized harzburgite from the modern MAR (data from Paulick et al. [2006]). 


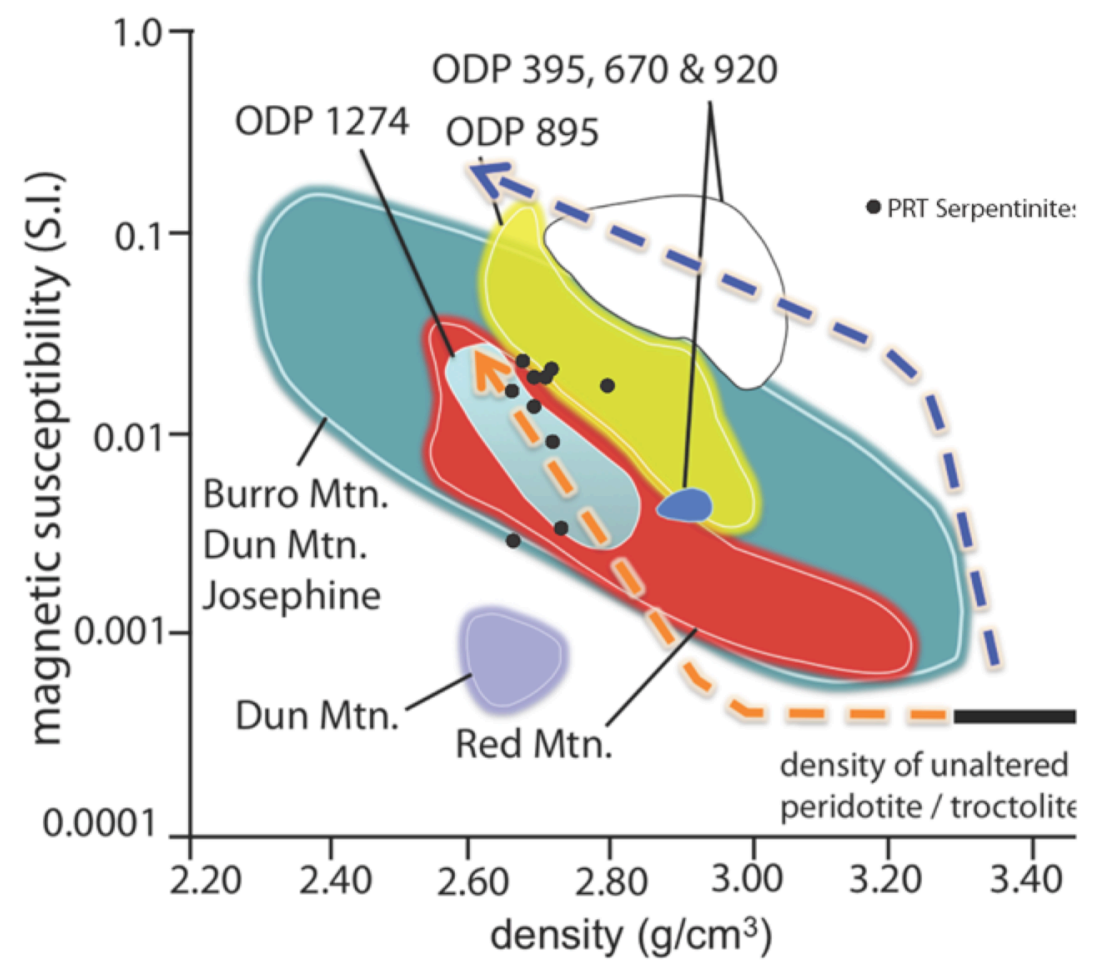

Figure 4-8. Magnetic susceptibility of PRT serpentinites with plots of typical values for ultramafics. Modified from Toft et al. [1990]; Oufi et al. [2002]; Bach et al. [2006]. 


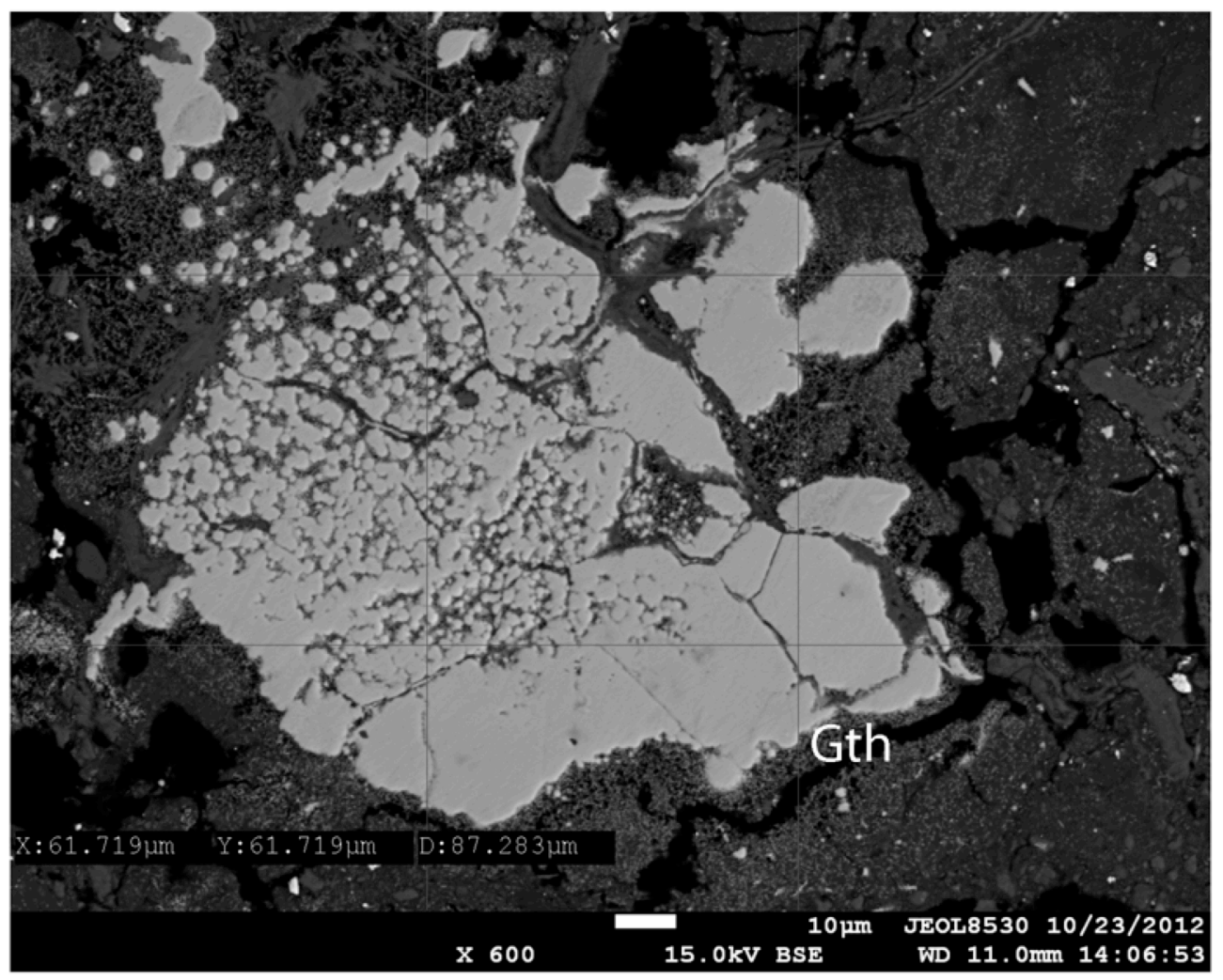

Figure 4-9. Electron backscatter image of goethite rim after magnetite 


\section{REFERENCES}

Alt, J. C., J. Honnorez, C. Laverne, and R. Emmerman (1986), Hydrothermal alteration of a $1 \mathrm{~km}$ section through the upper oceanic crust, Deep Sea Drilling Project Hole 504B: mineralogy, chemistry, and evolution of sea-water-basalt interactions, J. Geophys. Res., 91(B10), 10309-10335.

Andreani, M., J. Escartin, A. Delacour, B. Ildefonse, M. Godard, J. Dyment, A. E. Fallick, and Y. Fouquet (2014), Tectonic structure, lithology, and hydrothermal signature of the Rainbow massif (Mid-Atlantic Ridge 36 degrees 14 ' N), Geochem Geophy Geosy, 15(9), 3543-3571.

Arnulf, A. F., A. J. Harding, G. M. Kent, S. M. Carbotte, J. P. Canales, and M. R. Nedimović (2014), Anatomy of an active submarine volcano, Geology, 42(8), 655-658.

Audet, P., M. G. Bostock, N. I. Christensen, and S. M. Peacock (2009), Seismic evidence for overpressured subducted oceanic crust and megathrust fault sealing, Nature, 457, 7678.

Bécel, A., D. J. Shillington, M. R. Nedimović, S. C. Webb, and H. Kuehn (2015), Origin of dipping structures in fast-spreading oceanic lower crust offshore Alaska imaged by multichannel seismic data, Earth Planet. Sci. Lett., 424, 26-37.

Ben Ismail, W., and D. Mainprice (1998), An olivine fabric database: an overview of upper mantle fabrics and seismic anisotropy, Tectonophysics, 296(1-2), 145-157.

Billen, M. I., and M. Gurnis (2001), A low viscosity wedge in subduction zones, Earth Planet. Sci. Lett., 193(1-2), 227-236.

Blackman, D. K., G. Karner, and R. C. Searle (2008), Three-dimensional structure of oceanic core complexes: Effects on gravity structure and ridge flank morphology, MidAtlantic Ridge $30^{\circ} \mathrm{N}$, Geochem. Geophys. Geosyst., 6(9), Q06007, doi:06010.01029/02008GC001951.

Blackman, D. K., et al. (2011), Drilling constraints on lithospheric accretion and evolution at Atlantis Massif, Mid-Atlantic Ridge $30^{\circ} \mathrm{N}, J$. Geophys. Res., 116, B07103.

Bonatti, E. (1976), Serpentinite protrusions in the oceanic crust, Earth Planet. Sci. Lett., $32,107-113$.

Bostock, M. G., R. D. Hyndman, S. Rondenay, and S. M. Peacock (2002), An inverted continental Moho and serpentinization of the forearc mantle, Nature, 417, 536-538.

Bowin, C., A. J. Nalwalk, and J. B. Hersey (1966), Serpentinized peridotite from the north wall of the Puerto Rico Trench, Geol. Soc. Am. Bull., 77, 257-270.

Brune, J. N. (1970), Tectonic Stress and Spectra of Seismic Shear Waves from Earthquakes, J. Geophys. Res., 75(26), 4997-\&. 
Canales, J. P., and S. M. Carbotte (2012), Evolution and hydration of the Juan de Fuca crust and uppermost mantle. International Federation of Digital Seismograph Networks. Other/Seismic Network., edited.

Canales, J. P., R. S. Detrick, D. R. Toomey, and W. S. D. Wilcock (2003), Segment-scale variations in the crustal structure of 150-300 kyr old fast spreading oceanic crust (East Pacific Rise, $8^{\circ} 15^{\prime} \mathrm{N}-10^{\circ} 15^{\prime} \mathrm{N}$ ) from wide-angle seismic refraction profiles, Geophys $J$. Int., 152, 766-794.

Canales, J. P., R. A. Dunn, R. Arai, and R. A. Sohn (2017), Seismic imaging of magma sills beneath an ultramafic-hosted hydrothermal system, Geology, submitted.

Canales, J. P., R. S. Detrick, S. M. Carbotte, G. M. Kent, J. B. Diebold, A. J. Harding, J. Babcock, M. R. Nedimović, and E. van Ark (2005), Upper crustal structure and axial topography at intermediate-spreading ridges: seismic constraints from the Southern Juan de Fuca Ridge, J. Geophys. Res., 110, B12104, doi:12110.11029/12005JB003630.

Canales, J. P., et al. (2013), MARINER: Seismic Investigation of the Rainbow Hydrothermal Field and its Tectono/Magmatic Setting, Mid-Atlantic Ridge 36 14'N- A Report from RV M.G. Langseth Cruise MGL1305, InterRidge News, 22, 43-50.

Cann, J. R., and M. R. Strens (1982), Black smokers fuelled by freezing magma, Nature, 298(5870), 147-149.

Cannat, M. (1993), Emplacement of mantle rocks in the seafloor at mid-ocean ridges, $J$. Geophys. Res., 98, 4163-4172.

Cannat, M., et al. (1995), Thin crust, ultramafic exposures, and rugged faulting patterns at the Mid-Atlantic Ridge $\left(22^{\circ}-24^{\circ} \mathrm{N}\right)$, Geology, 23, 49-52.

Carbotte, S. M., J. P. Canales, H. Carton, and M. R. Nedimović (2014), Multi-channel seismic shot data from the Cascadia subduction zone acquired during the R/V Marcus Langseth expedition MGL1211 (2012). , edited, Integrated Earth Data Applications (IEDA).

Carbotte, S. M., M. R. Nedimović, J. P. Canales, G. M. Kent, A. J. Harding, and M. Marjanović (2008), Variable crustal structure along the Juan de Fuca Ridge; influence of on-axis hotspots and absolute plate motions, Geochem. Geophys. Geosyst., 9, Q08001, doi:08010.01029/02007GC001922.

Carbotte, S. M., R. S. Detrick, A. J. Harding, J. P. Canales, J. Babcock, G. M. Kent, E. van Ark, M. R. Nedimović, and J. B. Diebold (2006), Rift topography linked to magmatism at the intermediate spreading Juan de Fuca Ridge, Geology, 34(3), 209-212.

Carlson, R. L. (2001), The abundance of ultramafic rocks in Atlantic Ocean crust, Geophys J. Int., 144, 37-48. 
Carlson, R. L. (2014), The influence of porosity and crack morphology on seismic velocity and permeability in the upper oceanic crust, Geochem. Geophys. Geosyst., 15(1), $10-27$.

Charlou, J. L., J. P. Donval, Y. Fouquet, P. Jean-Baptiste, and N. Holm (2002), Geochemistry of high $\mathrm{H}(2)$ and $\mathrm{CH}(4)$ vent fluids issuing from ultramafic rocks at the Rainbow hydrothermal field (36 degrees 14 ' N, MAR), Chem. Geol., 191(4), 345-359.

Christensen, N. I. (1979), Compressional wave velocities in rocks at high temperatures and pressures, critical thermal gradients, and crustal low-velocity zones, J. Geophys. Res., $84,6849-6857$.

Christensen, N. I. (2004), Serpentinites, Peridotites, and Seismology, International Geology Review, 46, 795-816.

Coleman, R. G. (1971), Petrological and geophysical nature of serpentinites, Geol. Soc. Am. Bull., 82, 897-918.

Collins, J. A., D. K. Smith, and J. J. McGuire (2012), Seismicity of the Atlantis Massif detachment fault, $30^{\circ} \mathrm{N}$ at the Mid-Atlantic Ridge, Geochem. Geophys. Geosyst., 13(1), Q0AG11.

Contreras-Reyes, E., I. Grevemeyer, E. R. Flueh, M. Scherwath, and M. Heesemann (2007), Alteration of the subducting oceanic lithosphere at the southern central Chile trench-outer rise, Geochem. Geophys. Geosyst., 8, Q07003, doi:07010.01029/02007GC001632.

Davis, E. E., K. Wang, J. He, D. S. Chapman, H. Villinger, and A. Rosenberger (1997), An unequivocal case for high Nusselt number hydrothermal convection in sedimentburied igneous oceanic crust, Earth Planet. Sci. Lett., 146, 137-150.

deMartin, B. J., R. Reves-Sohn, J. P. Canales, and S. E. Humphris (2007), Kinematics and geometry of active detachment faulting beneath the Trans-Atlantic Geotraverse (TAG) hydrothermal field on the Mid-Atlantic Ridge, Geology, 35(8), 711-714.

Douville, E., J. J. Charlou, E. H. Oelkers, P. Bienvenu, C. F. Jove Colon, J. P. Donval, Y. Fouquet, D. Prieur, and P. Appriou (2002), The Rainbow vent fluids (36 14 'N, MAR): the influence of ultramafic rocks and phase separation on trace metal content in MidAtlantic Ridge hydrothermal fluids, Chem. Geol., 184, 37-48.

Dragert, H., K. L. Wang, and T. S. James (2001), A silent slip event on the deeper Cascadia subduction interface, Science, 292(5521), 1525-1528.

Dubinska, E., P. Bylina, A. Kozlowski, W. Dorr, K. Nejbert, J. Schastok, and C. Kulicki (2004), U-Pb dating of serpentinization: hydrothermal zircon from a metasomatic rodingite shell (Sudetic ophiolite, SW Poland), Chem. Geol., 203(3-4), 183-203. 
Dziewonski, A. M., T. A. Chou, and J. H. Woodhouse (1981), Determination of Earthquake Source Parameters from Waveform Data for Studies of Global and Regional Seismicity, J. Geophys. Res., 86(Nb4), 2825-2852.

Eason, D. E., R. A. Dunn, J. Pablo Canales, and R. A. Sohn (2016), Segment-scale variations in seafloor volcanic and tectonic processes from multibeam sonar imaging, Mid-Atlantic Ridge Rainbow region $\left(35^{\circ} 45^{\prime}-36^{\circ} 35^{\prime} \mathrm{N}\right)$, Geochem. Geophys. Geosyst., 17(9), 3560-3579.

Ekstrom, G., and P. England (1989), Seismic Strain Rates in Regions of Distributed Continental Deformation, J Geophys Res-Solid, 94(B8), 10231-10257.

Ekstrom, G., M. Nettles, and A. M. Dziewonski (2012), The global CMT project 20042010: Centroid-moment tensors for 13,017 earthquakes, Phys. Earth Planet. In., 200, 1-9.

Elderfield, H., and A. Schulz (1996), Mid-Ocean ridge hydrothermal fluxes and the chemical composition of the ocean, Ann. Rev. Earth Planet. Sci., 24, 191-224.

Escartín, J., G. Hirth, and B. Evans (2001), Strength of slightly serpentinized peridotites: implications for the tectonics of oceanic lithosphere, Geology, 29(11), 1023-1026.

Escartín, J., D. K. Smith, J. Cann, H. Schouten, C. H. Langmuir, and S. Escrig (2008), Central role of detachment faults in accretion of slow-spreading oceanic lithosphere, Nature, 455, 790-794.

Faccenda, M., T. V. Gerya, and L. Burlini (2009), Deep slab hydration induced by bending-related variations in tectonic pressure, Nat. Geosci., 790-793, doi: 710.1038/NGEO1656.

Fisher, A. T., and R. P. Von Herzen (2005), Models of hydrothermal circulation within 106 Ma seafloor: Constraints on the vigor of fluid circulation and crustal properties, below the Madeira Abyssal Plain, Geochem. Geophys. Geosyst., 6(11), Q11001, doi:11010.11029/12005GC001013.

Fisher, A. T., K. Becker, T. N. Narasimhan, M. G. Langseth, and M. J. Mottl (1990), Passive, off-axis convection through the southern flank of the Costa Rica Rift, $J$. Geophys. Res., 95, 9343-9370.

Fouquet, Y., et al. (1998), FLORES diving cruise with the Nautile near the Azores - First dives on the Rainbow field: hydrothermal seawater/mantle interaction, InterRidge News, 7(1), 24-28.

Fu, B., T. P. Mernagh, N. T. Kita, A. I. S. Kemp, and J. W. Valley (2009), Distinguishing magmatic zircon from hydrothermal zircon: A case study from the Gidginbung highsulphidation $\mathrm{Au}-\mathrm{Ag}-(\mathrm{Cu})$ deposit, SE Australia, Chem. Geol., 259(3-4), 131-142.

Gerdom, M., A. M. Trehu, E. R. Flueh, and D. Klaeschen (2000), The continental margin off Oregon from seismic investigations, Tectonophysics, 329, 79-97. 
German, C. R., and L. M. Parson (1998), Distributions of hydrothermal activity along the Mid-Atlantic Ridge: interplay of magmatic and tectonic controls, Earth Planet. Sci. Lett., $160,327-341$.

German, C. R., L. M. Parson, and H. S. Team (1996), Hydrothermal exploration near the Azores Triple Junction: tectonic control of venting at slow-spreading ridges, Earth Planet. Sci. Lett., 138, 93-104.

German, C. R., A. M. Thurnherr, J. Knoery, J. L. Charlou, P. Jean-Baptiste, and H. N. Edmonds (2010), Heat, volume and chemical fluxes from submarine venting: A synthesis of results from the Rainbow hydrothermal field, 36 degrees N MAR, Deep-Sea Res Pt I, $57(4), 518-527$.

Germanovich, L. N., G. Genc, R. P. Lowell, and P. A. Rona (2012), Deformation and surface uplift associated with serpentinization at mid-ocean ridges and subduction zones, J Geophys Res-Sol Ea, 117.

Gràcia, E., J.-L. Charlou, J. Radford-Knoery, and L. M. Parson (2000), Non-transform offsets along the Mid-Atlantic Ridge south of the Azores $\left(38^{\circ} \mathrm{N}-34^{\circ} \mathrm{N}\right)$ : ultramafic exposures and hosting of hydrothermal vents, Earth Planet. Sci. Lett., 177, 89-103.

Gresens, R. L. (1967), Composition-Volume Relatioships of Metasomatism, Chem. Geol., 2, 47-65.

Grevemeyer, I., W. Weigel, and C. Jennrich (1998), Structure and ageing of oceanic crust at $14^{\circ} \mathrm{S}$ on the East Pacific Rise, Geophys J. Int., 135, 573-584.

Grevemeyer, I., T. J. Reston, and S. Moeller (2013), Microseismicity of the Mid-Atlantic Ridge at 7 degrees S-8 degrees 15 ' S and at the Logatchev Massif oceanic core complex at 14 degrees 40'N-14 degrees 50'N, Geochem Geophy Geosy, 14(9), 3532-3554.

Grevemeyer, I., N. Kaul, H. Villinger, and W. Weigel (1999), Hydrothermal activity and the evolution of the seismic properties of upper oceanic crust, J. Geophys. Res., 104(B3), 5069-5079.

Grindlay, N. R., and P. J. Fox (1993), Lithospheric Stresses Associated with Nontransform Offsets of the Mid-Atlantic Ridge - Implications from a Finite-Element Analysis, Tectonics, 12(4), 982-1003.

Hacker, S. M. Peacock, G. A. Abers, and S. D. Holloway (2003), Subduction factory: 2. Are intermediate-depth earthquakes in subducting slabs linked to metamorphic dehydration reactions?, J. Geophys. Res., 108(B1), 2030, doi:2010.1029/2001JB001129.

Hacker, B. R. (2008), H2O subduction beyond arcs, Geochem. Geophys. Geosyst., 9.

Han, S., S. M. Carbotte, J. P. Canales, M. R. Nedimović, H. Carton, J. C. Gibson, and G. W. Horning (2016), Seismic reflection imaging of the Juan de Fuca plate from ridge to 
trench: New constraints on the distribution of faulting and evolution of the crust prior to subduction, J. Geophys. Res. Solid Earth, 121(2), 1849-1872.

Hardebeck, J. L., and P. M. Shearer (2002), A new method for determining first-motion focal mechanisms, Bulletin of the Seismological Society of America, 92(6), 2264-2276.

Hardebeck, J. L., and P. M. Shearer (2003), Using S/P amplitude ratios to constrain the focal mechanisms of small earthquakes, Bulletin of the Seismological Society of America, 93(6), 2434-2444.

Harding, A. J., A. F. Arnulf, and D. K. Blackman (2016), Velocity structure near IODP Hole U1309D, Atlantis Massif, from waveform inversion of streamer data and borehole measurements, Geochem Geophy Geosy, 17(6), 1990-2014.

Hey, R. N., F. K. Dunnebier, and W. J. Morgan (1980), Propagating rifts on mid-ocean ridges, J. Geophys. Res., 85, 3647-3658.

Hirth, G., J. Escartín, and J. Lin (1998), The rheology of the lower oceanic crust: implications for lithospheric deformation at Mid-Ocean ridges, in Faulting and Magmatism at Mid-Ocean Ridges, edited by W. R. Buck, P. T. Delaney, J. A. Karson and Y. Lagabrielle, pp. 291-303, AGU, Washington, D.C.

Hooft, E., and R. S. Detrick (1993), The role of density in the accumulation of basaltic melts at mid-ocean ridges, Geophys. Res. Lett., 20(6), 423-426.

Hunter, A. G., P. D. Kempton, and P. Greenwood (1999), Low-temperature interaction an isotopic and mineralogical perspective of upper crustal evolution, eastern flank of the Juan de Fuca Ridge (JdFR), ODP Leg 168, Chem. Geol., 155(1-2), 3-28.

Hyndman, R. D., and K. Wang (1993), Thermal constraints on the zone of major thrust earthquake failure: The Cascadia subduction zone, J. Geophys. Res., 98(B2), 2039-2060.

Ivandic, M., I. Grevemeyer, A. Berhorst, E. R. Flueh, and K. McIntosh (2008), Impact of bending related faulting on the seismic properties of the incoming oceanic plate offshore of Nicaragua, J. Geophys. Res., 113, B05410, doi:05410.01029/02007JB005291.

Jechumtalova, Z., J. Sileny, and C. I. Trifu (2014), Microearthquake mechanism from wave amplitudes recorded by a close-to-surface seismic array at Ocnele Mari, Romania, Geophys J. Int., 197(3), 1608-1626.

Jones, R. H., and R. C. Stewart (1997), A method for determining significant structures in a cloud of earthquakes, $J$ Geophys Res-Sol Ea, 102(B4), 8245-8254.

Kao, H., S. J. Shan, H. Dragert, G. Rogers, J. F. Cassidy, and K. Ramachandran (2005), A wide depth distribution of seismic tremors along the northern Cascadia margin, Nature, 436(7052), 841-844. 
Kao, H., K. Wang, R. Y. Chen, I. Wada, J. H. He, and S. D. Malone (2008), Identifying the rupture plane of the 2001 Nisqually, Washington, earthquake, Bulletin of the Seismological Society of America, 98(3), 1546-1558.

Karson, J. A., G. L. Früh-Green, D. S. Kelley, E. A. Williams, D. R. Yoerger, and M. Jakuba (2006), Detachment shear zone of the Atlantis Massif core complex, Mid-Atlantic Ridge, $30^{\circ} \mathrm{N}$, Geochem. Geophys. Geosyst., 7(6), Q06016, doi:06010.01029/02005GC001109.

Karsten, J. L., and J. R. Delaney (1989), Hot Spot-Ridge Crest Convergence in the Northeast Pacific, J Geophys Res-Solid, 94(B1), 700-712.

Kawakatsu, H., and S. Watada (2007), Seismic evidence for deep-water transportation in the mantle, Science, 316, 1468-1471.

Kelemen, P. B., and G. Hirth (2012), Reaction-driven cracking during retrograde metamorphism: Olivine hydration and carbonation, Earth Planet. Sci. Lett., 345, 81-89.

Klein, F., W. Bach, N. Jöns, T. McCollom, B. Moskowitz, and T. Berquó (2009), Iron partitioning and hydrogen generation during serpentinization of abyssal peridotites from $15^{\circ} \mathrm{N}$ on the Mid-Atlantic Ridge, Geochim. Cosmochim. Acta, 73(22), 6868-6893.

Kodaira, S., G. Fujie, M. Yamashita, T. Sato, T. Takahashi, and N. Takahashi (2014), Seismological evidence of mantle flow driving plate motions at a palaeo-spreading centre, Nat. Geosci., 7(5), 371-375.

Korenaga, J., W. S. Holbrook, G. M. Kent, P. B. Kelemen, R. S. Detrick, H.-C. Larsen, J. R. Hopper, and T. Dahl-Jensen (2000), Crustal structure of the southeast Greenland margin from joint refraction and reflection seismic tomography, J. Geophys. Res., 105, 21,591-521,614.

Kuster, G. T., and M. N. Toksöz (1974), Velocity and attenuation of seismic waves in two-phase media: Part I. Theoretical formulations, Geophysics, 39(5), 587-606.

Le Douaran, S., H. D. Needham, and J. Francheteau (1982), Pattern of opening rates along the axis of the Mid-Atlantic Ridge, Nature, 300, 254-257.

Lécuyer, C., and B. Reynard (1996), High-temperature alteration of oceanic gabbros by seawater (Hess Deep, Ocean Drilling Program Leg 147): Evidence from oxygen isotopes and elemental fluxes, J. Geophys. Res., 101(B7), 15883-15897.

Liu, L., and R. P. Lowell (2009), Models of hydrothermal heat output from a convecting, crystallizing, replenished magma chamber beneath an oceanic spreading center, $J$. Geophys. Res., 114, B02102, doi:02110.01029/02008JB005846.

Marjanović, M., S. M. Carbotte, M. R. Nedimović, and J. P. Canales (2011), Gravity and seismic study of crustal structure along the Juan de Fuca Ridge axis and across pseudofaults on the ridge flanks, Geochem. Geophys. Geosyst., 12, Q05008. 
McCaig, A. M., R. A. Cliff, J. Escartín, A. E. Fallick, and C. J. MacLeod (2007), Oceanic detachment faults focus very large volumes of black smoker fluids, Geology, 35(10), 935-938.

McClymont, A. F., and R. M. Clowes (2005), Anomalous lithospheric structure of Northern Juan de Fuca plate - a consequence of oceanic rift propagation?, Tectonophysics, 406, 213-231.

McCollom, T. M., and E. L. Shock (1998), Fluid-rock interactions in the lower oceanic crust: Thermodynamic models of hydrothermal alteration, J. Geophys. Res., 103(B1), 547-575.

McCrory, P. A., and D. S. Wilson (2013), A kinematic model for the formation of the Siletz-Crescent forearc terrane by capture of coherent fragments of the Farallon and Resurrection plates, Tectonics, 32(3), 718-736.

Mcgarr, A. (1976), Seismic Moments and Volume Changes, J. Geophys. Res., 81(8), 1487-1494.

Menke, W. (2005), Case Studies of Seismic Tomography and Earthquake Location in a Regional Context, in Seismic Earth: Array Analysis of Broadband Seismograms (eds A. Levander and G. Nolet), American Geophysical Union, Washington, D. C.

Miller, D. J., and N. I. Christensen (1997), Seismic velocities of lower crustal and upper mantle rocks from the slow spreading Mid-Atlantic Ridge, south of the Kane transform zone (MARK), Proc. ODP, Sci. Results, 153, 437-454.

Müller, R. D., M. Sdrolias, C. Gaina, and W. R. Roest (2008), Age, spreading rates, and spreading asymmetry of the world's ocean crust, Geochem. Geophys. Geosyst., 9(4), Q04006, doi:04010.01029/02007GC001743.

Nedimović, M. R., R. D. Hyndman, K. Ramachandran, and G. D. Spence (2003), Reflection signature of seismic and aseismic slip on the northern Cascadia subduction interface, Nature, 424, 416-420.

Nedimović, M. R., D. R. Bohnenstiehl, S. M. Carbotte, J. P. Canales, and R. P. Dziak (2009), Faulting and hydration of the Juan de Fuca Plate system, Earth Planet. Sci. Lett., 284, 94-102.

Nedimović, M. R., S. M. Carbotte, J. B. Diebold, A. J. Harding, J. P. Canales, and G. M. Kent (2008), Upper crustal evolution across the Juan de Fuca Ridge flanks, Geochem. Geophys. Geosyst., 9, Q09006, doi:09010.01029/02008GC002085.

Nedimović, M. R., S. M. Carbotte, A. J. Harding, R. S. Detrick, J. P. Canales, J. B. Diebold, G. M. Kent, M. Tischer, and J. Babcock (2005), Frozen magma lenses below the oceanic crust, Nature(436), 1149-1152. 
Newman, K. R., M. R. Nedimović, J. P. Canales, and S. M. Carbotte (2011), Evolution of seismic layer 2B across the Juan de Fuca Ridge from hydrophone streamer 2D traveltime tomography, Geochem. Geophys. Geosyst., 12, Q05009.

Obara, K. (2002), Nonvolcanic Deep Tremor Associated with Subduction in Southwest Japan, Science, 296(5573), 1679-1681.

Olive, J.-A., M. D. Behn, and B. E. Tucholke (2010), The structure of oceanic core complexes controlled by the depth distribution of magma emplacement, Nat. Geosci., $3(7), 491-495$.

Parson, L., E. Gràcia, D. Coller, C. German, and D. Needham (2000), Second order segmentation; the relationship between volcanism and tectonism at the MAR, $38^{\circ}$ $35^{\circ} 40^{\prime} \mathrm{N}$, Earth Planet. Sci. Lett., 178, 231-251.

Paulatto, M., J. P. Canales, R. A. Dunn, and R. A. Sohn (2015), Heterogeneous and asymmetric crustal accretion: New constraints from multibeam bathymetry and potential field data from the Rainbow area of the Mid-Atlantic Ridge (36 degrees 15'N), Geochem Geophy Geosy, 16(9), 2994-3014.

Paulick, H., W. Bach, M. Godard, J. C. M. De Hoog, G. Suhr, and J. Harvey (2006), Geochemistry of abyssal peridotites (Mid-Atlantic Ridge, 15 degrees 20 ' N, ODP Leg 209): Implications for fluid/rock interaction in slow spreading environments, Chem. Geol., 234(3-4), 179-210.

Peacock, S. M. (2001), Are the lower zones of double seismic zones caused by serpentine dehydration in subduction oceanic mantle?, Geology, 29(4), 299-302.

Preston, L. A., K. C. Creager, R. S. Crosson, T. M. Brocher, and A. M. Trehu (2003), Intraslab Earthquakes: dehydration of the Cascadia slab, Science, 302, 1197-1200.

Prince, R. A., and D. W. Forsyth (1988), Horizontal extent of anomalously thin crust near the Vema Fracture Zone from three-dimensional analysis of gravity anomalies, $J$. Geophys. Res., 93(B7), 8051-8063.

Ranero, C. R., J. Phipps Morgan, K. McIntosh, and C. Reichert (2003), Bending-related faulting and mantle serpentinization at the Middle America trench, Nature, 425, 367-373.

Rogers, G., and H. Dragert (2003), Episodic tremor and slip on the Cascadia subduction zone: the chatter of silent slip, Science, 300, 1942.

Rüpke, L. H., J. Phipps Morgan, M. Hort, and J. A. D. Connolly (2004), Serpentine and the subduction zone water cycle, Earth Planet. Sci. Lett., 223, 17-34.

Schmidt, M. W., and S. Poli (1998), Experimentally based water budgets for dehydrating slabs and consequences for arc magma generation, Earth Planet. Sci. Lett., 163, 361-379. 
Simao, N., J. Escartín, J. Goslin, J. Haxel, M. Cannat, and R. P. Dziak (2010), Regional seismicity of the Mid-Atlantic Ridge: observations from autonomous hydrophone arrays, Geophys J. Int., 183, 1559-1578.

Singh, S. C., W. C. Crawford, H. Carton, T. Seher, V. Combier, M. Cannat, J. P. Canales, D. Dusunur, J. Escartín, and M. J. Miranda (2006), Discovery of a magma chamber and faults beneath a Mid-Atlantic Ridge hydrothermal field, Nature, 442, 1029-1032.

Sloan, H., and P. Patriat (1992), Kinematics of the North American-African plate boundary between $28^{\circ}$ and $29^{\circ}$ during the last $10 \mathrm{Ma}$ : Evolution of the axial geometry and spreading rate and direction, Earth Planet. Sci. Lett., 113, 323-341.

Snow, J. E., and H. J. B. Dick (1995), Pervasive magnesium loss by marine weathering of peridotite, Geochim. Cosmochim. Acta, in press.

Spencer, S., D. K. Smith, J. R. Cann, J. Lin, and E. McAllister (1997), Structure and stability of non-transform discontinuities on the Mid-Atlantic Ridge between $24^{\circ}$ and $30^{\circ} \mathrm{N}$, Mar. Geophys. Res., 19, 339-362.

Syracuse, E. M., P. E. van Keken, and G. A. Abers (2010), The global range of subduction zone thermal models, Phys. Earth Planet. In., 183(1-2), 73-90.

Tatsumi, Y. (1989), Migration of Fluid Phases and Genesis of Basalt Magmas in Subduction Zones, J. Geophys. Res., 94(B4), 4697-4707.

ten Brink, U. (2005), Vertical motions of the Puerto Rico Trench and Puerto Rico and their cause, J. Geophys. Res., 110, B06404.

ten Brink, U., W. Danforth, C. Polloni, B. Andrews, P. Llanes, S. Smith, E. Parker, and T. Uozomi (2004), New seafloor map of the Puerto Rico Trench helps assess earthquake and tsunami hazards, Eos Trans. AGU, 85(37), 349-360.

Thurnherr, A. M., and K. J. Richards (2001), Hydrography and high-temperature heat flux of the Rainbow hydrothermal site ( $36^{\circ} 14^{\prime} \mathrm{N}$, Mid-Atlantic Ridge), J. Geophys. Res., 106(C5), 9411-9426.

Trehu, A. M., et al. (2004), Three-dimensional distribution of gas hydrate beneath southern Hydrate Ridge: constraints from ODP Leg 204, Earth Planet. Sci. Lett., 222, 845-862.

Tréhu, A. M., I. Asudeh, T. M. Brocher, J. H. Luetgert, W. D. Mooney, J. L. Nabelek, and Y. Nakamura (1994), Crustal architecture of the Cascadia forearc, Science, 266, 237243.

Ulmer, P., and V. Trommsdorff (1995), Serpentine stability to mantle depths and subduction-related magmatism, Science, 268, 858-861. 
van Avendonk, H. J. A., A. J. Harding, J. A. Orcutt, and J. S. McClain (1998), A twodimensional tomography study of the Clipperton transform fault, J. Geophys. Res., 103, $17,885-817,899$.

van Avendonk, H. J. A., W. S. Holbrook, D. Lizarralde, and P. Denyer (2011), Structure and serpentinization of the subducting Cocos plate offshore Nicaragua and Costa Rica, Geochem. Geophys. Geosyst., 12(6), Q06009.

van Keken, P. E., B. R. Hacker, E. M. Syracuse, and G. A. Abers (2011), Subduction factory: 4. Depth-dependent flux of $\mathrm{H} 2 \mathrm{O}$ from subducting slabs worldwide, J. Geophys. Res., 116, B01401, doi:01410.01029/02010JB007922.

Wada, I., and K. L. Wang (2009), Common depth of slab-mantle decoupling: Reconciling diversity and uniformity of subduction zones, Geochem Geophy Geosy, 10(10), Q10009.

Waldhauser, F., and W. L. Ellsworth (2000), A double-difference earthquake location algorithm: Method and application to the northern Hayward fault, Bulletin of the Seismological Society of America, 90, 1353-1368.

Walowski, K. J., P. J. Wallace, E. H. Hauri, I. Wada, and M. A. Clynne (2015), Slab melting beneath the Cascade Arc driven by dehydration of altered oceanic peridotite, Nature Geosci, 8(5), 404-408.

Wang, K., and E. E. Davis (1992), Thermal Effects of Marine Sedimentation in Hydrothermally Active Areas, Geophys J. Int., 110(1), 70-78.

Weekly, R. T., W. S. D. Wilcock, D. R. Toomey, E. E. E. Hooft, and E. Kim (2014), Upper crustal seismic structure of the Endeavour segment, Juan de Fuca Ridge from traveltime tomography: Implications for oceanic crustal accretion, Geochem. Geophys. Geosyst., 15(4), 1296-1315.

Wilcock, W. S. D., S. D. Archer, and G. M. Purdy (2002), Microearthquakes on the Endeavour segment of the Juan de Fuca Ridge, J Geophys Res-Sol Ea, 107(B12).

Wilkens, R. H., G. J. Fryer, and J. Karsten (1991), Evolution of porosity and seismic structure of upper oceanic crust: Importance of aspect ratios, J. Geophys. Res., 96, $17,981-917,995$.

Wilson, D. A. Clague, N. H. Sleep, and J. L. Morton (1988), Implications of magma convection for the size and temperature of magma chambers at fast spreading ridges, $J$. Geophys. Res., 93, 11974-11984.

Wilson, D. S. (1988), Tectonic history of the Juan de Fuca ridge over the last 40 million years, J. Geophys. Res., 93(B10), 11863-11876.

Wilson, D. S. (1993), Confidence intervals for motion and deformation of the Juan de Fuca plate, J. Geophys. Res., 98(B9), 16,053-016,071. 
Wilson, D. S. (2002), The Juan de Fuca Plate and slab - Isochron structure and Cenozoic plate motions, in The Cascadia Subduction Zone and Related Subduction Systems.

Seismic Structure, Intraslab Earthquakes and Processes, and Earthquake Hazards, edited by S. Kirby, K. Wang and S. Dunlop, pp. 9-12, U.S. Geol. Survey Open-File Report 02328. 


\section{APPENDIX A}

\section{Supplementary Material for Chapter 3}

A

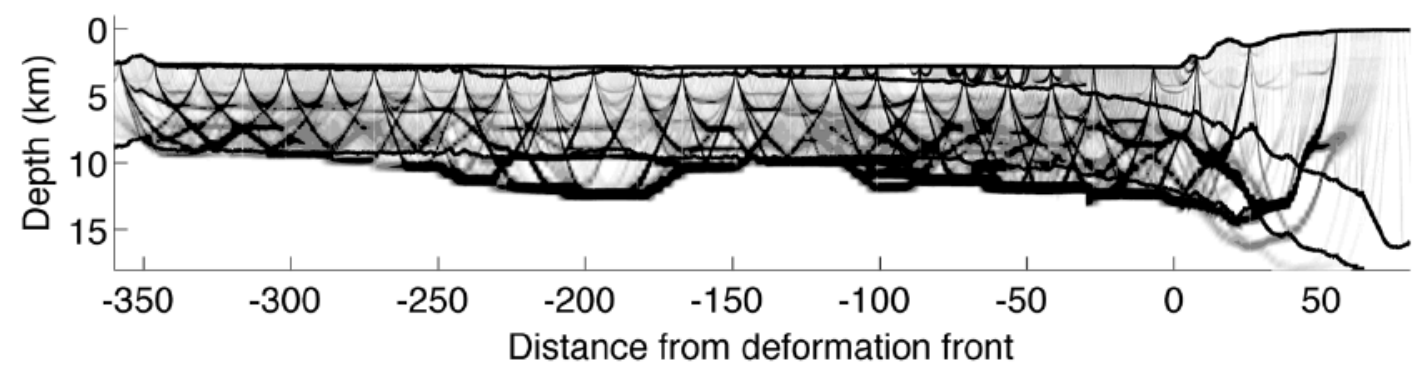

B

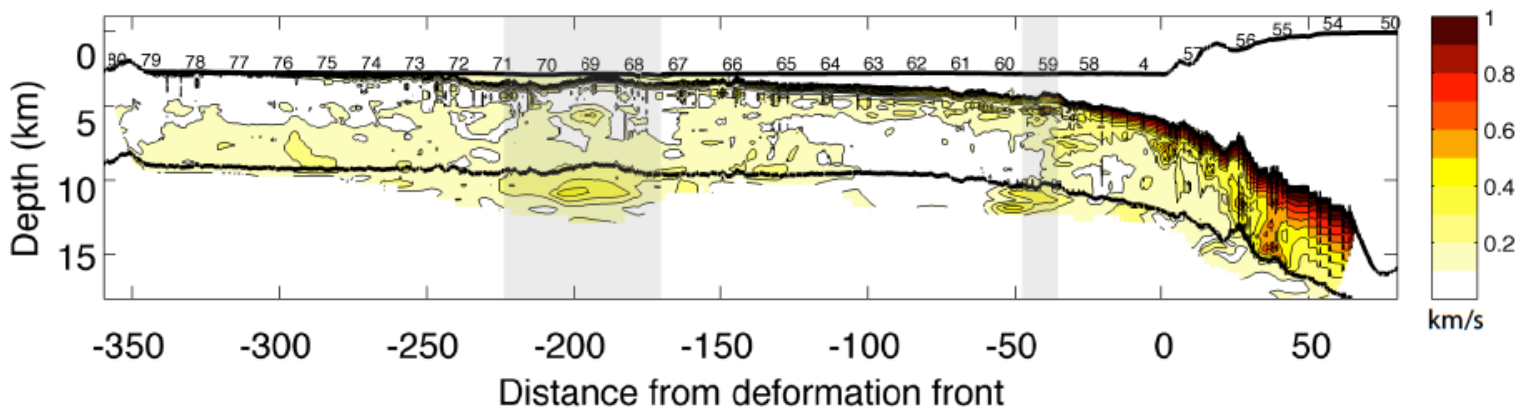

\section{Figure 3-S1}

(A) Relative ray coverage as derivative weight sum (DWS). Darker shading indicates greater ray coverage. (B) Standard deviation of the Monte Carlo solutions. Gray shading indicates location of propagator wakes. Seafloor, basement, and moho are show in bold lines. 

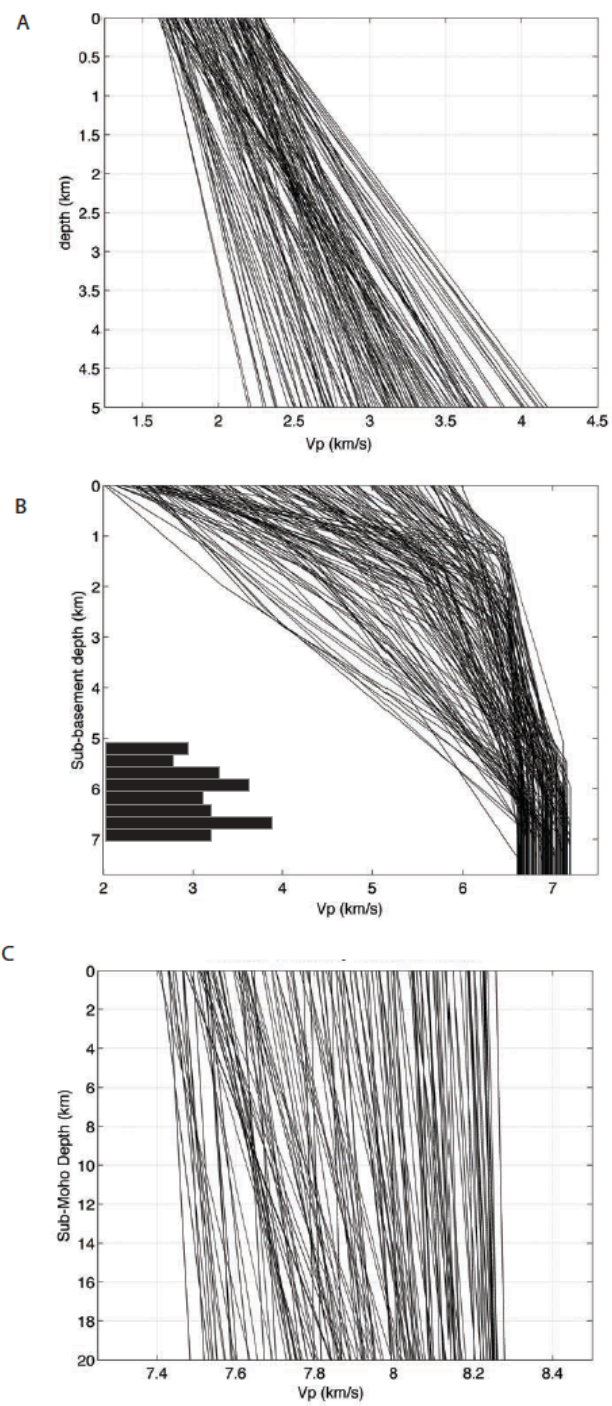

Figure 3-S2

Each 1D velocity model used to generate the 120 Monte Carlo iterations for the sediment (A), crust (B), and mantle (C). Histogram in the middle panel displays the range of uniformly distributed crustal thicknesses between 5 and $7.5 \mathrm{~km}$ used when inverting PmP picks $(\mathrm{n}=120)$. 

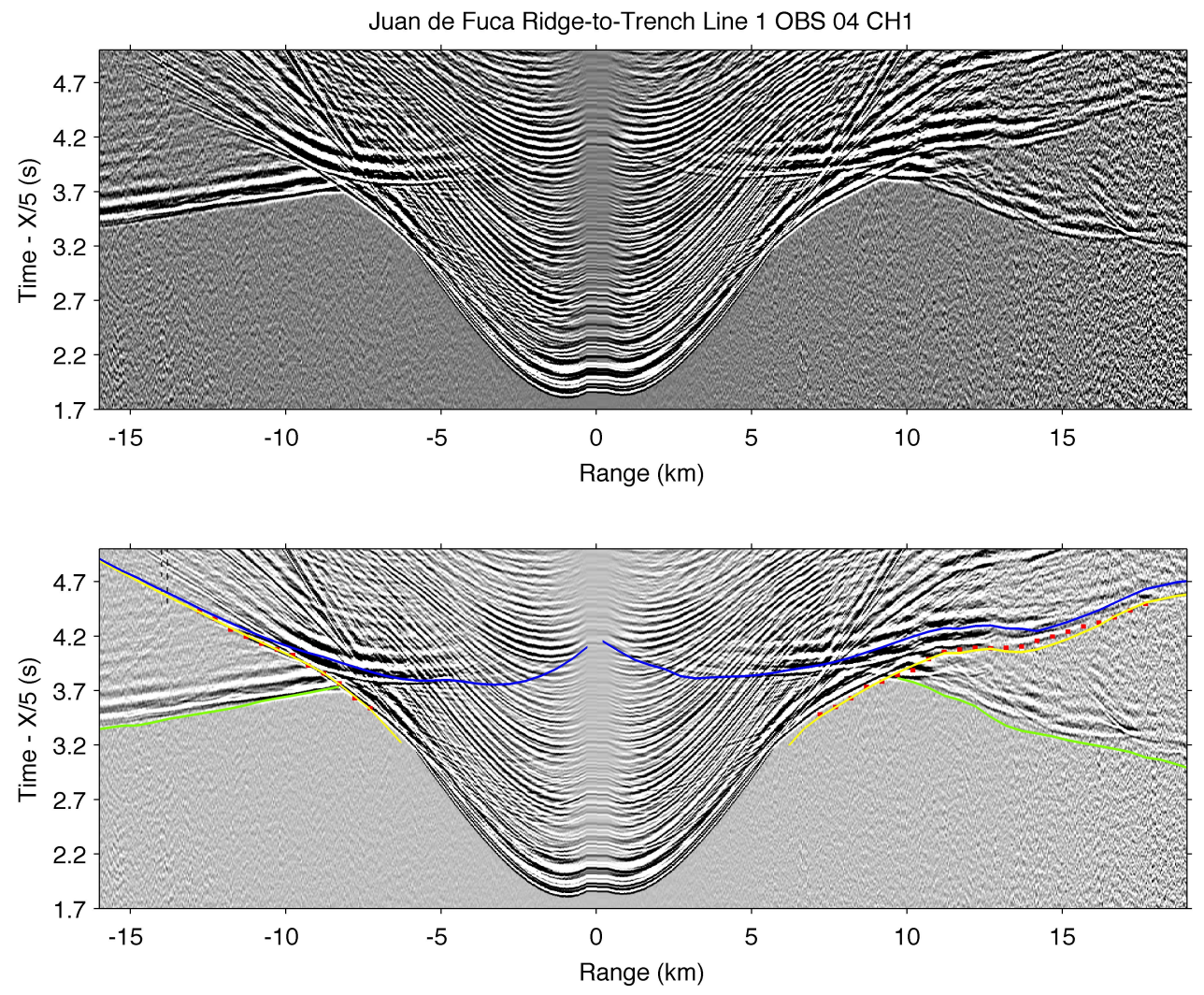

Figure 3-S3

Record Section for OBS 04. Details as in Figure 3-2. 

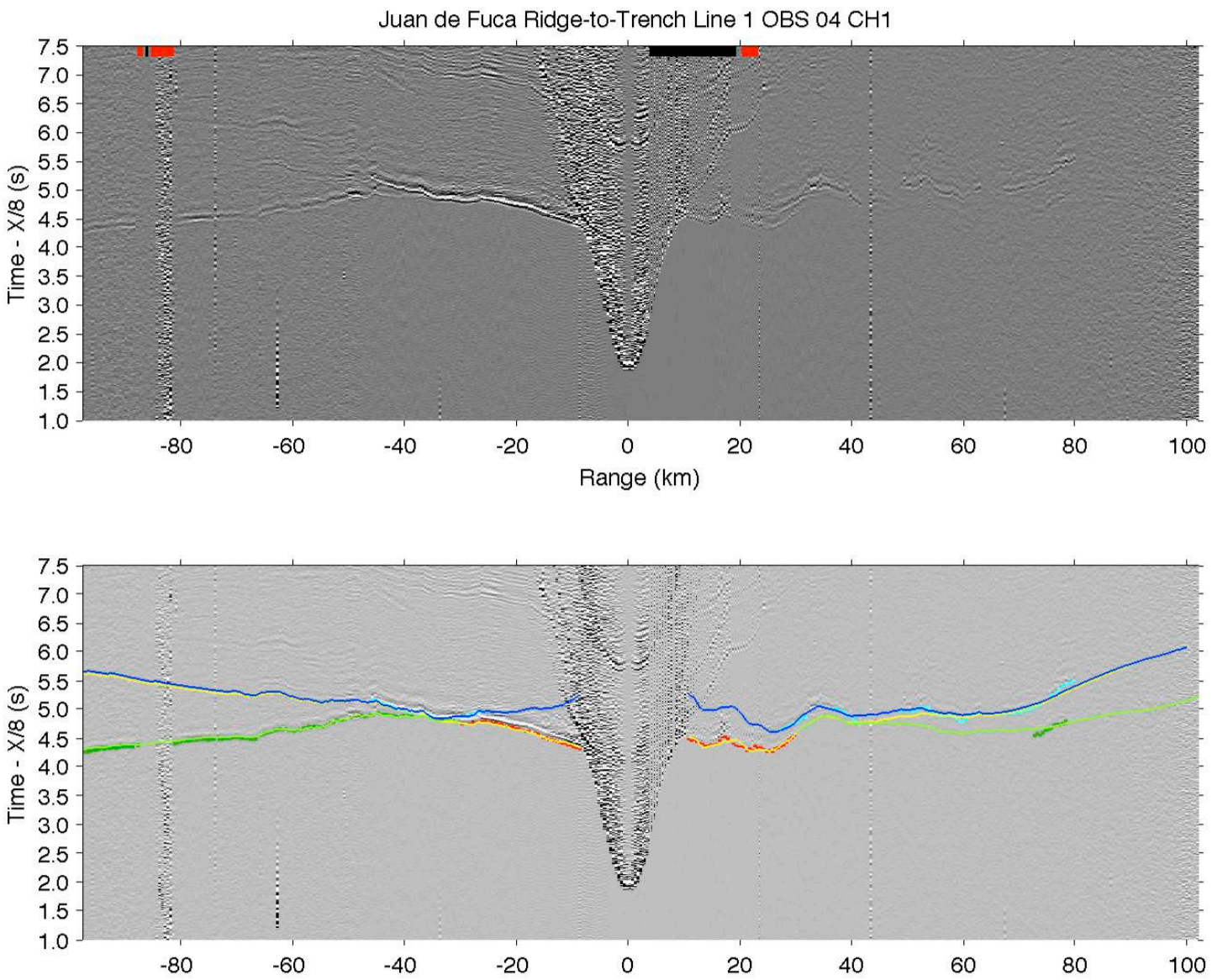

Figure 3-S4

Record Section for OBS 04. Details as in Figure 3-3. 

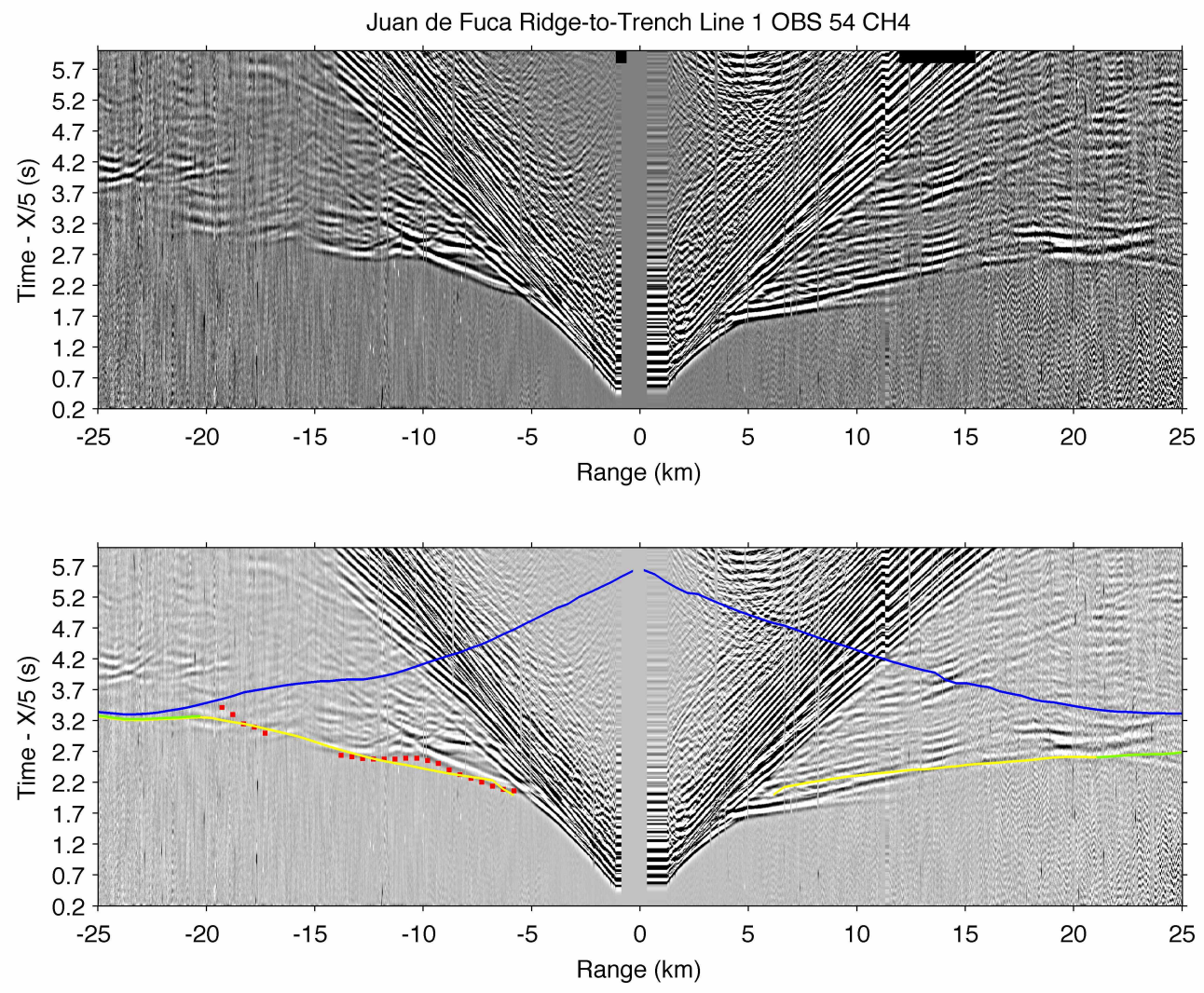

Figure 3-S5

Record Section for OBS 54. Details as in Figure 3-2. 

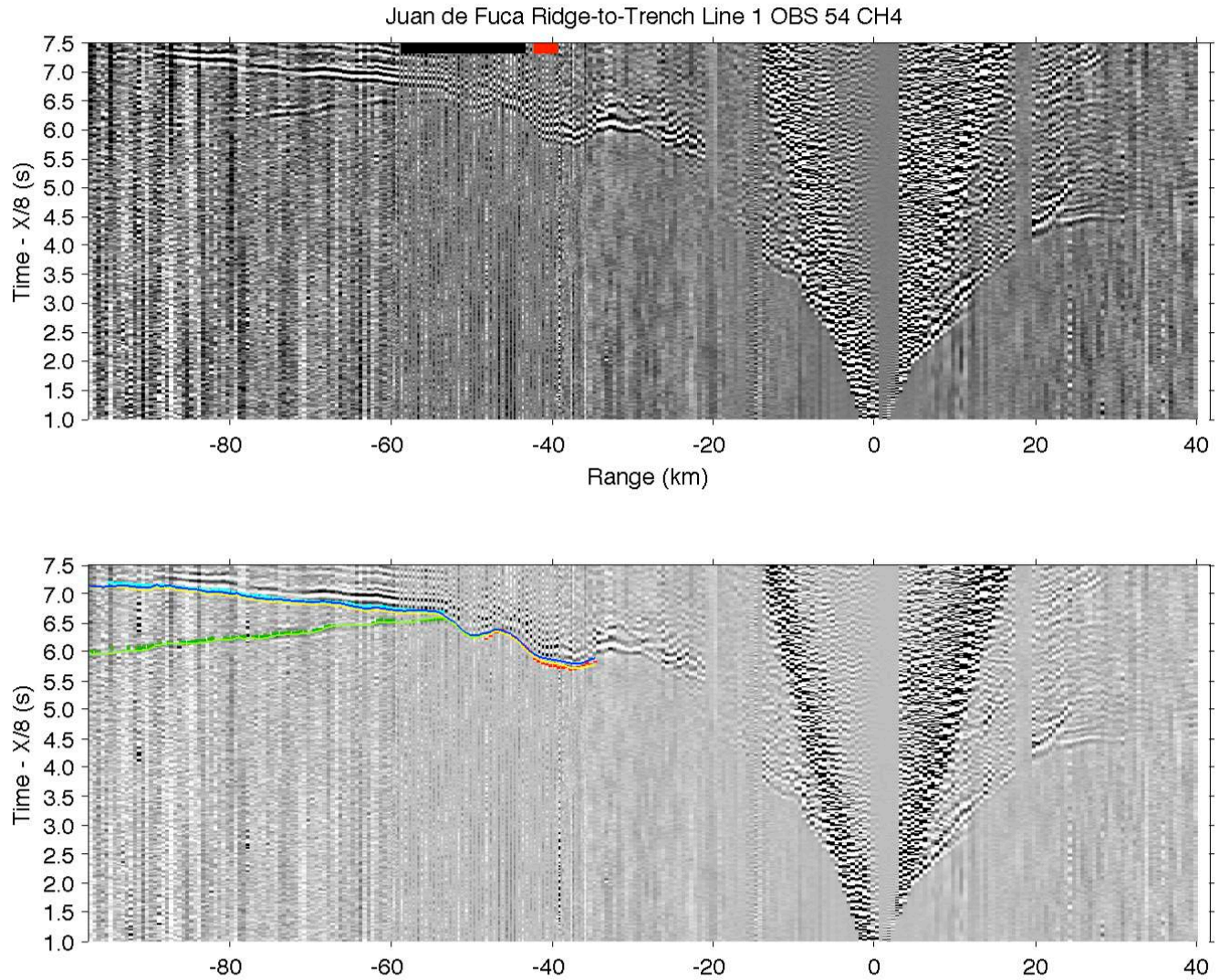

Figure 3-S6

Record Section for OBS 54. Details as in Figure 3-3. 

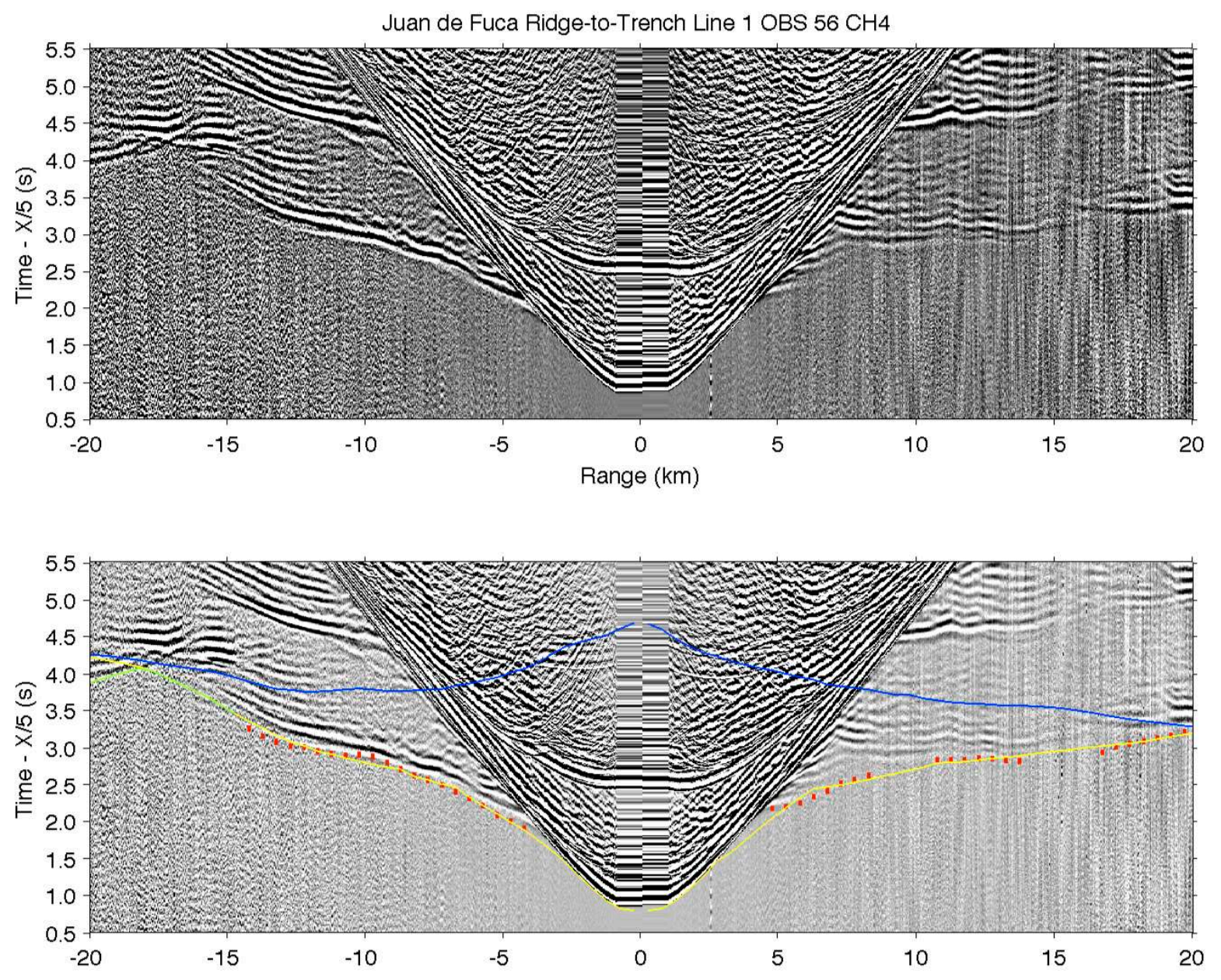

Figure 3-S7

Record Section for OBS 56. Details as in Figure 3-2. 

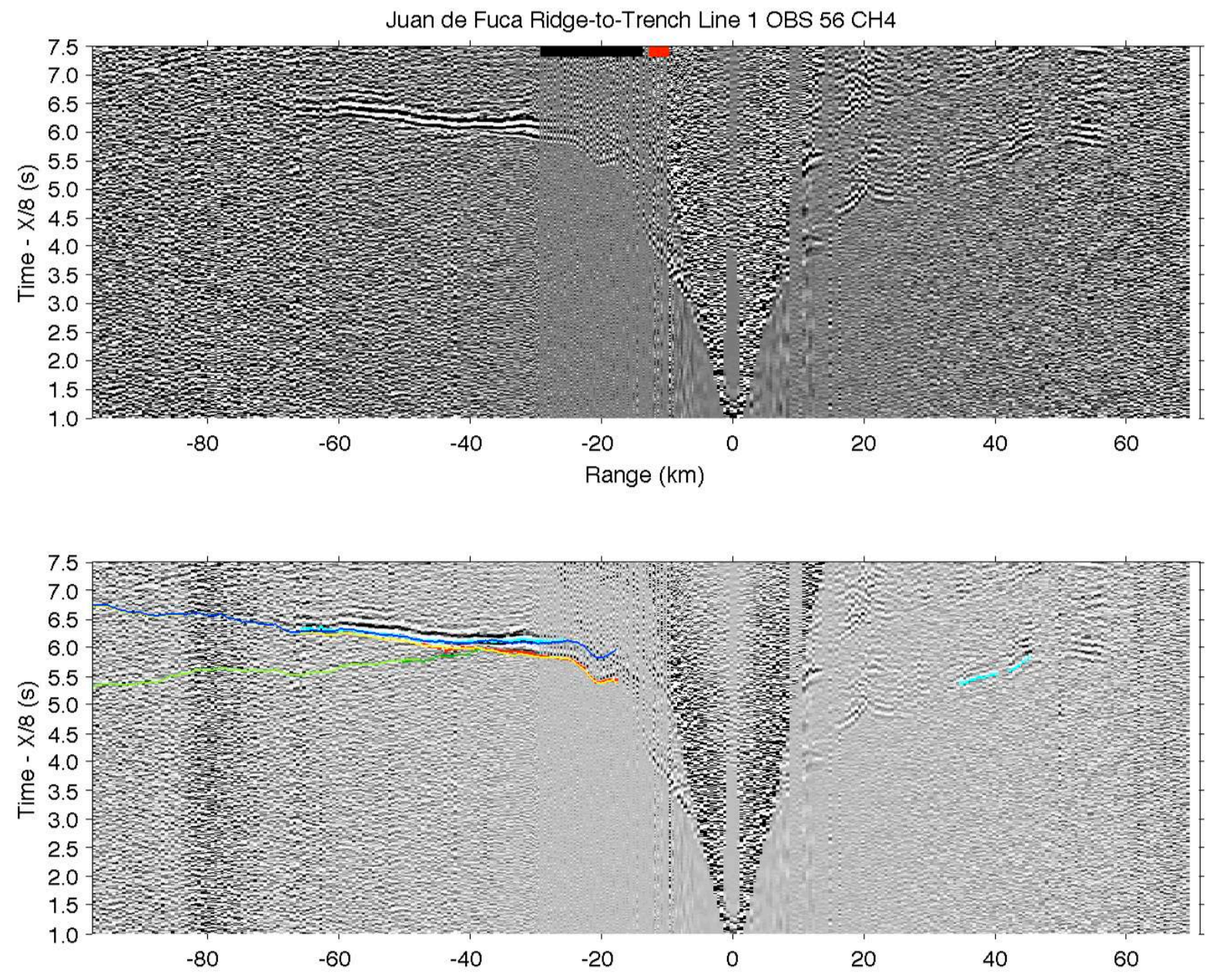

Figure 3-S8

Record Section for OBS 56. Details as in Figure 3-3. 

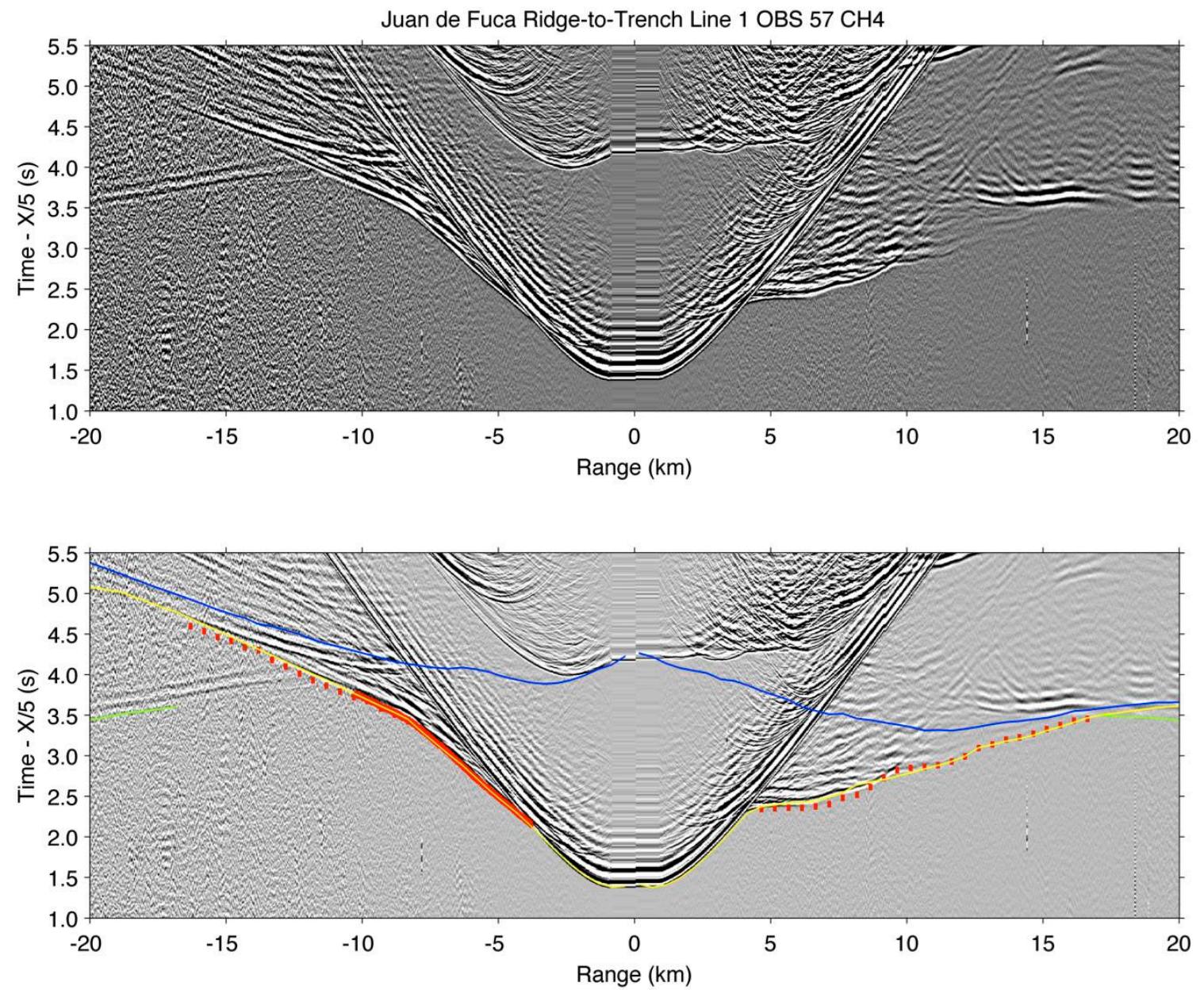

Figure 3-S9

Record Section for OBS 57. Details as in Figure 3-2. 

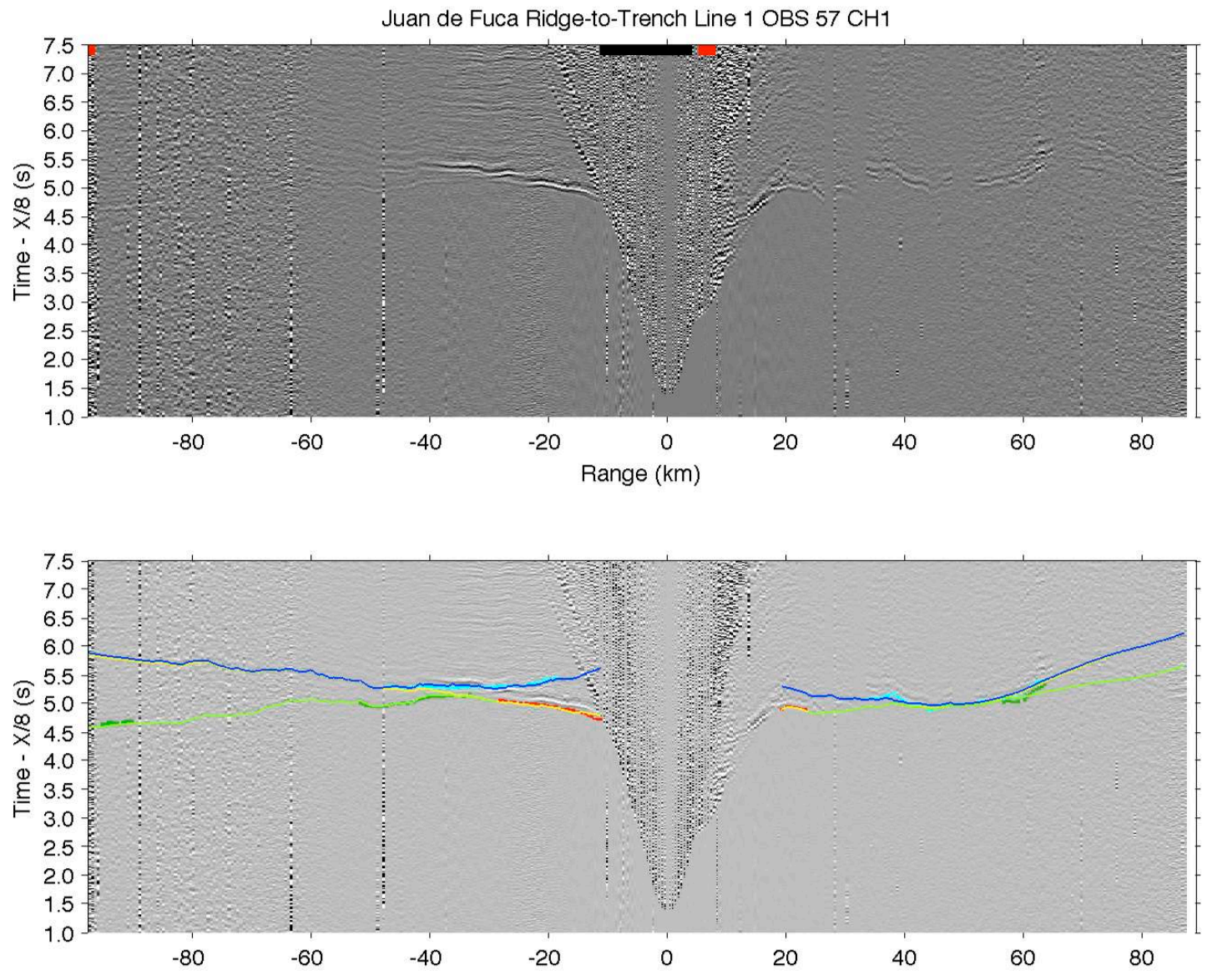

Figure 3-S10

Record Section for OBS 57. Details as in Figure 3-3. 

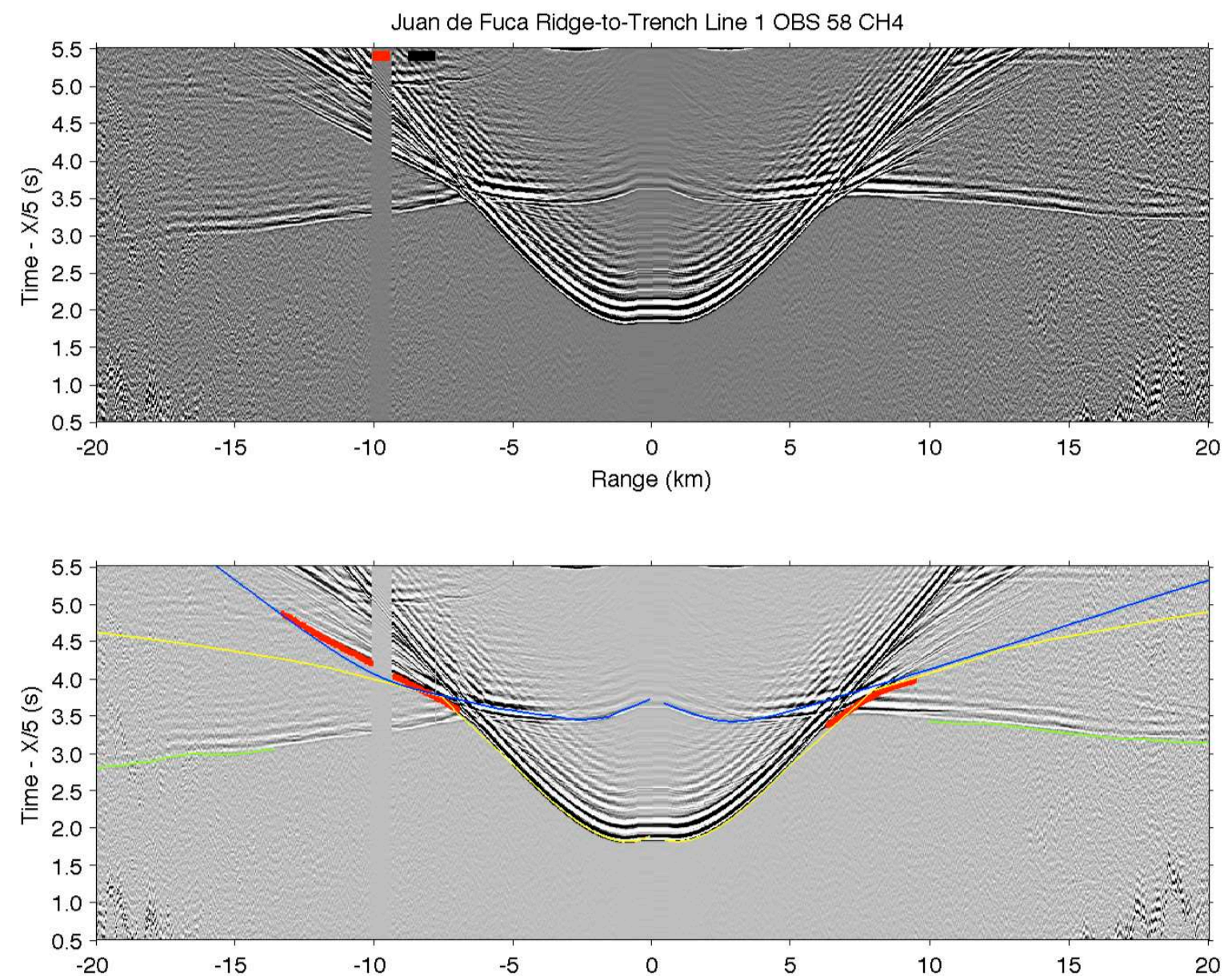

Figure 3-S11

Record Section for OBS 58. Details as in Figure 3-2. 

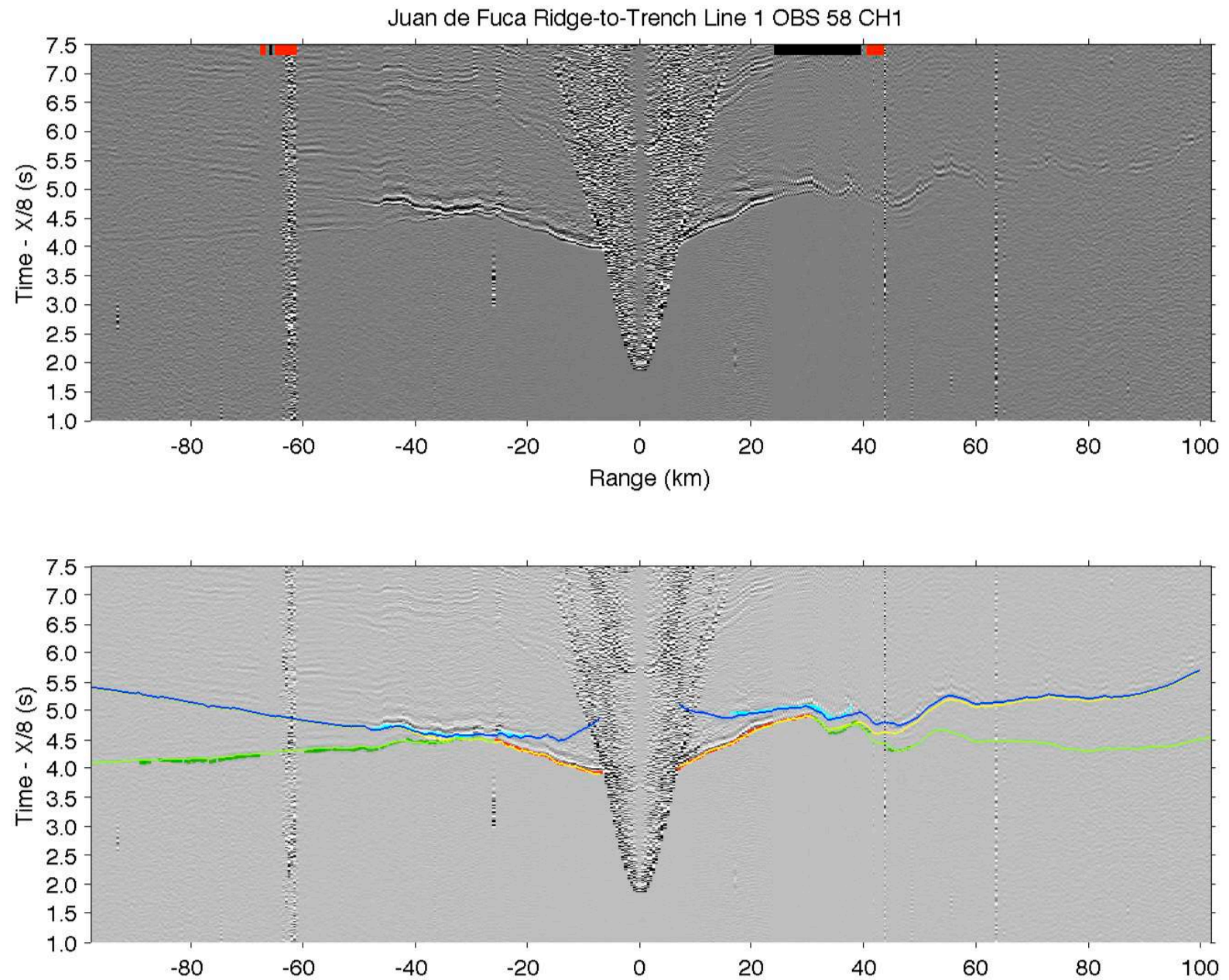

Figure 3-S12

Record Section for OBS 58. Details as in Figure 3-3. 

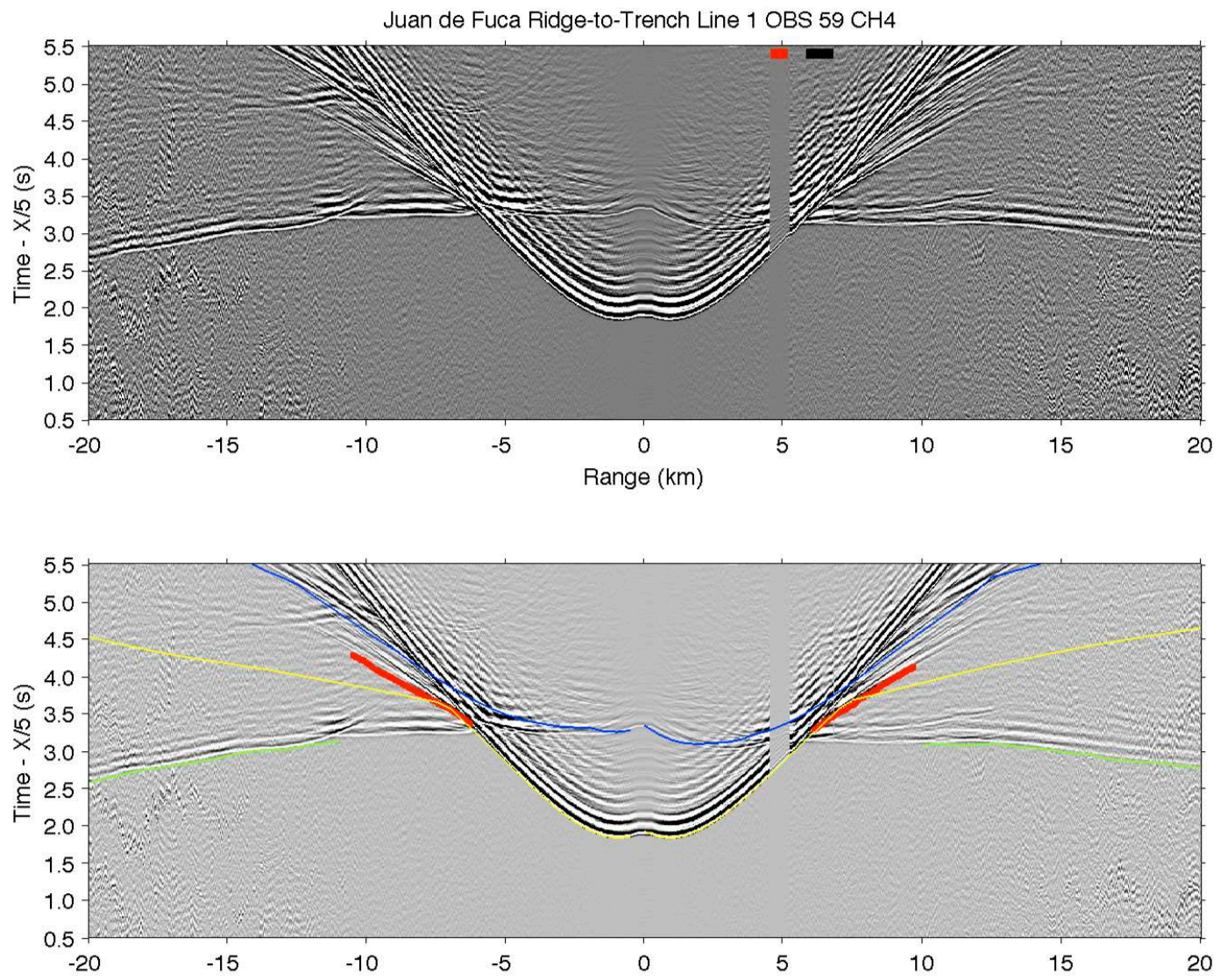

Figure 3-S13

Record Section for OBS 59. Details as in Figure 3-2. 

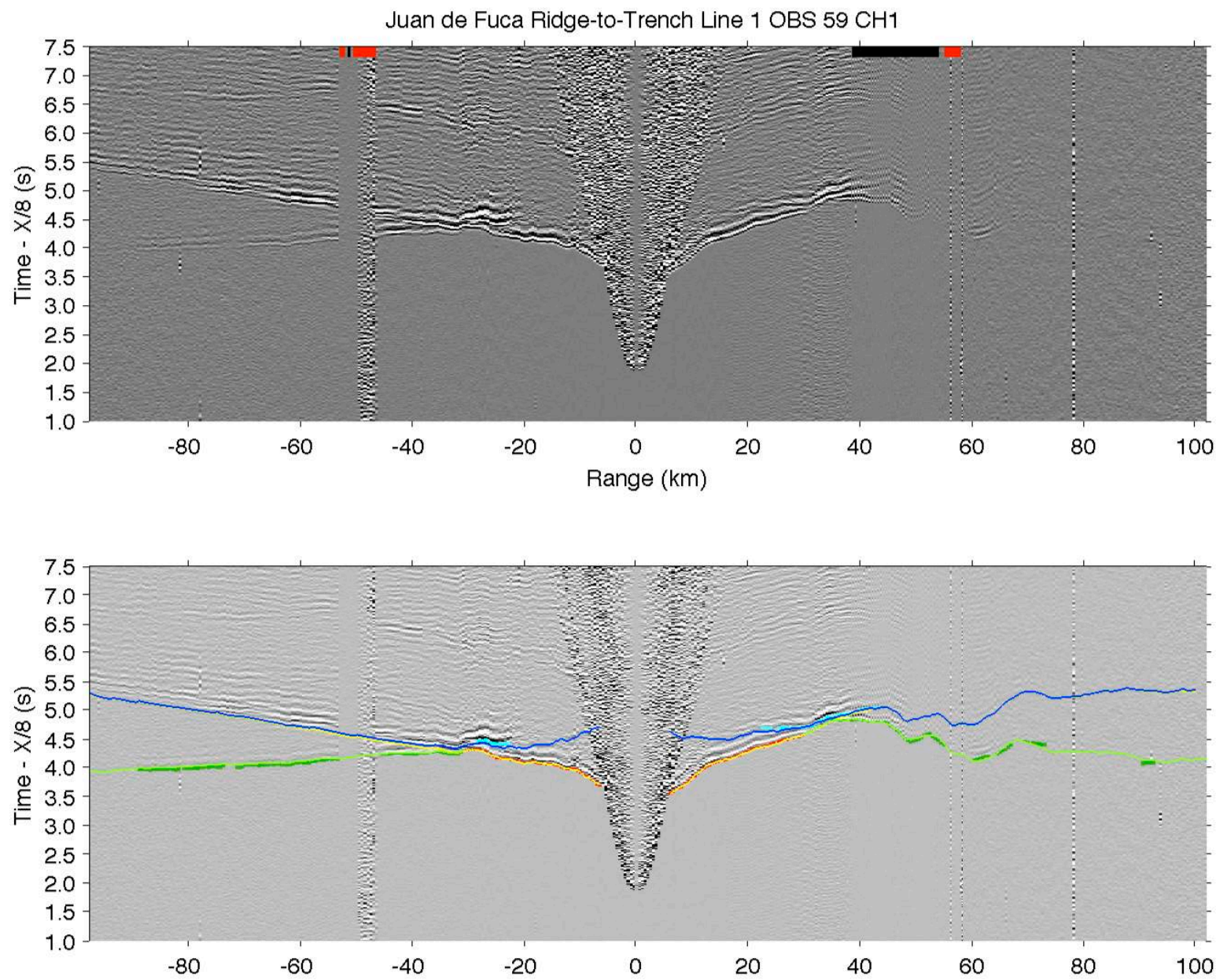

Figure 3-S14

Record Section for OBS 59. Details as in Figure 3-3. 
Juan de Fuca Ridge-to-Trench Line 1 OBS $60 \mathrm{CH} 4$
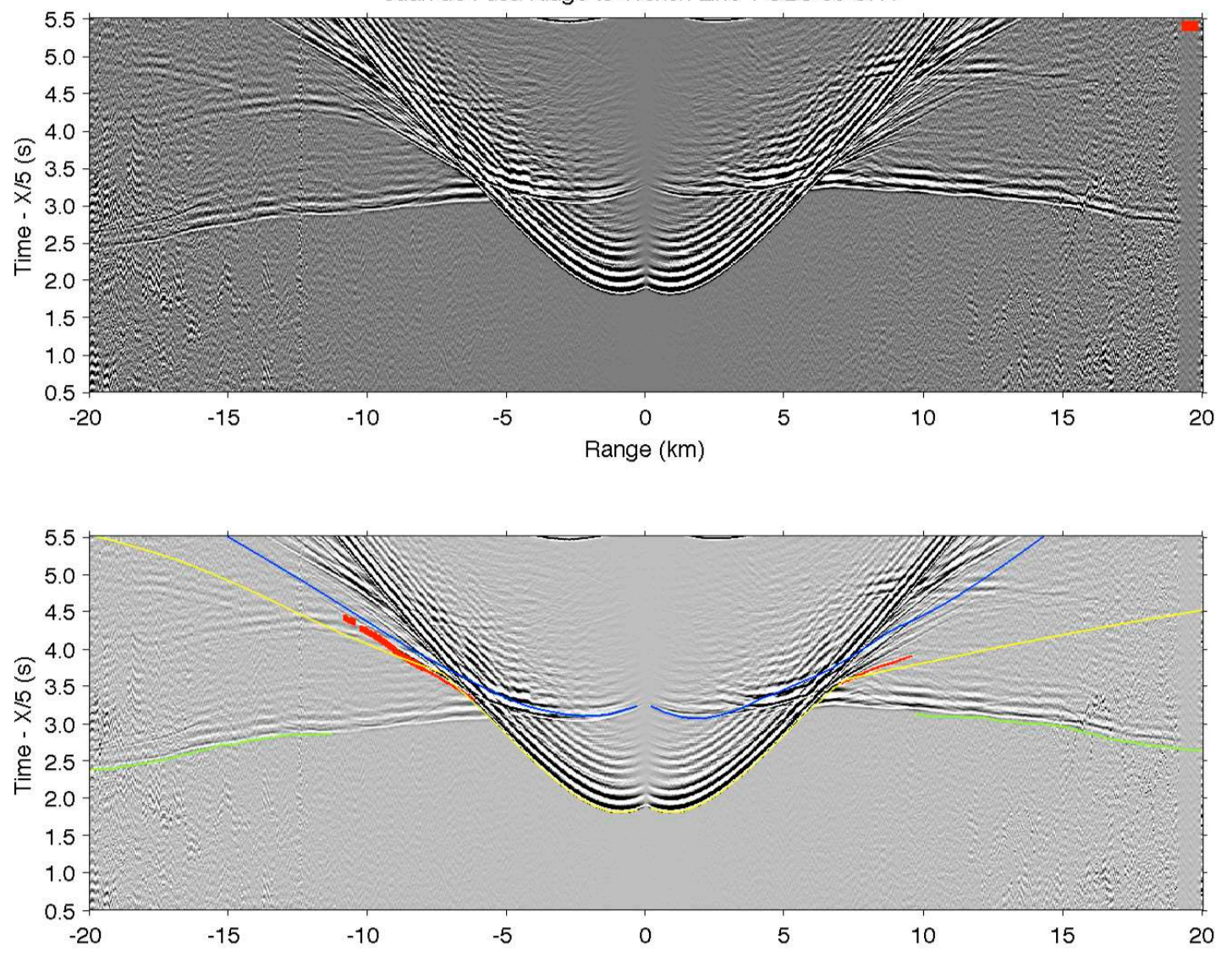

Figure 3-S15

Record Section for OBS 60. Details as in Figure 3-3. 

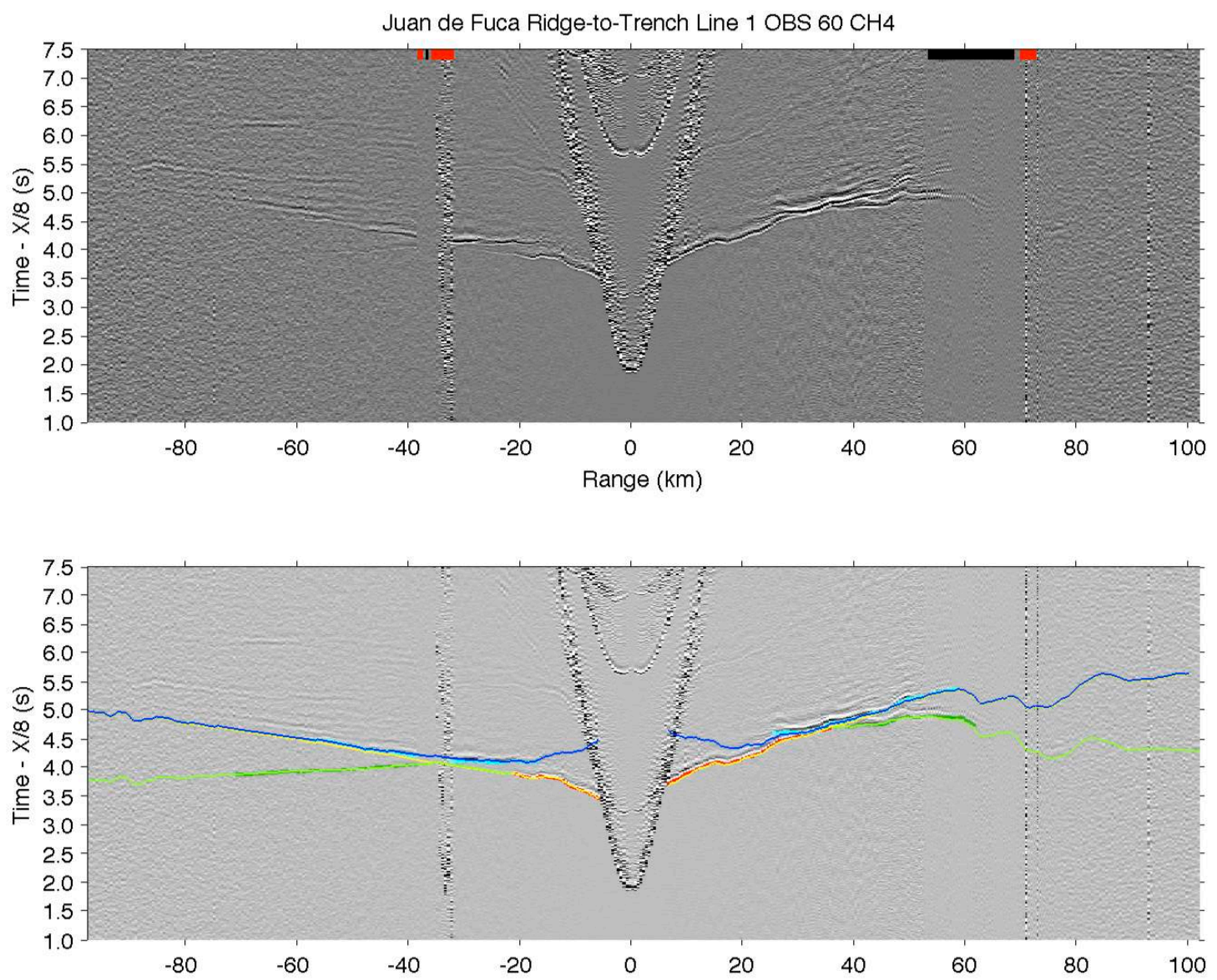

Figure 3-S16

Record Section for OBS 60. Details as in Figure 3-2. 

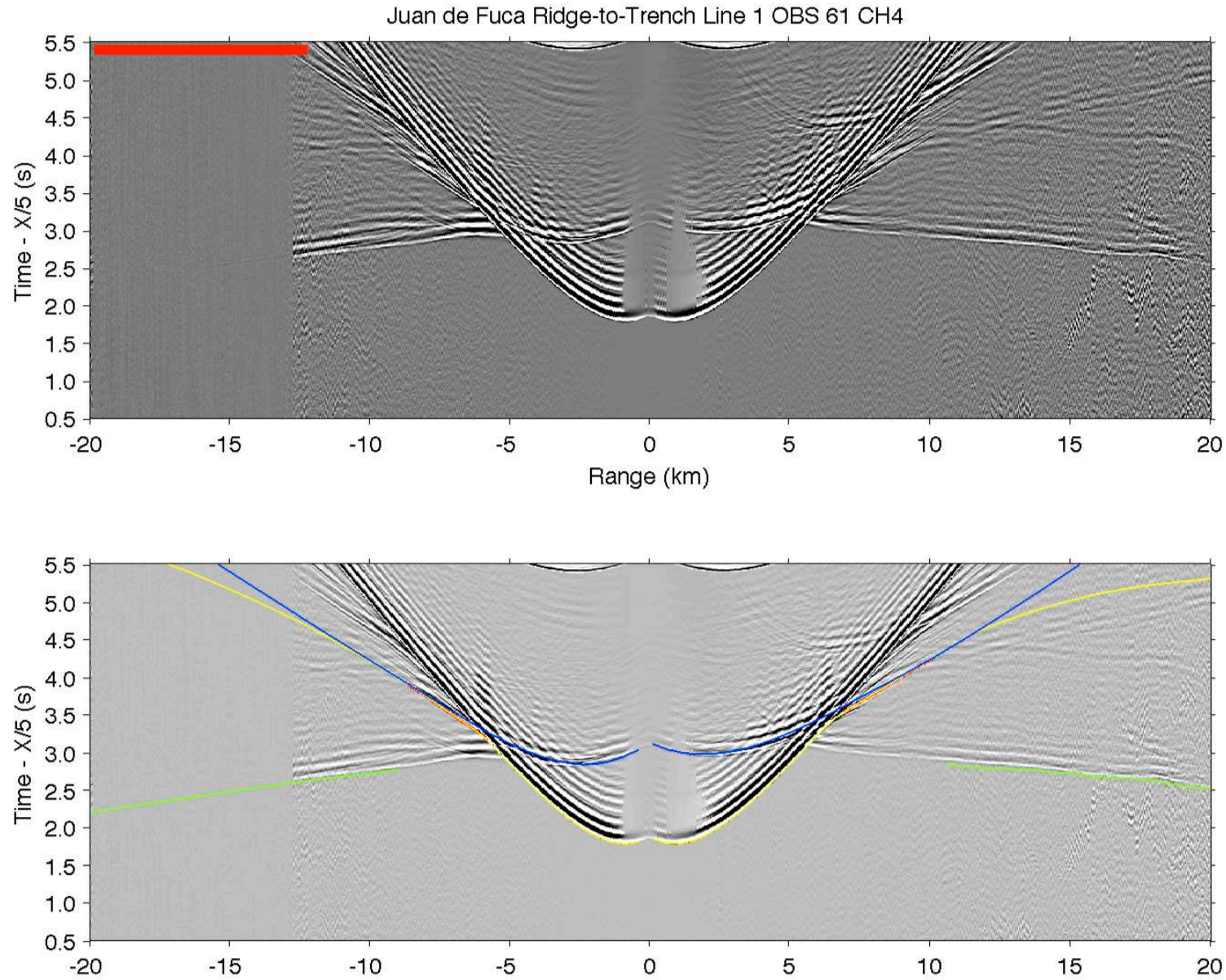

Figure 3-S17

Record Section for OBS 61. Details as in Figure 3-2. 

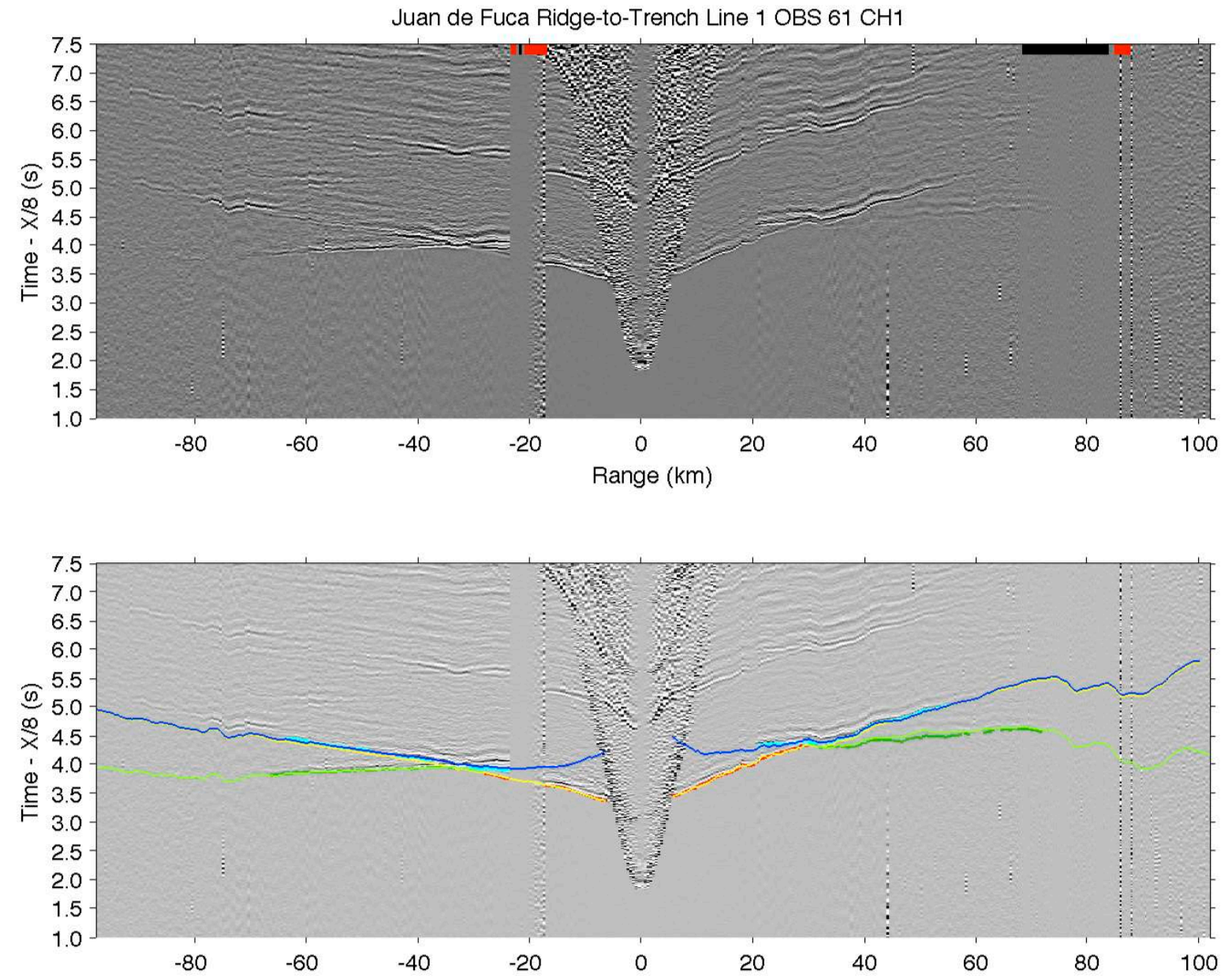

Figure 3-S18

Record Section for OBS 61. Details as in Figure 3-3. 

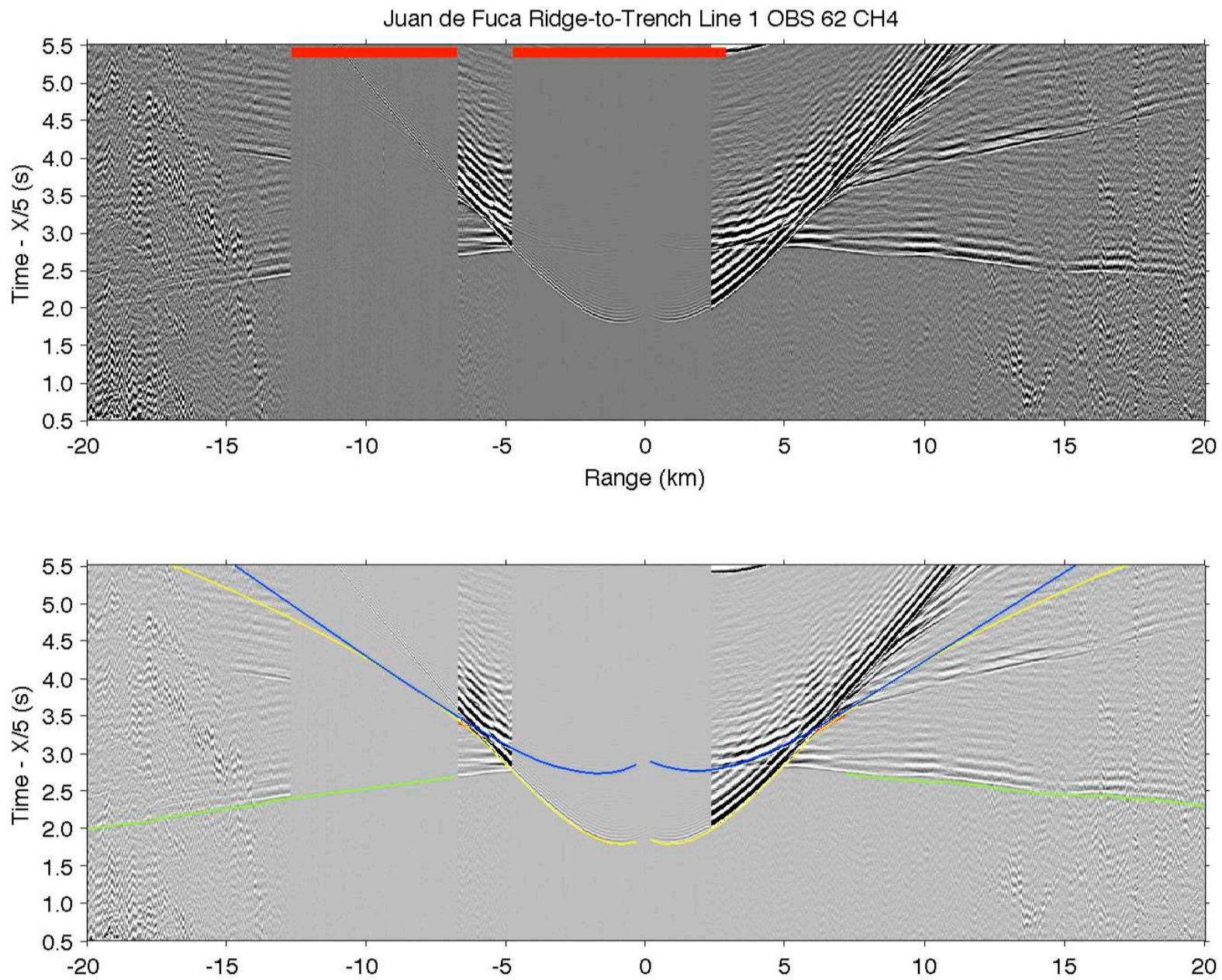

Figure 3-S19

Record Section for OBS 62. Details as in Figure 3-2. 

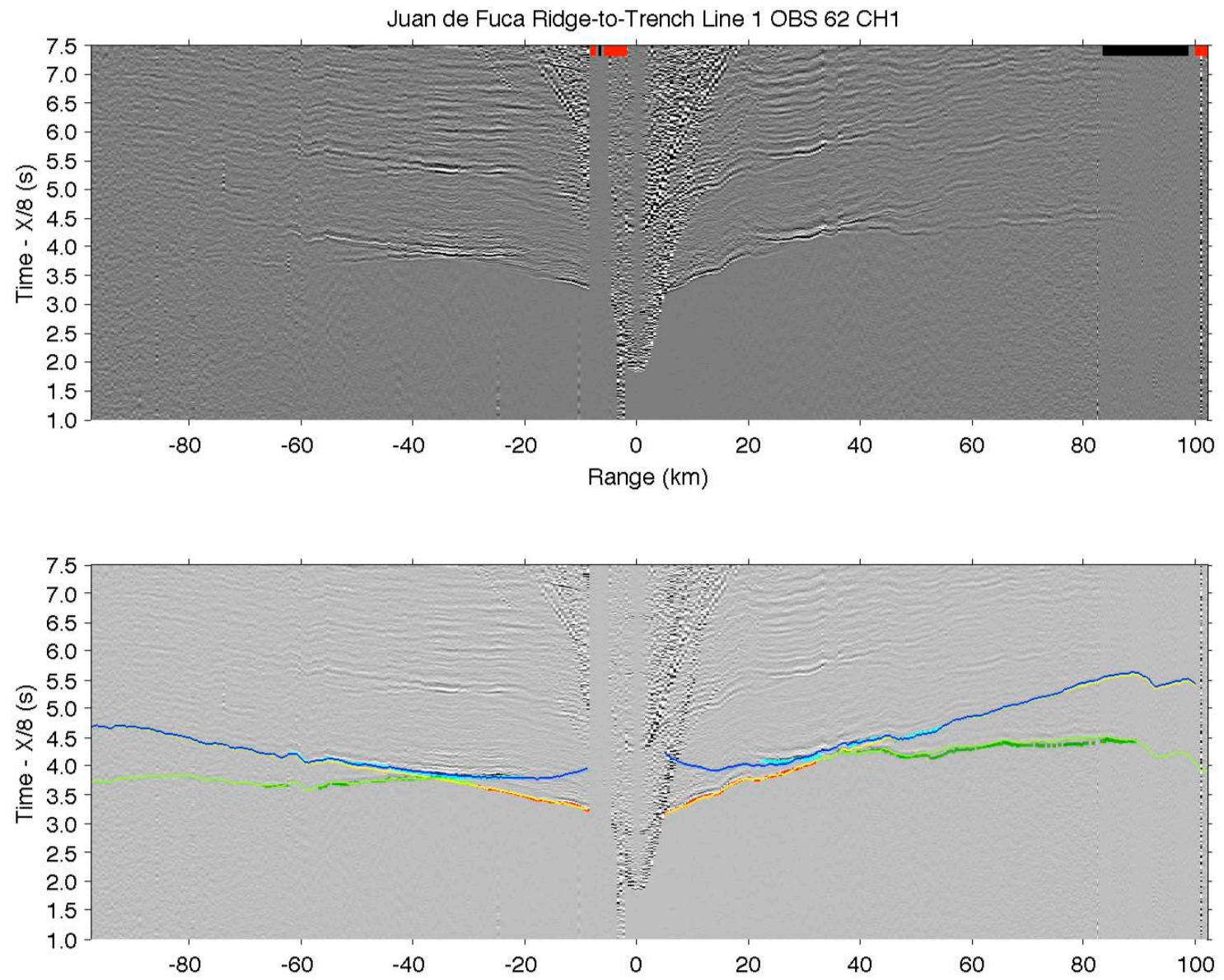

Figure 3-S20

Record Section for OBS 62. Details as in Figure 3-3. 

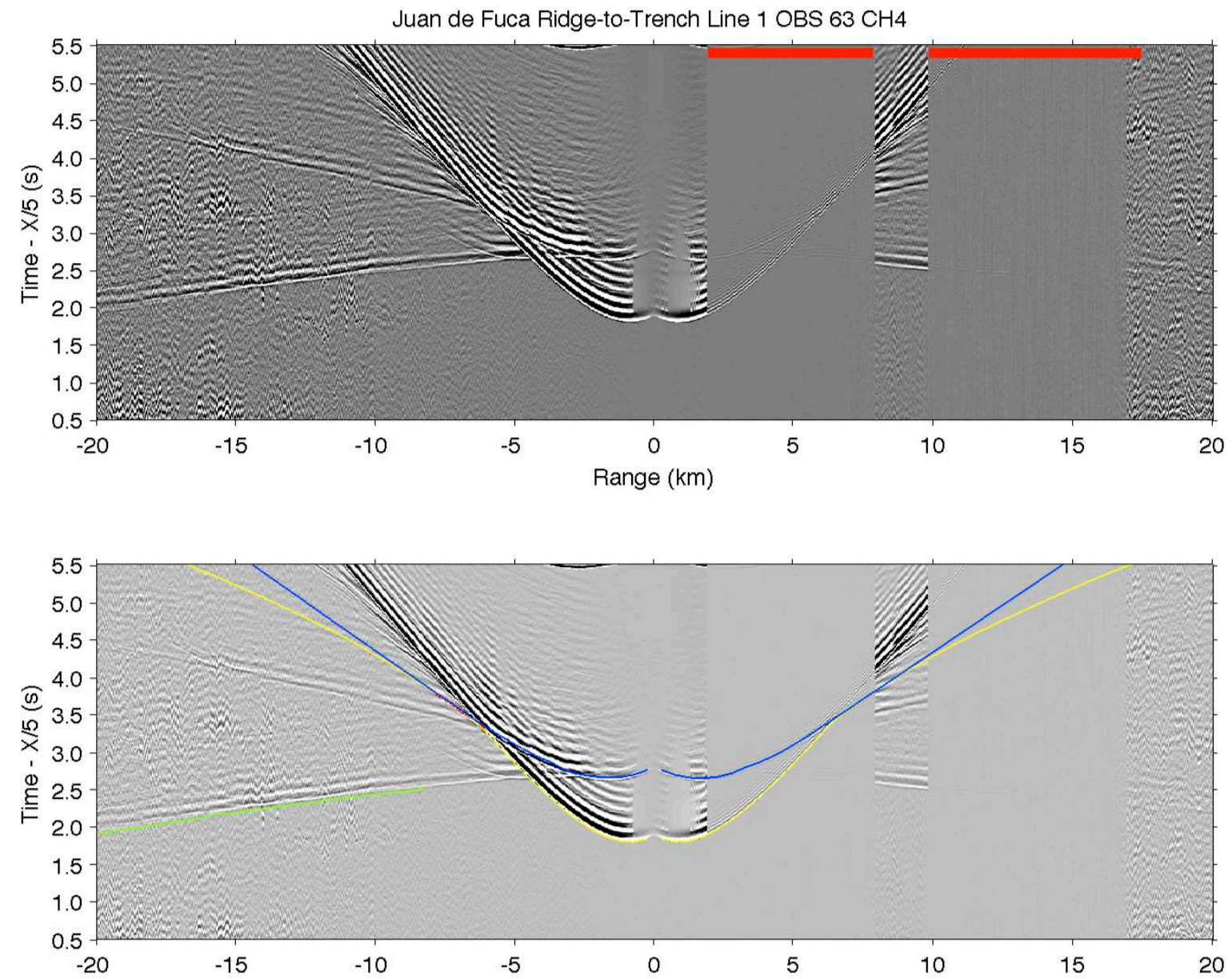

Figure 3-S21

Record Section for OBS 63. Details as in Figure 3-2. 

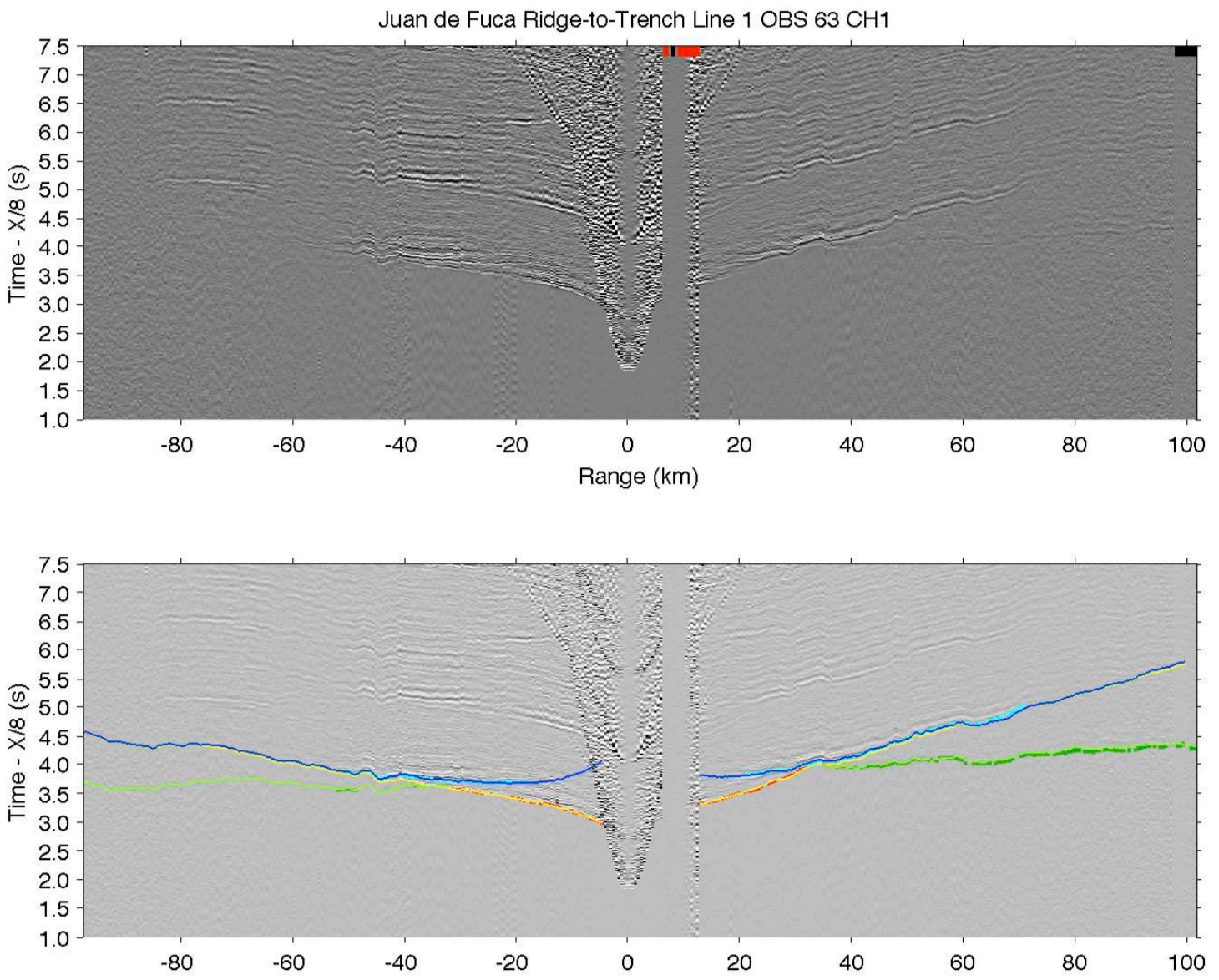

Figure 3-S22

Record Section for OBS 63. Details as in Figure 3-3. 

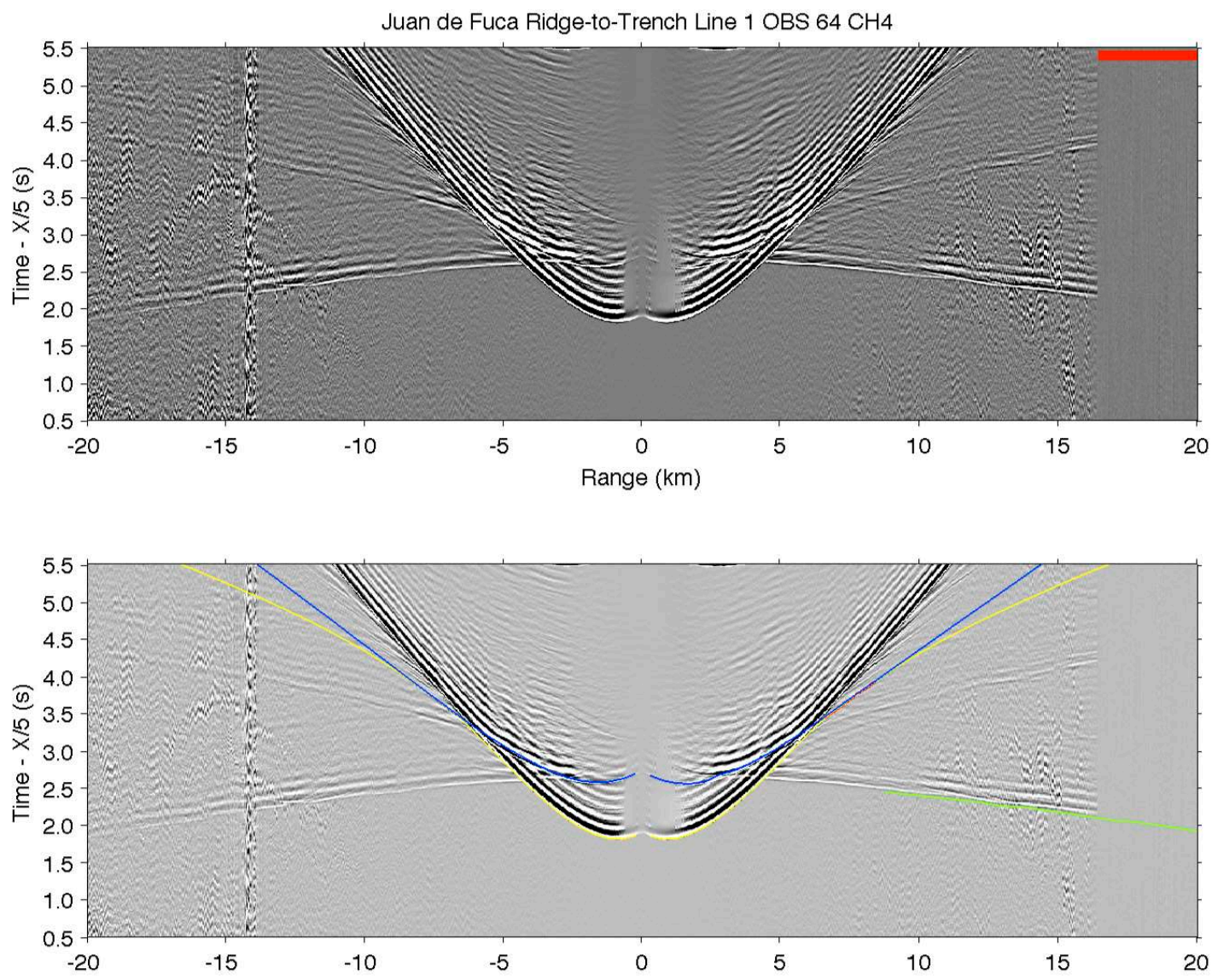

Figure 3-S23

Record Section for OBS 64. Details as in Figure 3-2. 

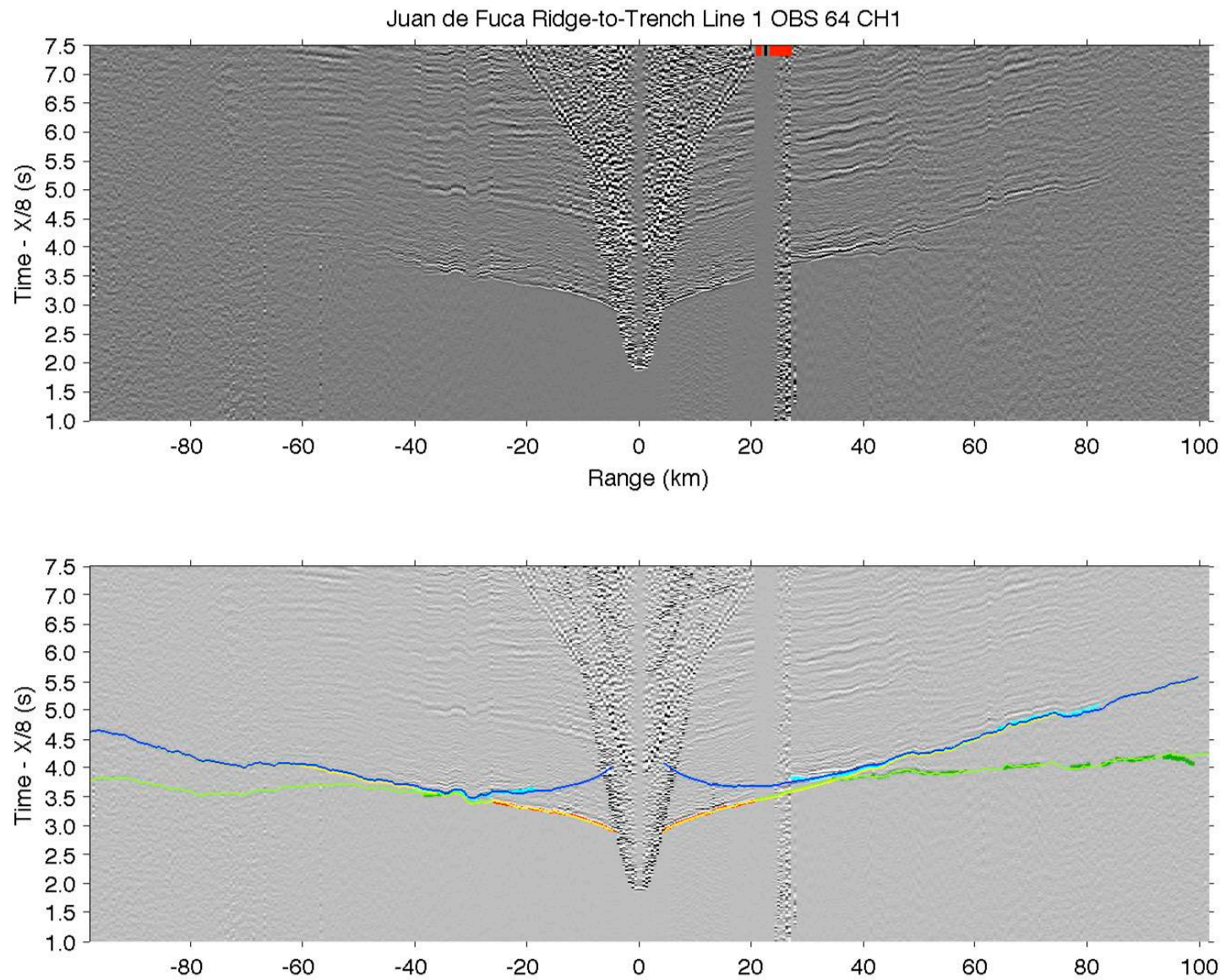

\section{Figure 3-S24}

Record Section for OBS 64. Details as in Figure 3-2. 

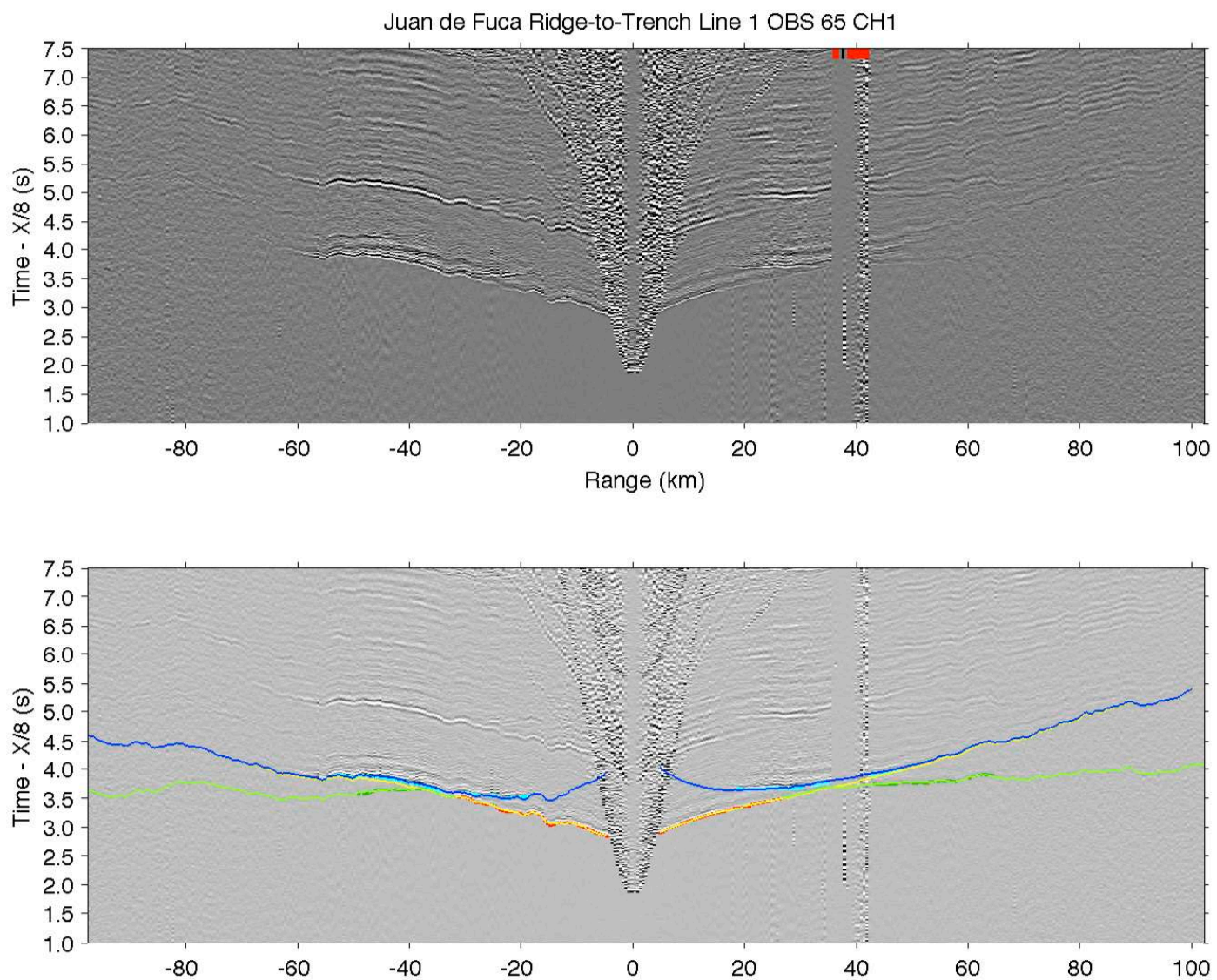

Figure 3-S25

Record Section for OBS 65. Details as in Figure 3-3. 

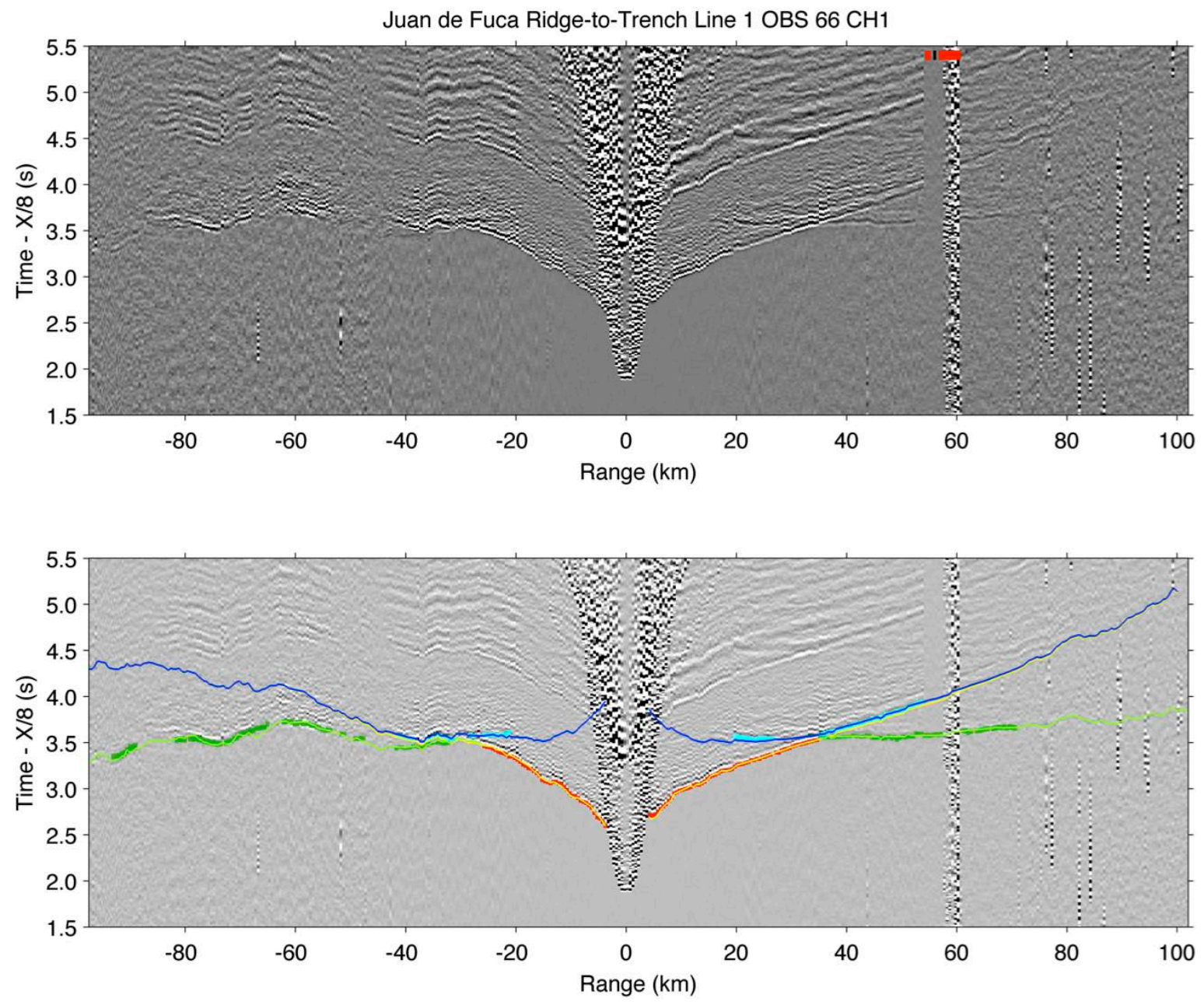

Figure 3-S26

Record Section for OBS 66. Details as in Figure 3-3. 

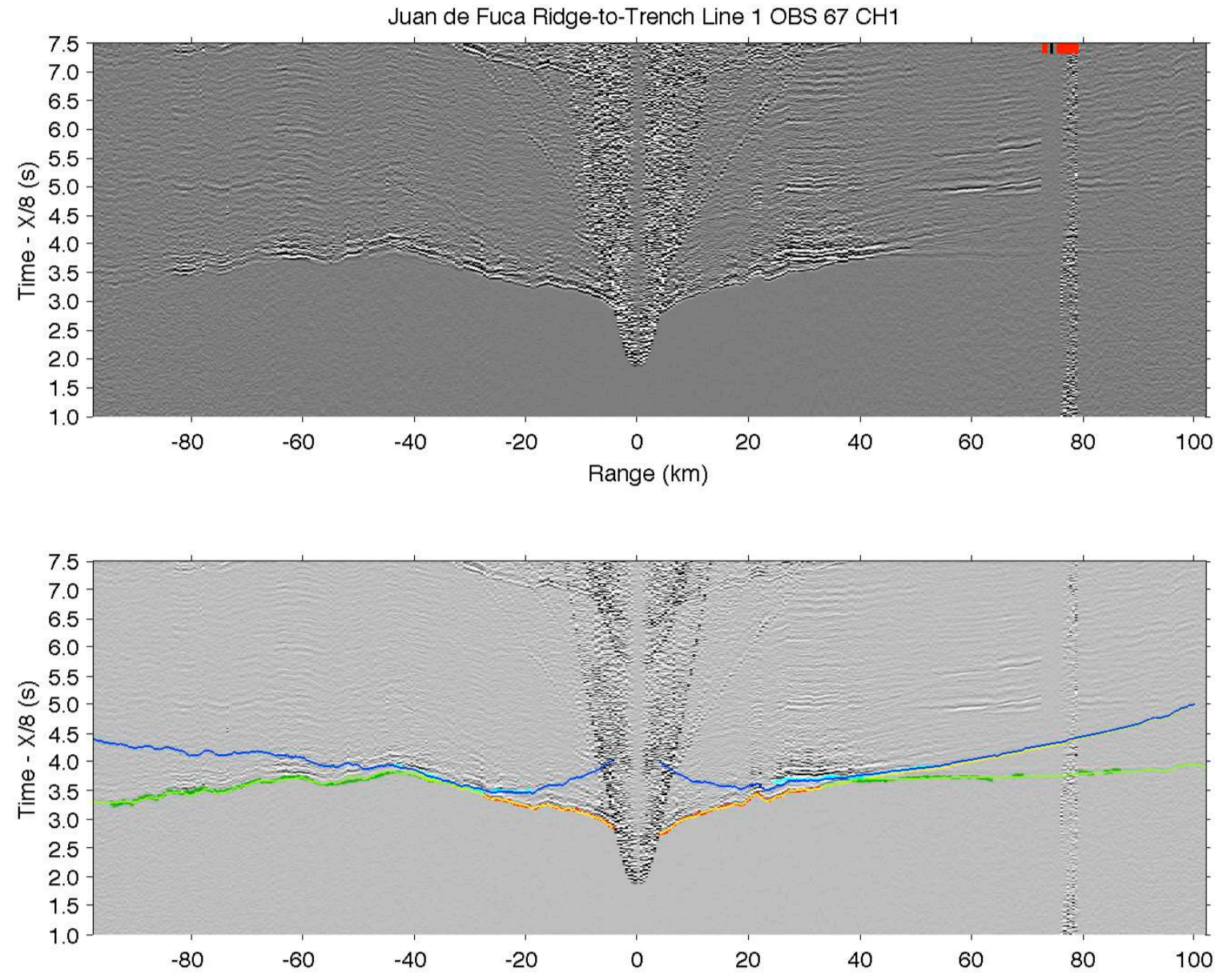

Figure 3-S27

Record Section for OBS 67. Details as in Figure 3-3. 

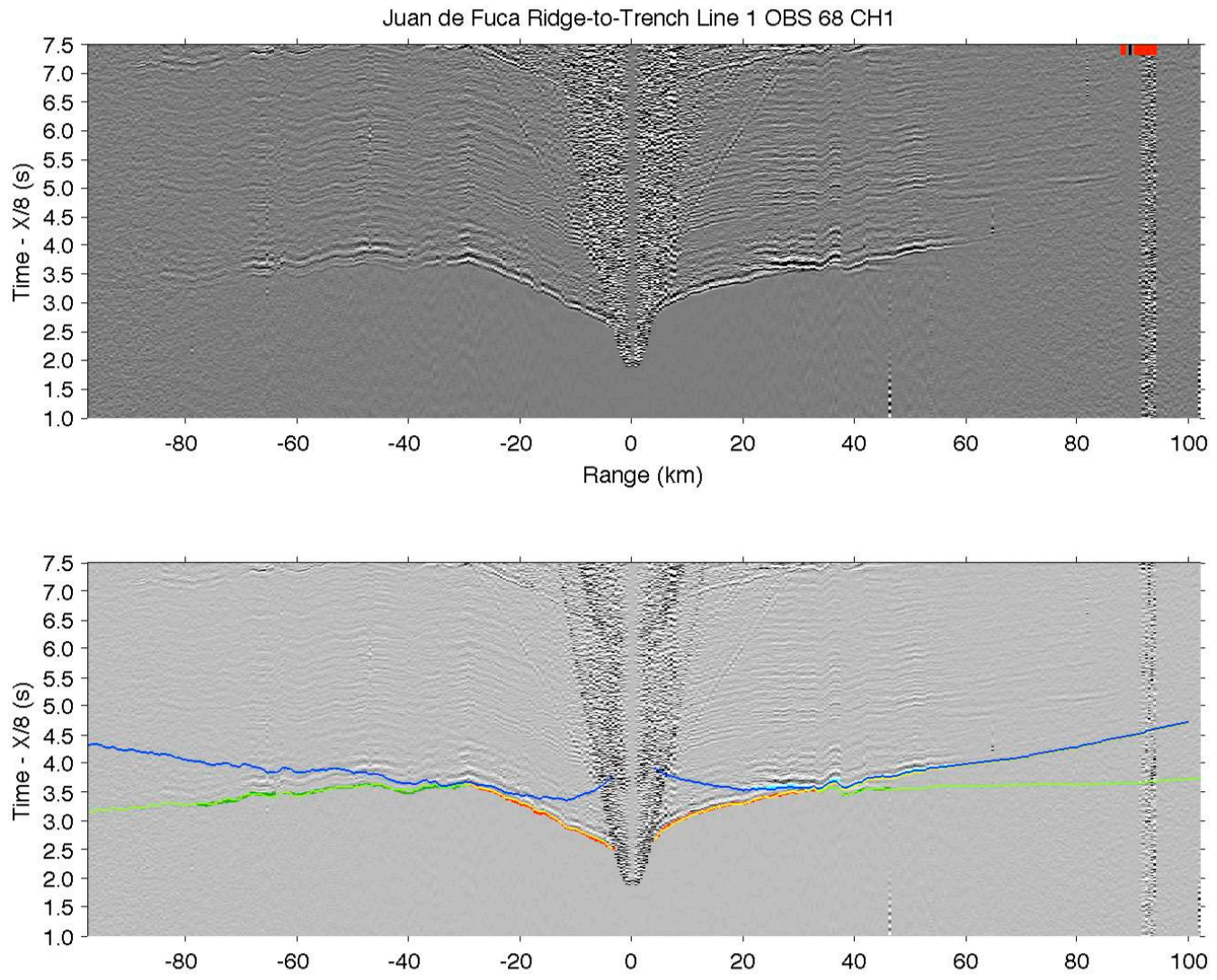

Figure 3-S28

Record Section for OBS 68. Details as in Figure 3-3. 

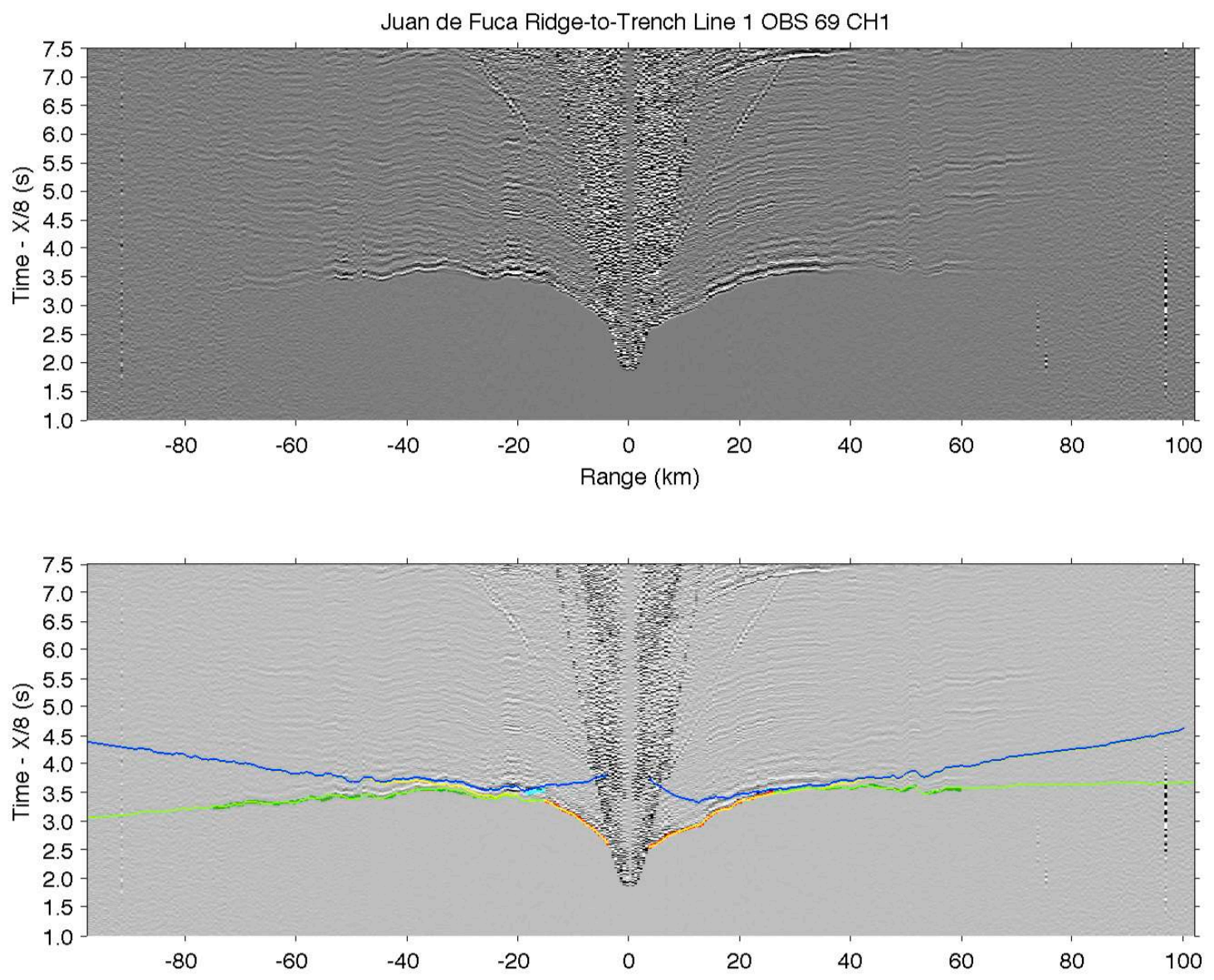

Figure 3-S29

Record Section for OBS 69. Details as in Figure 3-3. 

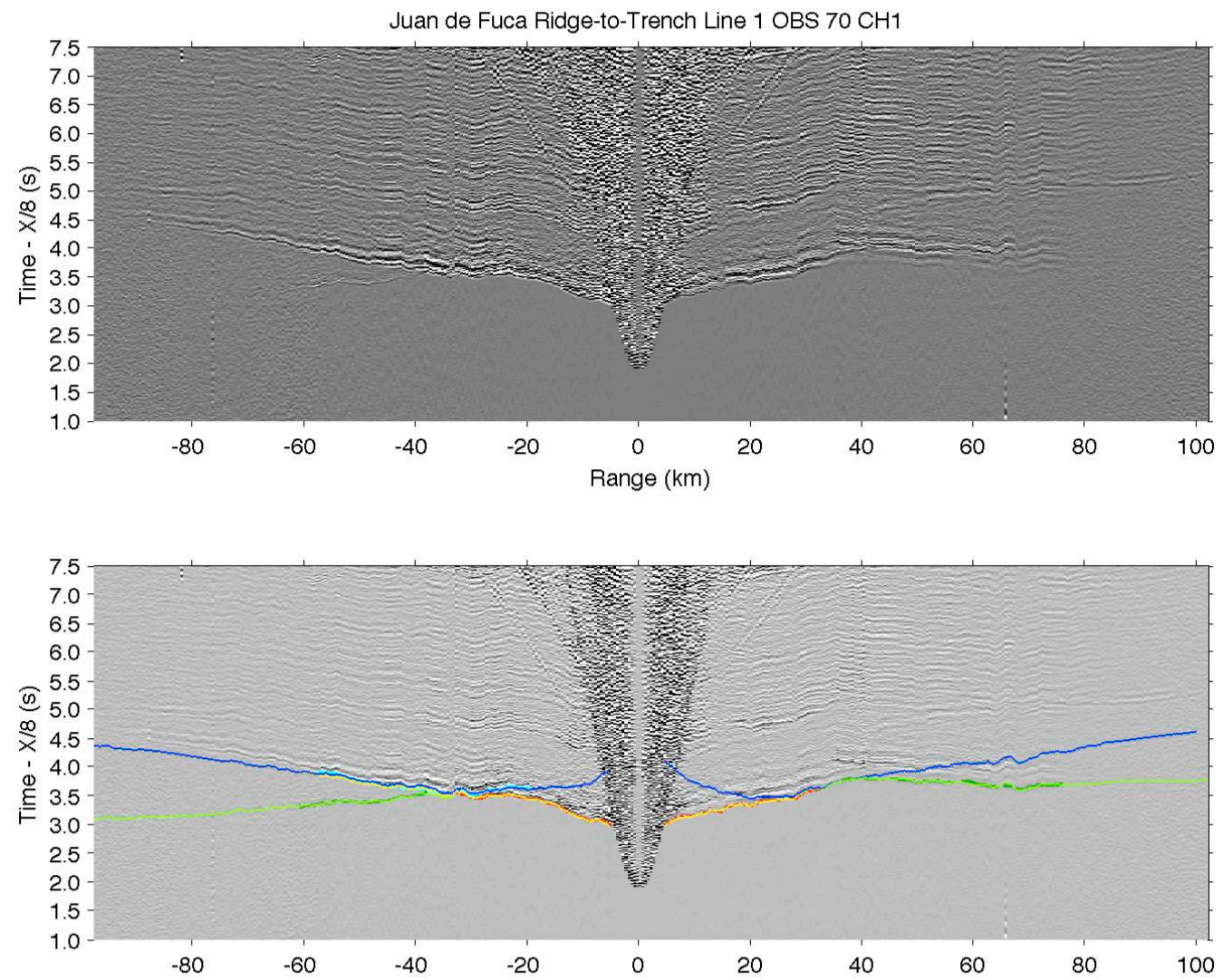

Figure 3-S30

Record Section for OBS 70. Details as in Figure 3-3. 

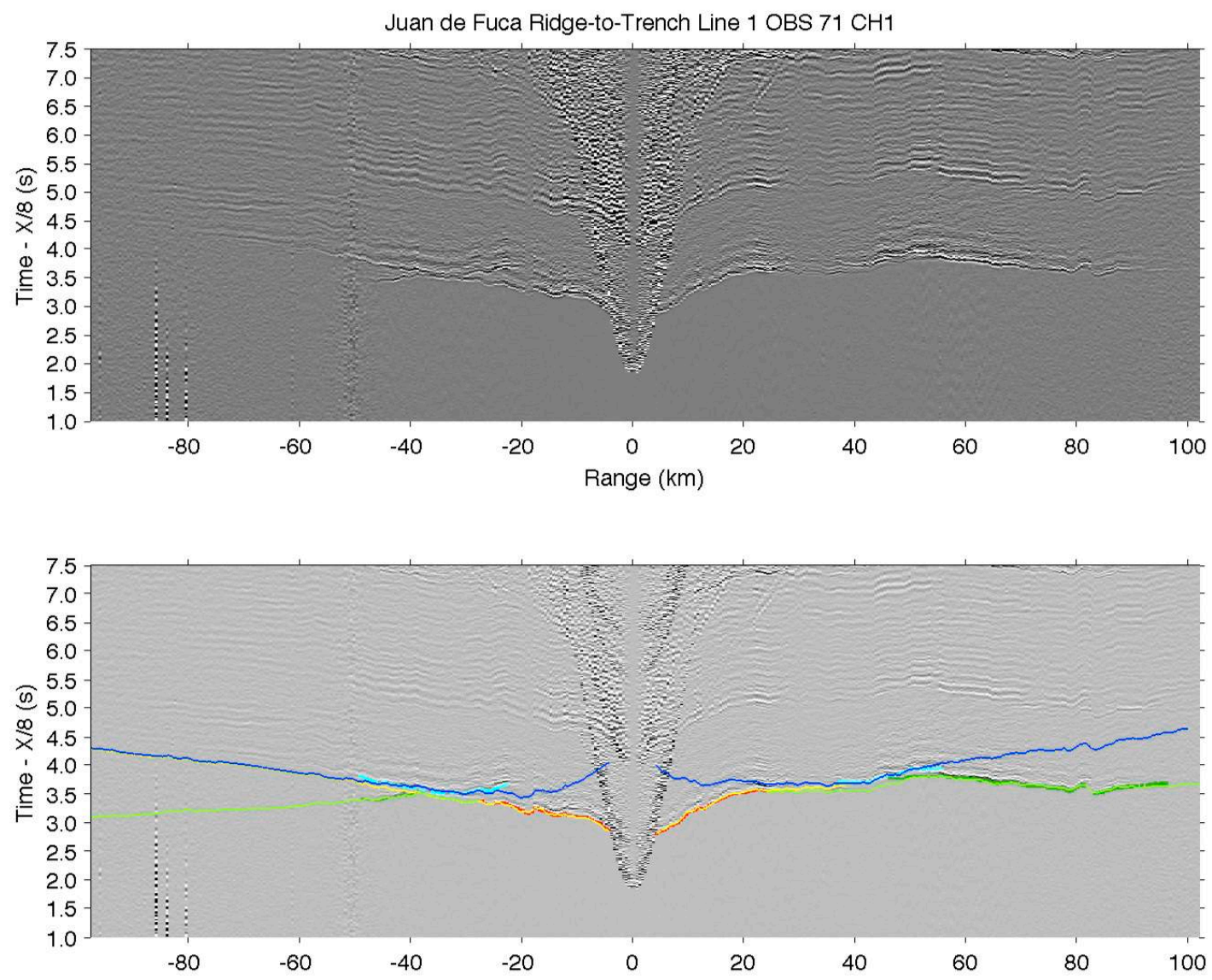

Figure 3-S31

Record Section for OBS 71. Details as in Figure 3-3. 

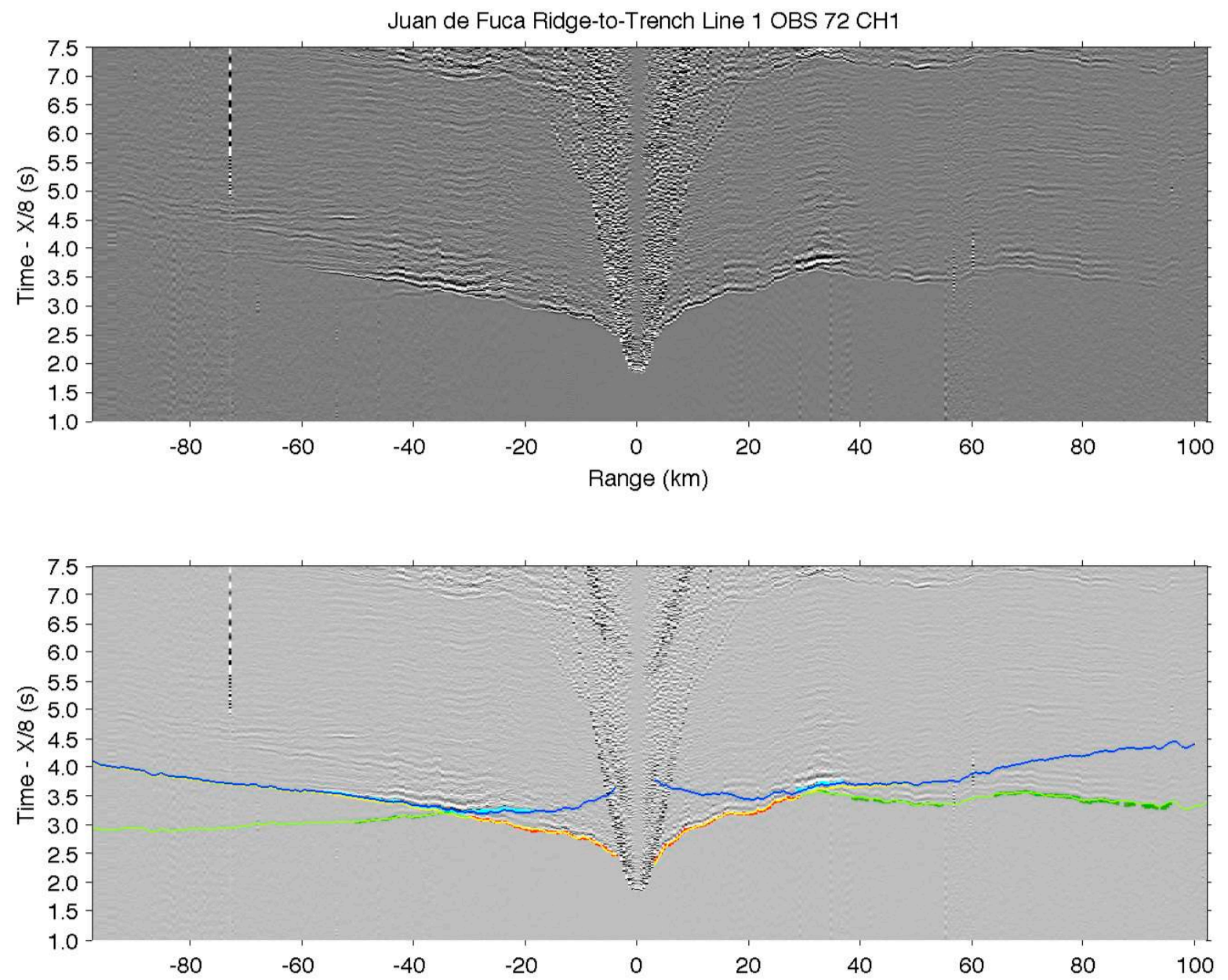

Figure 3-S32

Record Section for OBS 72. Details as in Figure 3-3. 

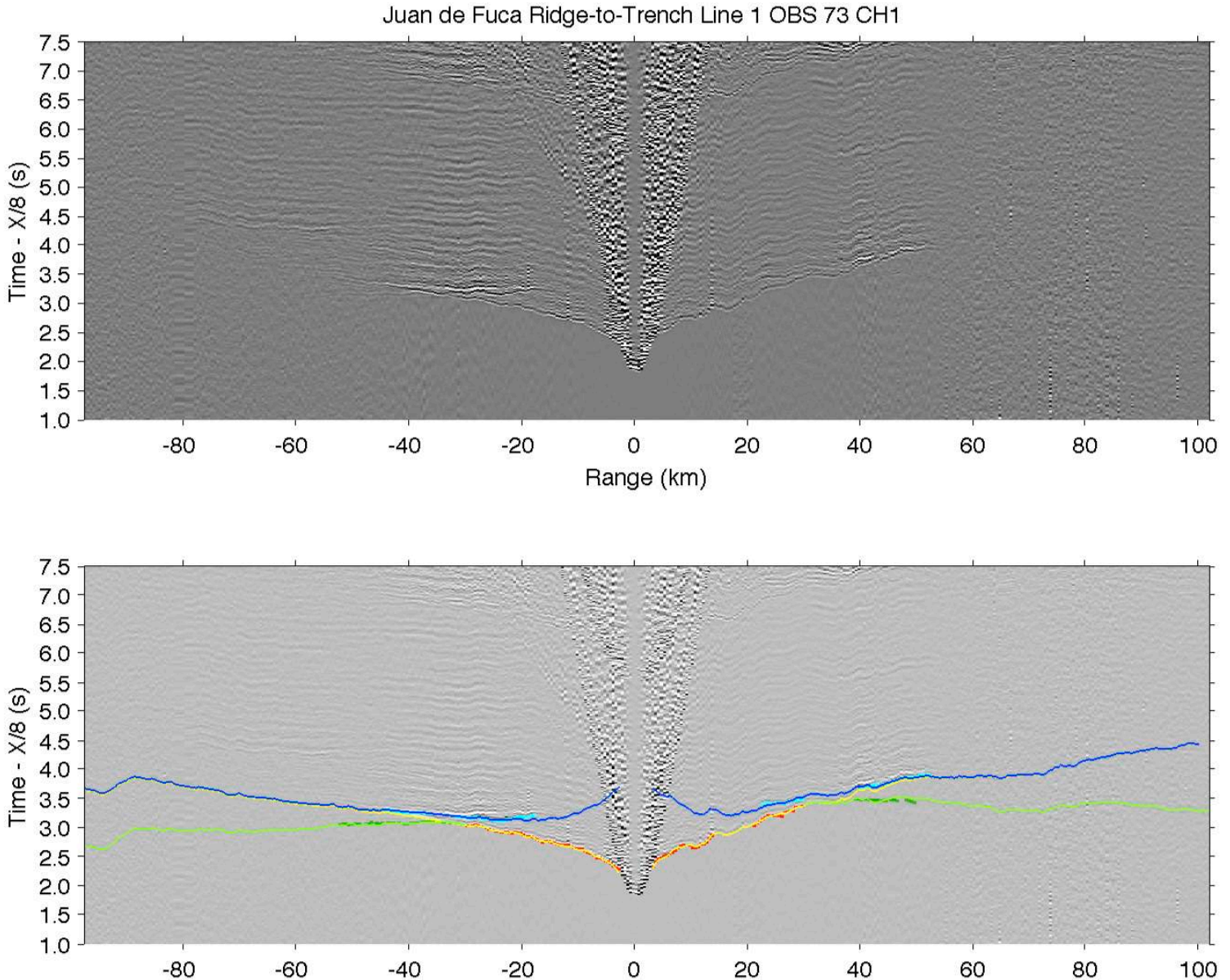

Figure 3-S33

Record Section for OBS 73. Details as in Figure 3-3. 

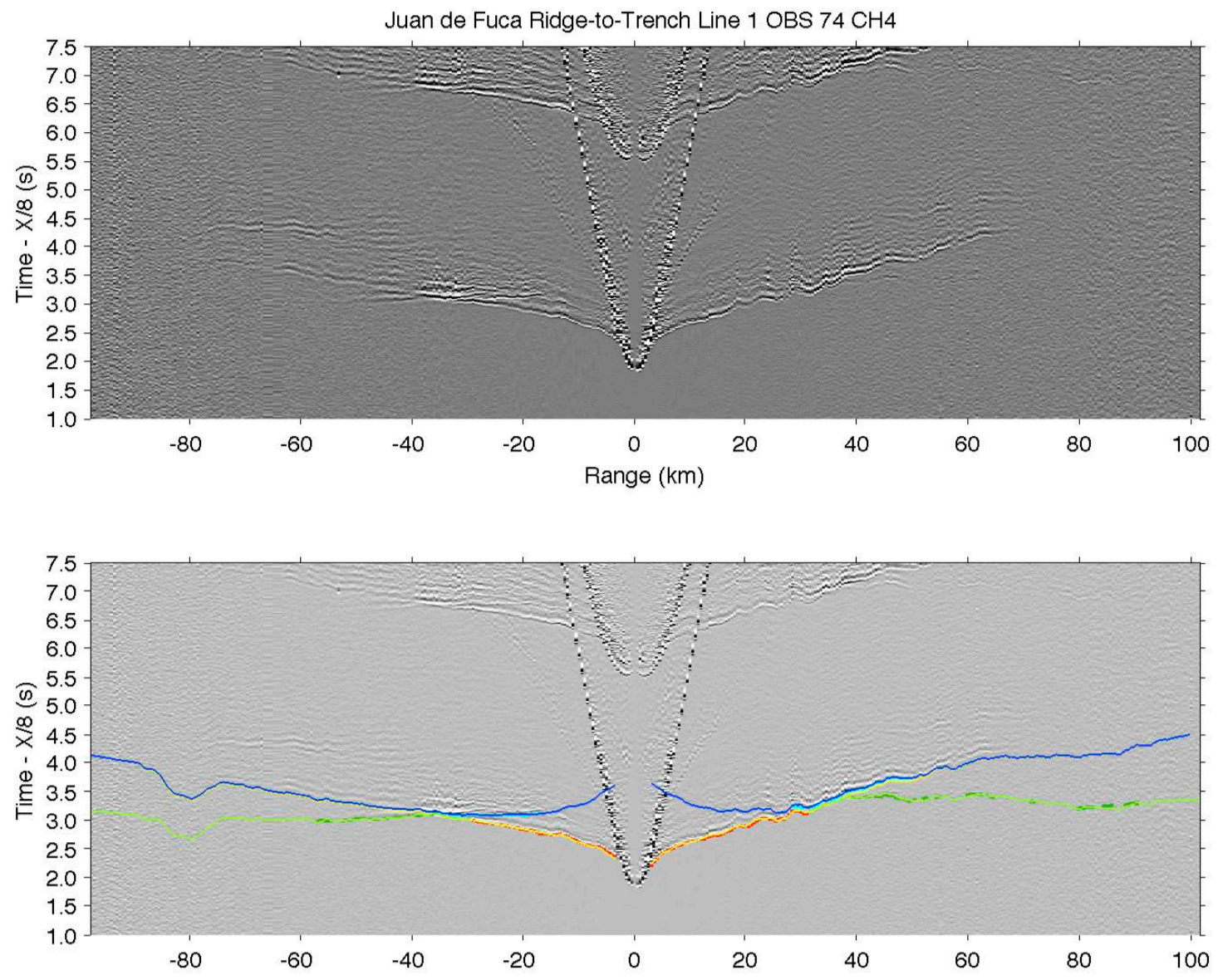

Figure 3-S34

Record Section for OBS 74. Details as in Figure 3-3. 

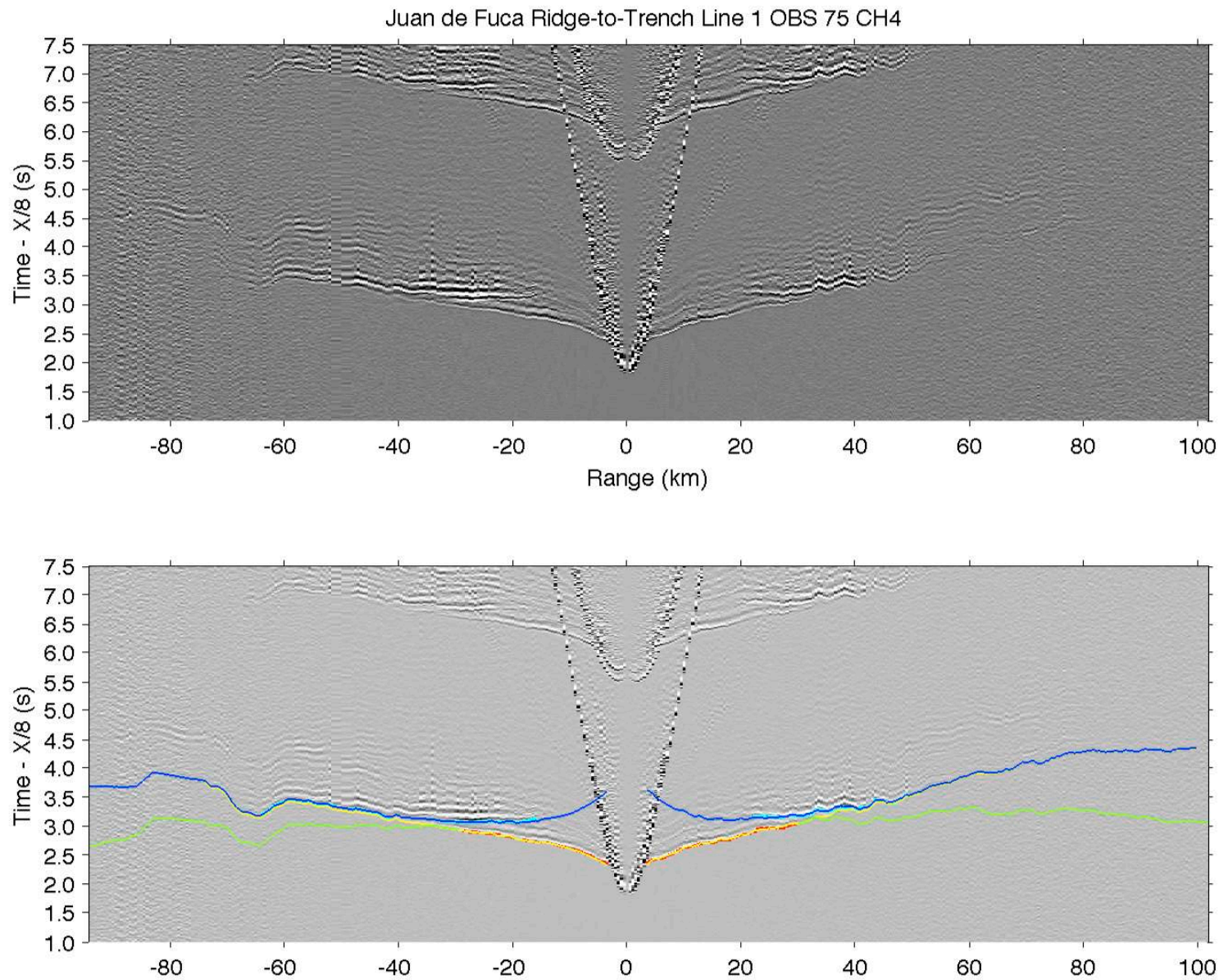

Figure 3-S35

Record Section for OBS 75. Details as in Figure 3-3. 

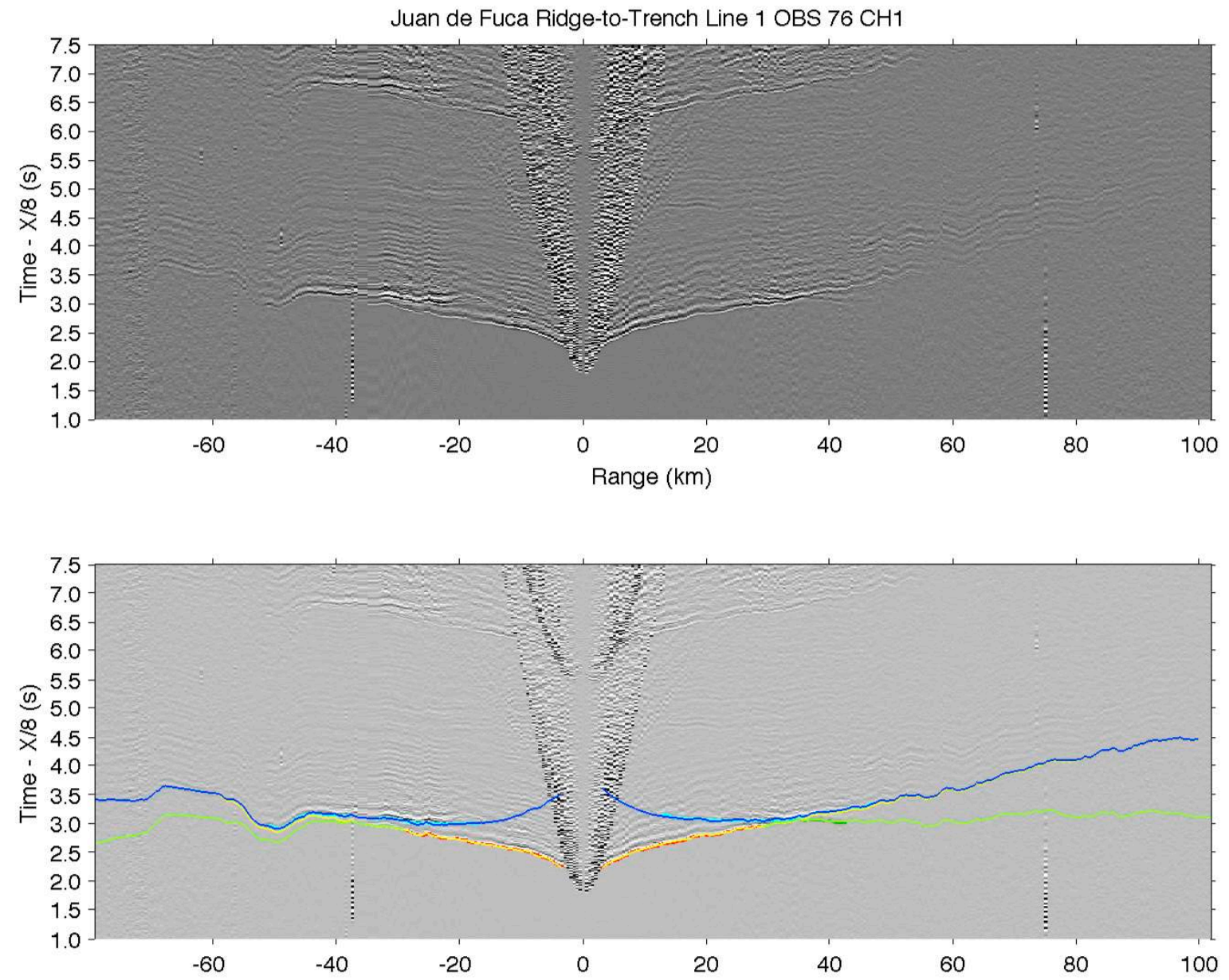

Figure 3-S36

Record Section for OBS 76. Details as in Figure 3-3. 

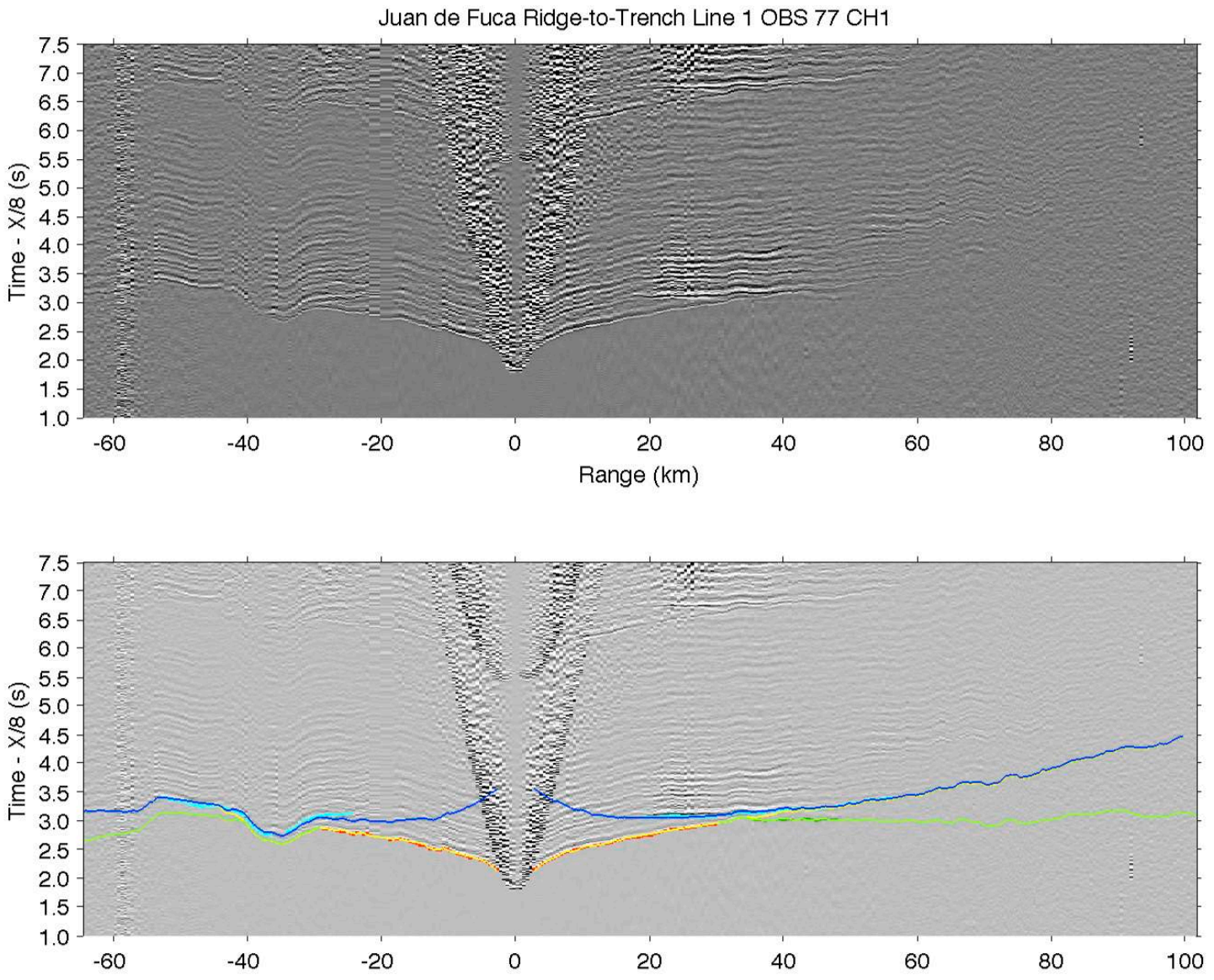

Figure 3-S37

Record Section for OBS 77. Details as in Figure 3-3. 

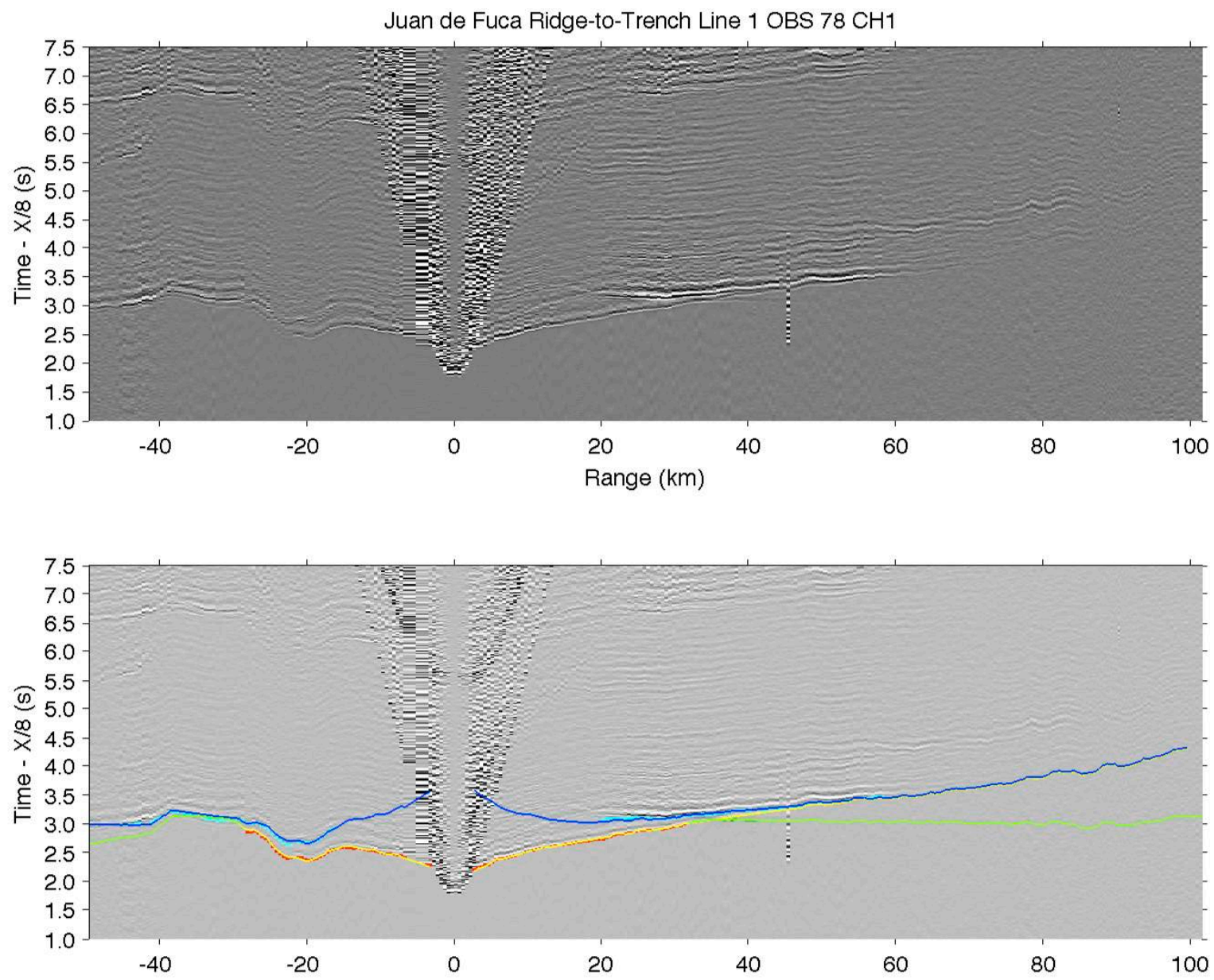

Figure 3-S38

Record Section for OBS 78. Details as in Figure 3-3. 

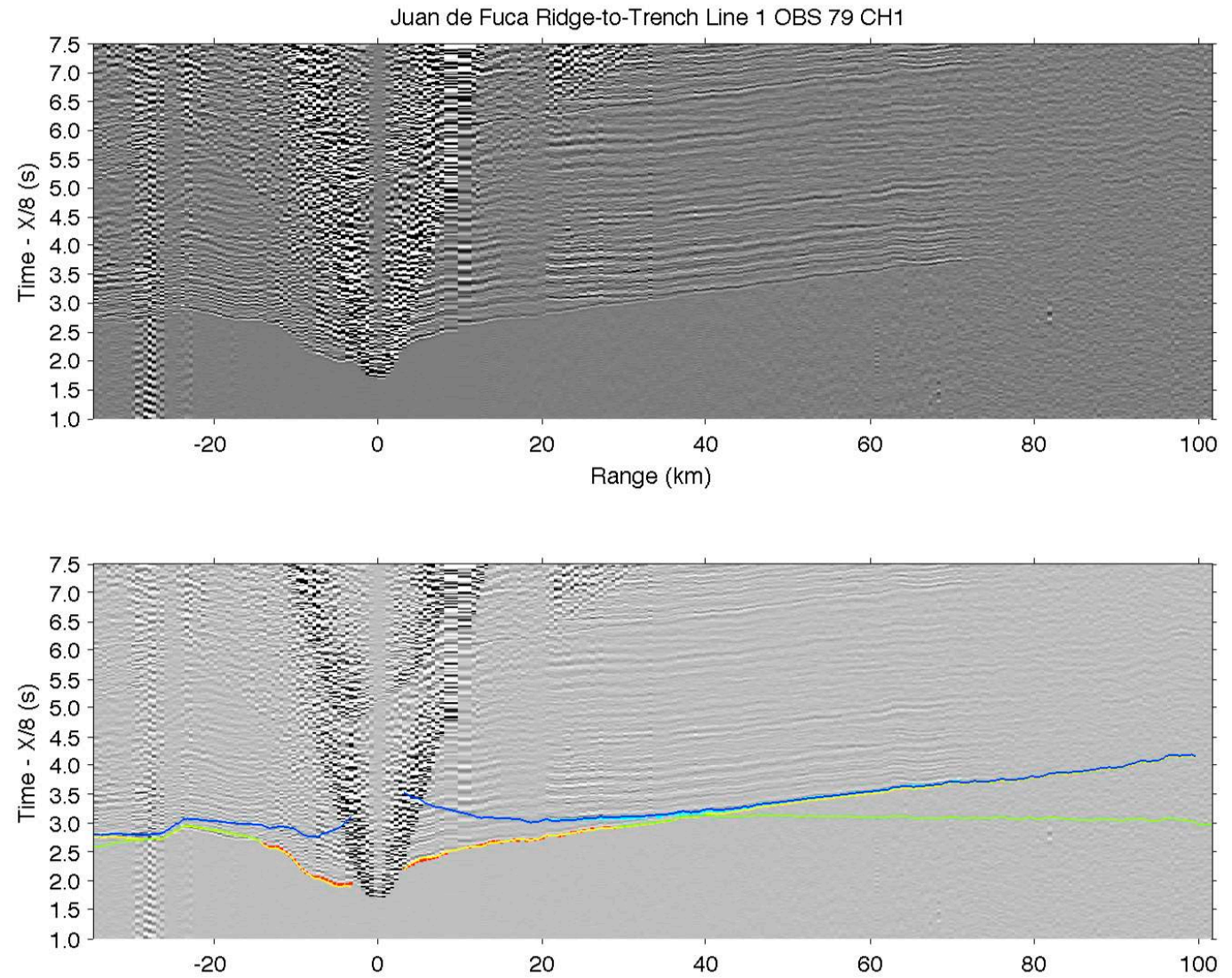

Figure 3-S39

Record Section for OBS 79. Details as in Figure 3-3. 

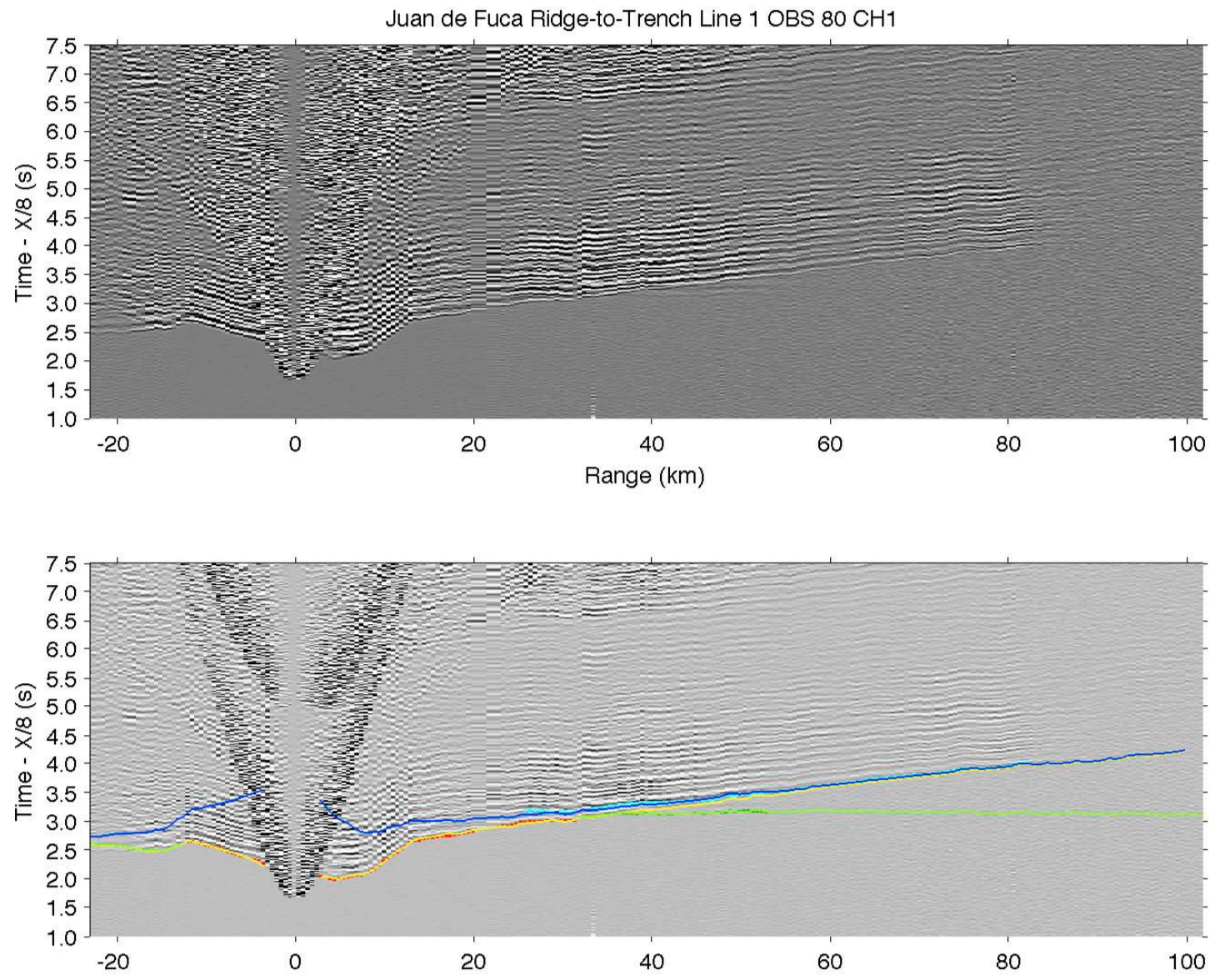

Figure 3-S40

Record Section for OBS 80. Details as in Figure 3-3. 